\title{
Experimental Results in Support of Simulating Progressive Crush in Carbon-Fiber Textile Composites
}

S. J. DeTeresa, L. M. Allison, B. J. Cunningham, D. C. Freeman, M. D. Saculla, R. J. Sanchez, S. W. Winchester

\section{April 2, 2001}

U.S. Department of Energy

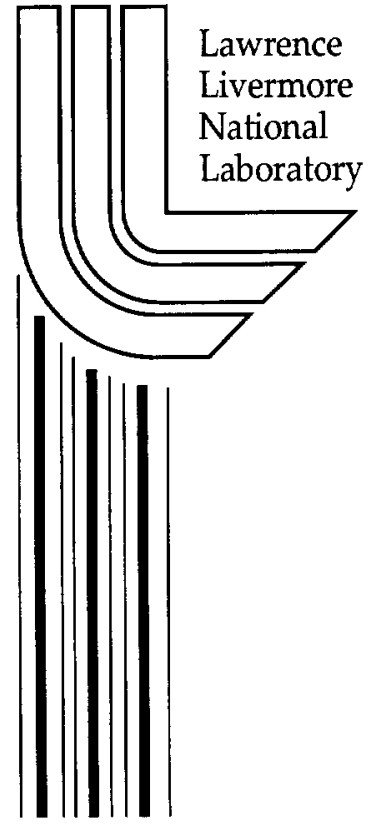




\section{DISCLAIMER}

This document was prepared as an account of work sponsored by an agency of the United States Government. Neither the United States Government nor the University of California nor any of their employees, makes any warranty, express or implied, or assumes any legal liability or responsibility for the accuracy, completeness, or usefulness of any information, apparatus, product, or process disclosed, or represents that its use would not infringe privately owned rights. Reference herein to any specific commercial product, process, or service by trade name, trademark, manufacturer, or otherwise, does not necessarily constitute or imply its endorsement, recommendation, or favoring by the United States Government or the University of California. The views and opinions of authors expressed herein do not necessarily state or reflect those of the United States Government or the University of California, and shall not be used for advertising or product endorsement purposes.

This work was performed under the auspices of the U.S. Department of Energy by the University of California, Lawrence Livermore National Laboratory under Contract No. W-7405-Eng-48.

This report has been reproduced directly from the best available copy.

Available electronically at http://www.doc.gov/bridge

Available for a processing fee to U.S. Department of Energy

And its contractors in paper from

U.S. Department of Energy

Office of Scientific and Technical Information

P.O. Box 62

Oak Ridge, TN 37831-0062

Telephone: (865) 576-8401

Facsimile: (865) 576-5728

E-mail: reports@adonis.osti.gov

Available for the sale to the public from

U.S. Department of Commerce

National Technical Information Service

5285 Port Royal Road

Springfield, VA 22161

Telephone: (800) 553-6847

Facsimile: (703) 605-6900

E-mail: orders@ntis.fedworld.gov

Online ordering: http://www.ntis.gov/ordering.htm

OR

Lawrence Livermore National Laboratory

Technical Information Department's Digital Library

http://www.llnl.gov/tid/Library.html 


\title{
Experimental Results in Support of Simulating Progressive Crush in Carbon-Fiber Textile Composites
}

\author{
Final Report
}

S. J. DeTeresa, L. M. Allison, B. J. Cunningham, D. C. Freeman, M. D. Saculla, R. J. Sanchez, and S. W. Winchester. 


\section{TABLE OF CONTENTS}

Summary

iii

1. Introduction

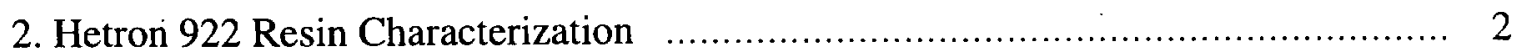

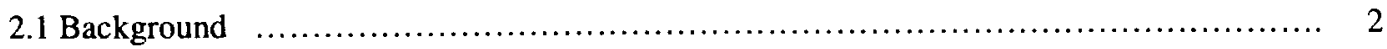

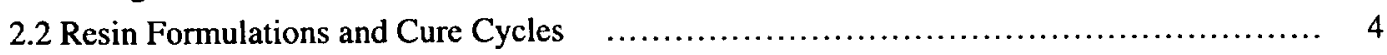

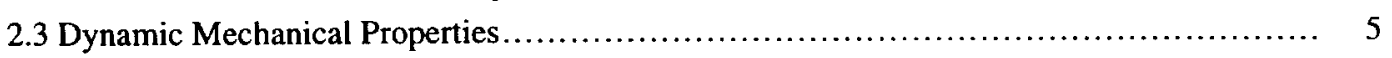

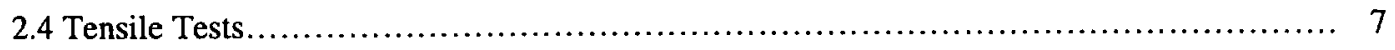

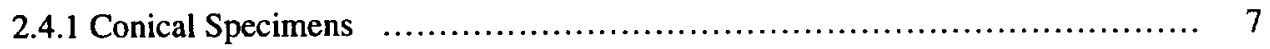

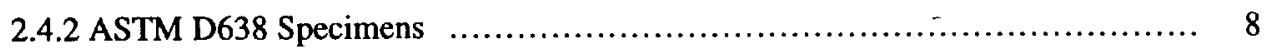

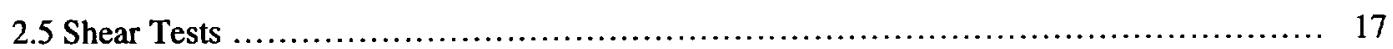

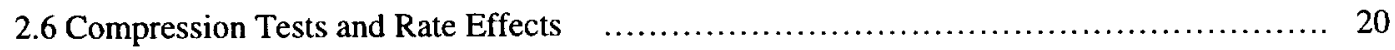

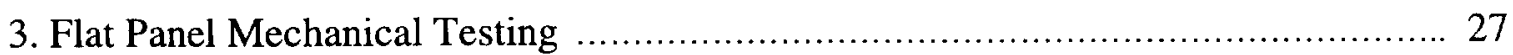

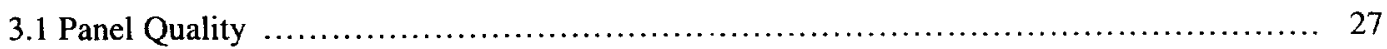

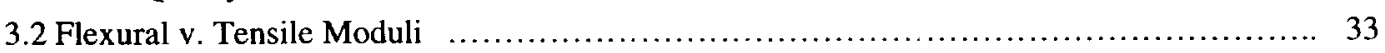

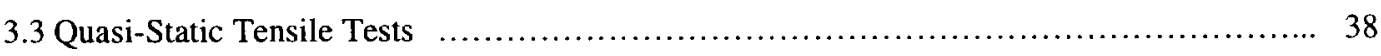

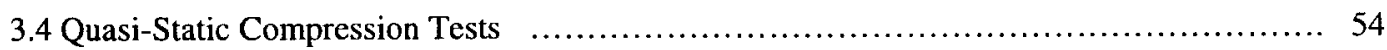

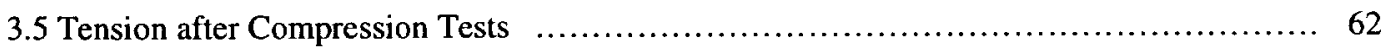

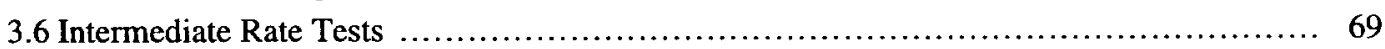

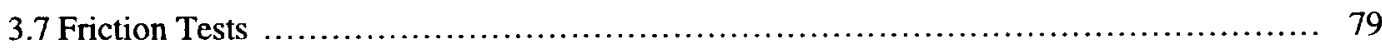

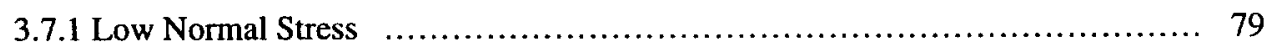

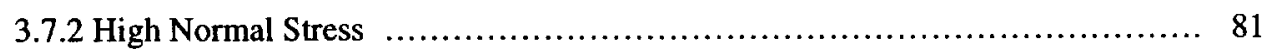

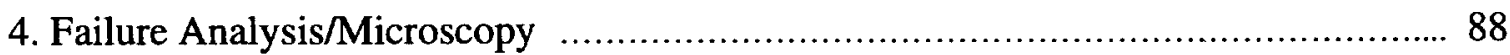

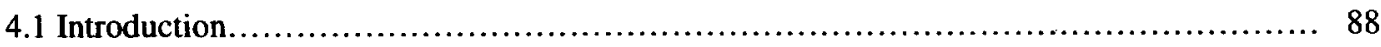

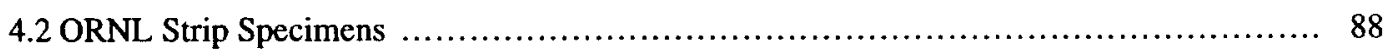

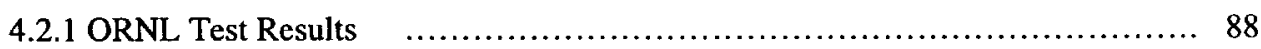

4.2.2 Failure Observations for Unconstrained Strip Specimens $\quad$................... 89

4.2.3 Failure Observations for Constrained Strip Specimens $\quad$..................... 90

4.2.4 Surface Area Determination by the BET Technique $\quad$......................... 90

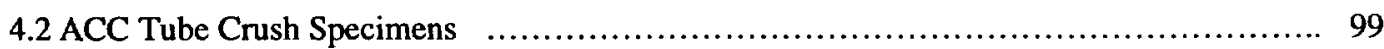

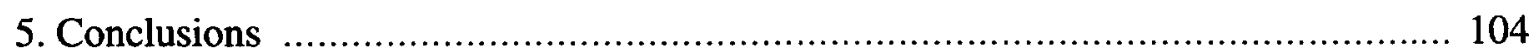

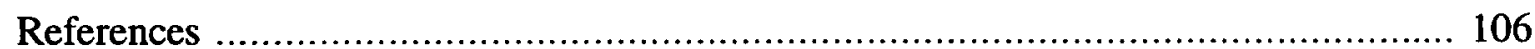




\section{Summary}

This report summarizes the findings of an experimental program conducted to support the modeling of the crush behavior of triaxial braid carbon fiber composites. The matrix material as well as braided panels and tubes were characterized in order to determine material properties, to assess failure modes, and to provide a test bed for new analytical and numerical tools developed specifically for braided composites.

The matrix material selected by the ACC was an epoxy vinyl ester (Ashland Hetron 922). Tensile tests were used to compare two formulations-one used by the ACC and one recommended by the resin supplier. The latter was a faster reacting system and gelled in one-third the time of the ACC formulation. Both formulations had an average elongation at failure that was only half of the resin supplier's reported value. Only one specimen of each type came close to the reported elongation value and it was shown that failure invariably initiated at both surface and internal defects. Overall, the tensile properties of the two formulations were nearly identical, but those of the ACC system were more consistent. The properties of the ACC matrix formulation were measured in tension, shear, and compression and the average properties obtained in these tests are summarized in Table I.

Table I. Mechanical Properties of Hetron 922 (ACC Formulation).

\begin{tabular}{|l|c|}
\hline \multicolumn{1}{|c|}{ Property } & Value \\
\hline Tensile Modulus (ksi): & 466 \\
\hline Shear Modulus (ksi): & 200 \\
\hline Compressive Modulus (ksi): & 475 \\
\hline Tensile Strength (ksi): & 12.1 \\
\hline Tensile Elongation at Break (\%): & 3.8 \\
\hline Shear Strength (ksi): & 5.2 \\
\hline Compression Strength (ksi): & 16.5 \\
\hline
\end{tabular}

(Nominal strain rate $=1 \mathrm{E}-3 \mathrm{~s}^{-1}$ ).

The effect of deformation rate on modulus and yield properties was examined up to rates of $1 \mathrm{E} 3 \mathrm{~s}^{-1}$ Modulus, yield and flow stress were all found to increase with rate and simple power law relationships adequately described the dependence of these properties on rate. The yield stress exhibited the strongest dependence on rate. This strength increased by 
approximately $10 \%$ for every decade increase in strain rate, which is typical behavior for polymeric materials. In general, this matrix material can be considered a relatively ductile, but defect- and rate-sensitive thermoset.

The composite braid panels exhibited nonuniform fiber (tow) distribution and alignment, poor wetting of fiber within the tows, and voids between the tows. A substantial difference in $0^{\circ}$ extensional and flexural modulus was measured and this disparity has been shown in other reported work to compare favorably with the predictions of a recently developed discrete tow model. Quasi-static tension and compression tests in the $0^{\circ}, 30^{\circ}, 60^{\circ}$, and $90^{\circ}$ directions were conducted and the average properties are summarized in Table II. Two strips cut from the wall of the square tubes were tested in tension along the $0^{\circ}$ direction and were found to have identical properties to the panels.

Table II: Average Properties of Hetron 922/Fortafil \#556 0/ \pm 30 Triaxial Braid, 2-Ply Composite Panels.

\begin{tabular}{|l|c|c|c|c|}
\hline \multirow{2}{*}{ Property } & \multicolumn{5}{c|}{ Orientation } \\
\cline { 2 - 5 } & $\mathbf{0}^{\circ}$ & $\mathbf{3 0}^{\circ}$ & $\mathbf{6 0}^{\circ}$ & $\mathbf{9 0}^{\circ}$ \\
\hline Tensile Modulus (Msi) & 6.01 & 6.05 & 2.0 & 1.02 \\
\hline Poisson's Ratio & 1.15 & - & - & 0.26 \\
\hline Tensile Strength (ksi) & 43.4 & 31.0 & 4.64 & 3.50 \\
\hline Compressive Strength (ksi) & 13.6 & 14.5 & 7.84 & 8.26 \\
\hline
\end{tabular}

The most notable observation in these test results is that all the strengths of the composite, with the exception of tensile strength in a tow $\left(0^{\circ}\right.$ or $\left.30^{\circ}\right)$ direction, were equivalent or inferior to the tensile and compressive strengths of the pure matrix material. Furthermore, the scatter in composite properties was found to be relatively large. This behavior is indicative of the poor quality of the composite.

The effect of deformation rate on tensile and compressive failure for loading in the matrixdominated directions $\left(60^{\circ}\right.$ and $\left.90^{\circ}\right)$ was also examined. Average strengths measured at $1 \mathrm{E}-$ $3 \mathrm{~s}^{-1}$ increased by 15 to $37 \%$ when tests were run at just over $1 \mathrm{E}-1 \mathrm{~s}^{-1}$. This improvement in composite strength compared well with the increases in matrix yield and flow stresses (33 and $22 \%$ ) measured at the same strain rates. Thus the strength increase with rate for matrix-dominated failure modes can be attributed to the rate-dependent plastic response of the matrix. 
It is generally believed that a major source of energy dissipation during composite crush is frictional loss due to composite sliding against metal parts and damaged composite sliding against composite. Measurements of static and dynamic friction coefficients for the composite panel against steel and aluminum yielded friction coefficients ranging from 0.15 to 0.40 . Surface roughening, done to mimic some of the composite damage during crush, was found to increase friction. The static and dynamic friction coefficients dropped from 0.4 to about 0.15 when the normal stress was increased from 1 to $5 \mathrm{ksi}$.

Visual and microscopic failure analysis of panel specimens, strip crush specimens, and tube crush specimens revealed failure modes that were dominated by the weak (or nonexistent) coupling between tows and between fiber and matrix. Failure of the bond between tows, either in-plane or though-thickness, was a common failure mode. Intra-tow failure occurred mostly due to shear of off-axis tows in the matrix-dominated directions $\left(60^{\circ}\right.$ and $\left.90^{\circ}\right)$. Strip crush specimens tested by ORNL under loose and unconstrained boundary conditions were measured for surface area using the BET gas isotherm technique. These measurements revealed a large amount of surface area in as-fabricated composites, which most likely corresponded to the dry fiber tows. Comparison of the surface areas generated during strip crush tests with the values of Specific Energy Absorption showed that the higher level of energy absorption in the loosely constrained strips could be entirely accounted for by the additional surface area generated in this test.

Detailed inspection of ACC crush tubes was difficult despite efforts to obtain wellpolished sections using vacuum potting of pigmented epoxy. The commonly observed debris wedge was seen in the tube sections as well as delamination ahead of the debris wedge. Failure of the tubes seemed to be dominated by in-plane and through-thickness matrix cracking. Individual tows remained relatively intact with little fiber fracture. In general the failure of tubes was different than the strip crush specimens, but it was more like the loosely constrained than the unconstrained ones.

It was evident from the test results and failure observations that due to the poor quality of composites, the carbon fiber properties were not fully exploited in the panels and tubes. The matrix material was found to be defect sensitive, which would further limit the translation of carbon fiber properties to the composite. Better reproducibility would be expected from higher quality composites, but it is not clear that these would yield better energy absorption properties. Carbon fiber is not a high energy-absorbing material. The failure of the tubes and loosely constrained strip crush specimens was dominated by matrix failures and a higher quality composite that achieves more fiber fracture may not improve crashworthiness. While it is always desirable to improve material quality and therefore the 
repeatability of its performance, it is not clear what combination of matrix properties and fiber/matrix adhesion would yield optimum crashworthy carbon composite structures. 


\section{Introduction}

The work described herein summarizes an experimental program to support the development of new analytical and numerical tools to predict the performance of structural composites in vehicular crash and energy management applications. The combined analytical and experimental project was led by Edward Zywicz of Lawrence Livermore National Laboratory and is one of several in the Automotive Composite Consortium (ACC) Energy Management Working Group (EMWG). This particular project addresses the following goals of the EMWG as outlined by Richard Jeryan in the FY 1999 Progress Report on Modeling of Composite Materials for Energy Absorption:

- Experimentally determine the effects of material design, environment and loading on macroscopic crash performance to guide design and the development of predictive tools.

- Determine the key mechanisms responsible for crash energy absorption and examine the microstructural behavior of composites during crash to direct the development of material models.

- Develop analytical models for the prediction of energy absorption and crash behavior of components and structures.

The experimental work presented in this report is divided into three main sections: resin matrix characterization, braid panel characterization, and failure analysis of strip and tube crush specimens. The bulk of the work focussed on panel characterization to understand basic material response and failure mechanisms. A substantial effort was made to determine matrix properties for use in micromechanical modeling approaches. Failure characteristics of panels tested in uniaxial stress and panels and tubes tested in crush experiments were examined to pinpoint key failure mechanisms. 


\section{Hetron 922 Resin Characterization}

\subsection{Background}

The selection of a particular matrix material for crashworthy braided carbon fiber composites is based on a set of processing and performance criteria. These were specified by ACC and are listed in Table 2.1 below. The key criterion is the processing time; mold fill times are required to be 5-10 min. and the matrix must cure to adequate strength within 15-30 minutes after injection to allow demolding of the part. This relatively rapid processing requirement limits the choices of matrix materials to those based on free-radical polymerization. Such resins are typically not ductile materials, but ACC identified an epoxy vinyl ester resin, Hetron 922, produced by Ashland Chemical Co. (Columbus, $\mathrm{OH}$ ) which reportedly exhibits a tensile strain at failure of more than $6 \%$.

Table 2.1. Matrix Processing and Performance Specifications

\begin{tabular}{|l|l|}
\hline \multicolumn{1}{|c|}{ Processing Requirements } & \multicolumn{1}{c|}{ Performance Requirements } \\
\hline Injection pressure: $<80$ psi & Glass transition temp. $\left(\mathrm{T}_{\mathrm{q}}\right) ;>100^{\circ} \mathrm{C}$ \\
\hline Mold fill time: $5-10$ minutes & Tough resin (high tensile elongation). \\
\hline Amenable to vacuum-assisted injection & \\
\hline Mold temperature: $150^{\circ} \mathrm{F}$ & \\
\hline Demold after $15-30$ minutes at $150^{\circ} \mathrm{F}$ & \\
\hline Post-cure out of mold & \\
\hline
\end{tabular}

The components of the particular matrix systems used in the ACC studies are listed in Table 2.2. The Hetron resin is a solution of $55 \mathrm{wt} . \%$ epoxy vinyl ester solids in styrene. The styrene reduces the viscosity to 4.5 Poise, which is suitable for meeting the 5-10 min. mold fill time requirement. The cobalt promoter is a mixture of cobalt carboxylates $(55$ wt.\%) in a mineral spirits carrier (43 wt.\%), which yields an overall cobalt concentration of $6 \mathrm{wt} . \%$. The initiator is a solution of $34 \mathrm{wt} . \%$ methyl ethyl ketone peroxide in phlegmatizer. This particular initiator contains $9 \mathrm{wt} . \%$ active oxygen. 
Table 2.2. Components and Formulations of Hetron 922 matrix materials.

\begin{tabular}{|l|c|c|c|c|}
\hline Component & $\begin{array}{c}\text { Commercial } \\
\text { Name }\end{array}$ & Source & $\begin{array}{c}\text { Formulation \#1 } \\
\text { (wt.\%) }\end{array}$ & $\begin{array}{c}\text { Formulation \#2 } \\
\text { (wt.\%) }\end{array}$ \\
\hline Resin & Hetron 922 & $\begin{array}{c}\text { Ashland } \\
\text { Chemical Corp., } \\
\text { (Columbus, OH) }\end{array}$ & 98.94 & 98.24 \\
\hline Promoter & $\begin{array}{c}6 \% \text { Cobalt NAP- } \\
\text { ALL }\end{array}$ & $\begin{array}{c}\text { OMG Americas, } \\
\text { Inc. } \\
\text { (Westlake, OH) }\end{array}$ & 0.46 & 0.45 \\
\hline Promoter & $\begin{array}{c}\text { N,N- } \\
\text { Dimethylaniline } \\
\text { (DMA) }\end{array}$ & $\begin{array}{c}\text { Buffalo Color } \\
\text { Corp. } \\
\text { (Parsippany, NJ) }\end{array}$ & 0.057 & 0.057 \\
\hline Initiator & $\begin{array}{c}\text { NOROX MEKP-9 } \\
\text { Norac Co. } \\
\text { (Azusa, CA) }\end{array}$ & 0.54 & 1.25 \\
\hline
\end{tabular}

Typical physical properties given by the manufacturer for the cured Hetron 922 resin are summarized in Table 2.3. These are based on a resin cured with $1 \%$ BPO (benzoyl peroxide) using a cure cycle of $2 \mathrm{hr}$ at $160^{\circ} \mathrm{F}$, one hr at $200^{\circ} \mathrm{F}$, and $2 \mathrm{hr}$ at $280^{\circ} \mathrm{F}$. The most attractive property of this resin is the relatively high elongation at break. We did encounter problems reproducing this value consistently and this will be discussed later in the report. The disparity may be due to the different formulation and cure cycles used by us, but this was not investigated in our work.

Table 2.3. Typical room temperature physical properties of cured Hetron 922 castings.

\begin{tabular}{|l|c|c|}
\hline \multicolumn{1}{|c|}{ Property } & Value & Test Method \\
\hline Barcol Hardness & 30 & ASTM D-2583 \\
\hline Tensile Strength, ksi & 12.5 & ASTM D-638 \\
\hline Tensile Modulus, ksi & 460 & ASTM D-638 \\
\hline Tensile Elongation at Yield, \% & 4.9 & ASTM D-638 \\
\hline Tensile Elongation at Break, $\%$ & 6.7 & ASTM D-638 \\
\hline Flexural Strength, ksi & 20.5 & ASTM D-790 \\
\hline Flexural Modulus, $\mathrm{ksi}$ & 5.0 & ASTM D-790 \\
\hline Heat Distortion Temp. ${ }^{\circ} \mathrm{C}\left({ }^{\circ} \mathrm{F}\right)$ & $105(221)$ & ASTM D-648 \\
\hline Density, g/cc & 1.14 & \\
\hline
\end{tabular}




\subsection{Resin Formulations and Cure Cycles.}

Also given in Table 2.2 are the two formulations used in our studies of matrix properties. Formulation \#1 is approximately the same as that used by ACC to fabricate composite panels for our studies. The only difference is that we had a slightly reduced level of DMA ( 0.57 wt.\% v. 0.65 wt.\%) in our formulations, but this difference is not expected to have a significant effect on cured resin properties. The more important component is the MEKP initiator, which is normally kept at levels between 1.0 and $2.5 \mathrm{wt} . \%$ according to both the resin and initiator manufacturers. Thus the level of initiator chosen by ACC is below the normal range and we suspected that our initially poor tensile and shear test results were due to this difference in formulation. We examined the effect of the MEKP concentration by comparing the tensile performance of the ACC formulation (\#1) to one recommended by a technical representative of Ashland Chemical Corp., which is listed as formulation \#2 in Table 2.2 .

Initially we tried to mimic the actual curing of the Hetron resin that occurs during the molding of braided composite panels and tubes by curing at $66^{\circ} \mathrm{C}\left(150^{\circ} \mathrm{F}\right)$ for $30 \mathrm{~min}$. followed by a post-cure at $138^{\circ} \mathrm{C}\left(280^{\circ} \mathrm{F}\right)$ for 2 hours. The Hetron system is relatively exothermic (the manufacturer reports a peak exotherm temperature of $188^{\circ} \mathrm{C}\left(370^{\circ} \mathrm{F}\right)$ in a SPI Gel time test) and we encountered problems with shrinkage of the resin during this relatively rapid cure. Specimens cured in molds either fractured or solidified with poor surface quality due to this shrinkage. After discussion with technical representatives from Ashland, we altered the cure cycle to $24 \mathrm{hr}$ at room temperature followed by $2 \mathrm{hr}$ at $280^{\circ} \mathrm{F}$. This modified cycle resulted in much better quality specimens and fewer fractures during cure. 


\subsection{Dynamic Mechanical Properties}

The effect of altering the formulation and the cure cycle on the properties of the Hetron resin was examined using dynamic mechanical analysis (DMA). Cast cylinders having a diameter of $4.7 \mathrm{~mm}(0.185 \mathrm{in}$.) were tested in torsion using a Rheometrics RMS-800 Mechanical Spectrometer (Rheometrics, Inc., Piscataway, NJ). Tests were conducted by sweeping temperature from $30^{\circ}$ to $150^{\circ} \mathrm{C}$ at a ramp rate of $2^{\circ} \mathrm{C} / \mathrm{min}$. while deforming the specimen to a maximum shear strain of $0.2 \%$ at a frequency of $1 \mathrm{~Hz}$. Both formulations were examined and a typical set of viscoelastic data for a resin cured with $0.54 \mathrm{wt} . \%$ MEKP is shown in Fig. 2.1. The glass transition temperature $\left(T_{g}\right)$ is sensitive to degree of cure and changes in cure chemistry. This transition temperature can be defined three different ways from dynamic mechanical data and all three values are summarized in Table 2.4 for the two formulations. These values are the average of two runs for each formulation and they show that based on the thermal viscoelastic properties the two formulations are indistinguishable.

Table 2.4. Hetron $922 T_{g}$ values from DMA.

\begin{tabular}{|l|c|c|}
\hline \multirow{2}{*}{$T_{\mathbf{g}}$ Method } & \multicolumn{2}{|c|}{$\boldsymbol{T}_{\mathbf{g}}$ Value $\left({ }^{\circ} \mathbf{C}\right)$} \\
\cline { 2 - 3 } & $\begin{array}{c}\text { Formulation \#1 } \\
(0.54 \mathrm{wt} . \% \text { MEKP })\end{array}$ & $\begin{array}{c}\text { Formulation \#2 } \\
(1.25 \text { wt.\% MEKP })\end{array}$ \\
\hline Peak in $\tan \delta$ & 124 & 124 \\
\hline Peak in G' & 113 & 112 \\
\hline Line intersection in $\mathrm{G}^{\prime}$ & 112 & 110 \\
\hline
\end{tabular}


$\operatorname{Tan} \delta$

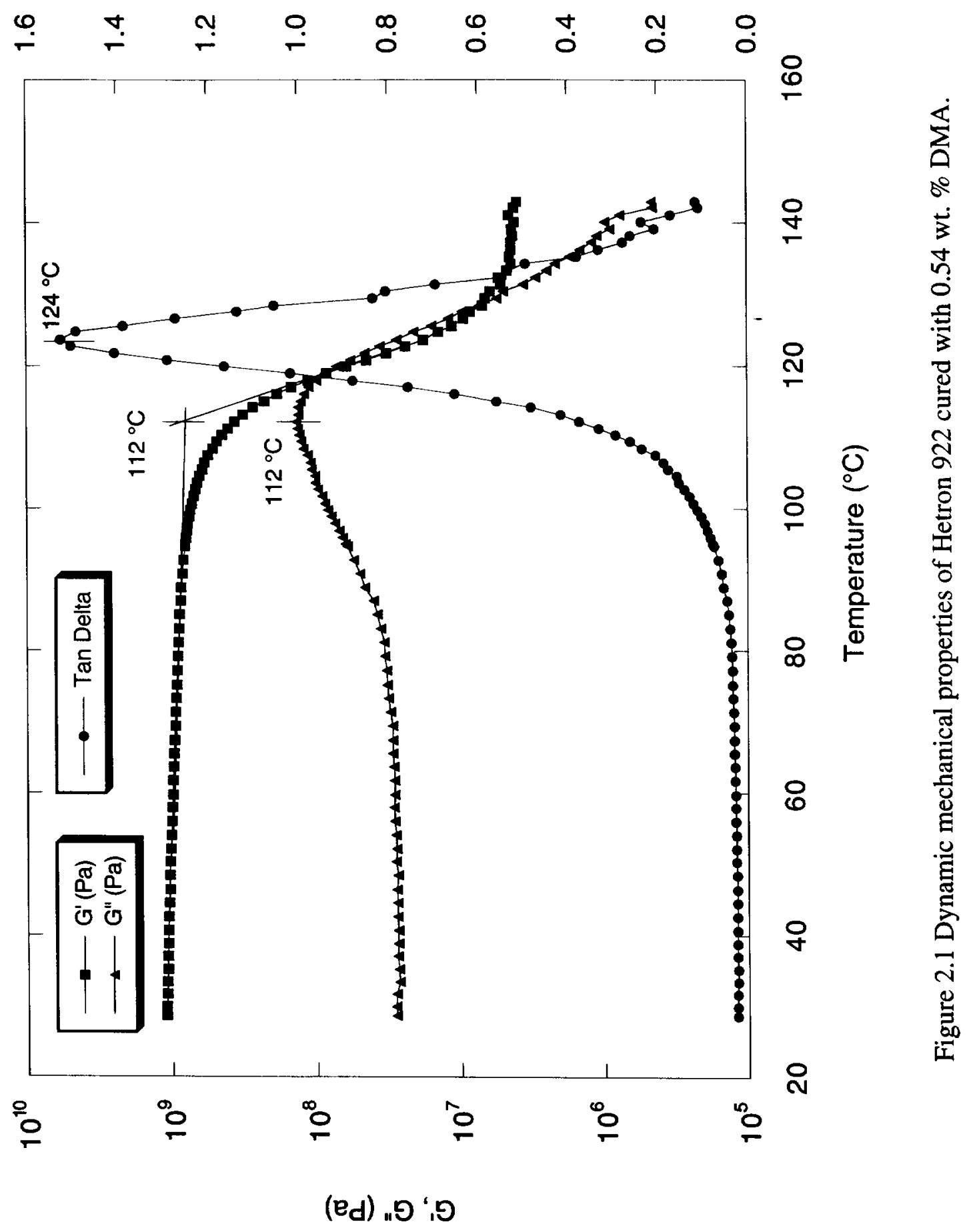




\subsection{Tensile Tests}

\subsubsection{Cylindrical Specimens}

It was our intention to investigate the effect of strain rate on the mechanical response of the Hetron 922 matrix material in both tensile and compressive loading. Past experience in performing high strain rate tensile tests with polymeric materials led to the development of a cylindrical specimen having conical ends [1]. A schematic of the specimen is shown in Fig. 2.2a. The advantages of the design are a relatively small size and gage length, which allows high strain rates to be generated in servo-hydraulic machines, and benign but firm gripping on the flared conical ends. This same specimen design has been used with brittle materials because specimen bending and stress concentrations in the grips are minimized. Conical specimens were cast using formulation \#1 and the cure cycle described in 2.2 . Initial attempts to cure the specimens in a manner similar to the composite panels resulted in fractures and poor surface quality as mentioned earlier. Specimens were then prepared using the room temperature cure and elevated temperature post-cure. The first specimens were left in the mold for the entire cure process and these exhibited surface defects and some fractures due to the restraint imposed by the mold on the conical ends during cooldown. A second set of specimens was prepared in a slightly different fashion in order to improve the quality of the surface. After curing for $24 \mathrm{hr}$ at room temperature, the molds were split open and the specimens were supported on one side for the post cure at $\left(138^{\circ} \mathrm{C}\right)$ $280^{\circ} \mathrm{F}$. This modification to the cure process resulted in much better quality specimens.

Specimens were tested using matched conical grips in an Instron Model 1125 mechanical test machine (Instron Corp., Canton, MA) at a strain rate of approximately $2 \mathrm{E}-4 \mathrm{~s}^{-1}$. Some of the first set of specimens were fitted with biaxial strain gages (Micromeasurements CEA-00-125UT-350, AE-10 epoxy adhesive) to allow determination of Young's modulus and Poisson's ratio. A plot of typical tensile response curves is shown in Fig. 2.3. Results of these tensile tests are summarized in Table 2.5. Values of Young's modulus determined from the first batch of specimens were widely scattered and this is most likely due to the poor quality of the specimens. Poisson's ratio was found to be approximately $1 / 3$. This value and the average value for Young's modulus were used in the identity relationship for elastic materials to determine an average shear modulus of $150 \mathrm{ksi}$. 
Table 2.5. Tensile properties of Hetron 922 obtained using cylindrical specimens.

\begin{tabular}{|c|c|c|c|c|c|}
\hline $\begin{array}{c}\text { Specimen } \\
\text { Type }\end{array}$ & $\begin{array}{c}\text { Specimen } \\
\text { Number }\end{array}$ & $\begin{array}{c}\text { Tensile } \\
\text { Modulus } \\
\text { (ksi) }\end{array}$ & $\begin{array}{c}\text { Poisson's } \\
\text { Ratio }\end{array}$ & $\begin{array}{c}\text { Tensile } \\
\text { Strength } \\
\text { (ksi) }\end{array}$ & $\begin{array}{c}\text { Tensile Elongation } \\
\text { at Break } \\
(\%)\end{array}$ \\
\hline $\begin{array}{c}\text { Post-cured in } \\
\text { mold }\end{array}$ & $1-2$ & 402.2 & 0.340 & 5.81 & 1.52 \\
\hline “ & $1-3$ & 464.1 & 0.339 & .5 .04 & 1.12 \\
\hline " & $2-1$ & 348.3 & 0.300 & 8.08 & 2.60 \\
\hline $\begin{array}{c}\text { Post-cured out } \\
\text { of mold }\end{array}$ & $4-1$ & - & - & 7.00 & - \\
\hline “ & $4-2$ & - & - & 9.40 & - \\
\hline “ & $4-3$ & - & - & 9.42 & - \\
\hline
\end{tabular}

There was an improvement in ultimate tensile strength for specimens that were post-cured in an open mold, but the average strength was still $30 \%$ lower than the manufacturer's value. Fracture surfaces were oriented at $90^{\circ}$ to the load direction and fracture initiated in all specimens at or near the surface as shown in Fig. 2.4a. In several specimens, the fracture occurred close to the transition region between the conical ends and the gage section. Both of these observations suggested that the cylindrical specimen was not suitable for determining tensile properties of the Hetron matrix material. Although we have had success with using this specimen for tensile tests of other thermosetting polymers, these relatively poor results obtained for the Hetron 922 resin prompted us to abandon the cylindrical tensile specimen and revert to the ASTM D-638 flat dogbone specimen. In doing so we sacrificed the ability to perform high rate tests in tension, but it was deemed more important to obtain valid data under quasi-static rates.

\subsubsection{ASTM D638 Specimens}

After further discussions with the technical support personnel of Ashland Chemical Co., we learned that they took several steps to achieve the high tensile properties reported in the Hetron 922 material datasheet. Plates are cast at room temperature for at least $24 \mathrm{hr}$ then machined into dogbone tensile specimens before post-curing. The machined specimens are post-cured for $2 \mathrm{hr}$ at $138^{\circ} \mathrm{C}\left(280^{\circ} \mathrm{F}\right)$ and slowly cooled back to room temperature. We followed these procedures using the two formulations and were able to produce Type I specimens that were free from surface defects. During fabrication of our plates, gel times were measured using a Shyodu Gel Timer (Paul Gardner Co., Pompano Beach, FL). The 
gel times for formulations \#1 and \#2 were $34 \mathrm{~min} ., 40 \mathrm{~s}$ and $13 \mathrm{~min} ., 12 \mathrm{~s}$, respectively. The increased concentration of MEKP initiator gave an expected increase in reaction rate, which might not be suitable for the ACC molding process. However, even at this higher initiator concentration, the reaction rate could be slowed to a level comparable to that observed for formulation \#1 by adjusting the concentrations of the promoters. It is usually more desirable to maintain the initiator concentration at recommended levels and adjust the promoter concentrations to achieve desired reaction rates. The polymeric network and therefore the properties of the cured material are mostly dependent on the initiator concentration.

These tensile specimens were also tested on the same test system used for cylindrical specimens, but only the axial strain was measured using an extensometer (MTS Corp., MN) with three-point contact. The strain rate for all tests was $7 \mathrm{E}-4 \mathrm{~s}^{-1}$. The tensile response curves for eight specimens each of formulations \#1 and \#2 are shown in Figs. 2.5 and 2.6, respectively. Property data obtained from these curves are summarized in Table 2.6. These data show that the tensile moduli of the two formulations are identical, which agrees with the DMA results discussed earlier. The ACC formulation (\#1) gave slightly higher strength and strain at failure, although the difference between the two formulations was not significant given the scatter of the results. The ultimate properties of formulation \#1 tended to be more consistent and the average tensile strength was close to that reported by the manufacturer (see Table 2.3). However, only one specimen of each formulation approached the reported value of elongation at break-most specimens failed at about $60 \%$ of this value. No clear relationship between ultimate properties and either the failure location (gage v. transition sections) or failure initiation points (surface v. interior) was observed. After discussing these results with technical support personnel from Ashland Chemical Co. it was learned that they also polish the machined edges of their specimens with fine abrasive paper prior to testing. Our results showed that failure occurred with equal likelihood from the interior and from the surface of specimens (see examples in Fig. 4b). This did not support the presumption that failure was initiated primarily by surface defects, so no attempt was made to repeat these tests using polished specimens. Compared to other thermosetting materials we have tested in the past, we would characterize the Hetron 922 system cured with either of the two formulations investigated here as a relatively ductile, but defect-sensitive material. 
Table 2.6. Tensile properties for two formulations of Hetron 922 obtained using ASTM D638 specimens.

\begin{tabular}{|c|c|c|c|c|c|}
\hline Specimen $^{(1)}$ & $\begin{array}{c}\text { Tensile } \\
\text { Modulus (ksi) }\end{array}$ & $\begin{array}{c}\text { Tensile } \\
\text { Strength (ksi) }\end{array}$ & $\begin{array}{c}\text { Elongation at } \\
\text { Break (\%) }\end{array}$ & $\begin{array}{c}\text { Fracture } \\
\text { Location }^{(2)}\end{array}$ & $\begin{array}{c}\text { Fracture } \\
\text { Initiation }^{(3)}\end{array}$ \\
\hline $1-1$ & 474 & 11.7 & 3.33 & $G$ & $S$ \\
\hline $1-2$ & 468 & 11.9 & 3.49 & $\mathrm{~T}$ & I \\
\hline $1-3$ & 470 & 12.3 & 3.77 & $\mathrm{~T}$ & $\cdot S$ \\
\hline $1-4$ & 469 & 12.4 & 3.78 & $\mathrm{~T}$ & $\mathrm{~S}$ \\
\hline $1-5$ & 464 & 10.9 & 2.92 & G & I \\
\hline $1-6$ & 431 & 13.1 & 6.25 & $\mathrm{~T}$ & $S$ \\
\hline $1-7$ & 466 & 11.8 & 3.29 & $\mathrm{~T}$ & $I$ \\
\hline $1-8$ & 487 & 12.6 & 3.74 & $\mathrm{~T}$ & $S$ \\
\hline $\begin{array}{r}\text { Avg: } \\
\text { SD: } \\
\text { CV }(\%): \\
\end{array}$ & $\begin{array}{c}466 \\
15.9 \\
3.4 \\
\end{array}$ & $\begin{array}{c}12.1 \\
0.7 \\
5.5 \\
\end{array}$ & $\begin{array}{c}3.82 \\
1.03 \\
26.8 \\
\end{array}$ & & \\
\hline $2-1$ & 465 & 13.0 & 4.54 & $\mathrm{~T}$ & $S$ \\
\hline $2-2$ & 484 & 12.0 & 3.27 & $\mathrm{G}$ & I \\
\hline $2-3$ & 461 & 10.0 & 2.48 & $\mathrm{G}$ & $\mathrm{I}$ \\
\hline $2-4$ & 476 & 13.0 & 5.60 & $\mathrm{~T}$ & $S$ \\
\hline $2-5$ & 480 & 7.35 & 1.70 & $\mathrm{~T}$ & $\mathrm{I}$ \\
\hline $2-6$ & 488 & 11.9 & 3.16 & $\mathrm{~T}$ & $S$ \\
\hline $2-7$ & 487 & 10.2 & 2.45 & $\mathrm{G}$ & I \\
\hline $2-8$ & 482 & 13.1 & 4.98 & $\mathrm{~T}$ & $\mathrm{I}$ \\
\hline $\begin{array}{r}\text { Avg: } \\
\text { SD: } \\
\text { CV }(\%):\end{array}$ & $\begin{array}{c}478 \\
10.0 \\
2.1\end{array}$ & $\begin{array}{c}11.3 \\
2.0 \\
17.8\end{array}$ & $\begin{array}{l}3.52 \\
1.37 \\
39.0\end{array}$ & & \\
\hline
\end{tabular}

(1) First number is formulation, second is specimen number.

(2) $\mathrm{G}=$ Gage section, $\mathrm{T}=$ near Transition between gage and grip sections.

(3) $\mathrm{S}=$ Surface. I = Internal 

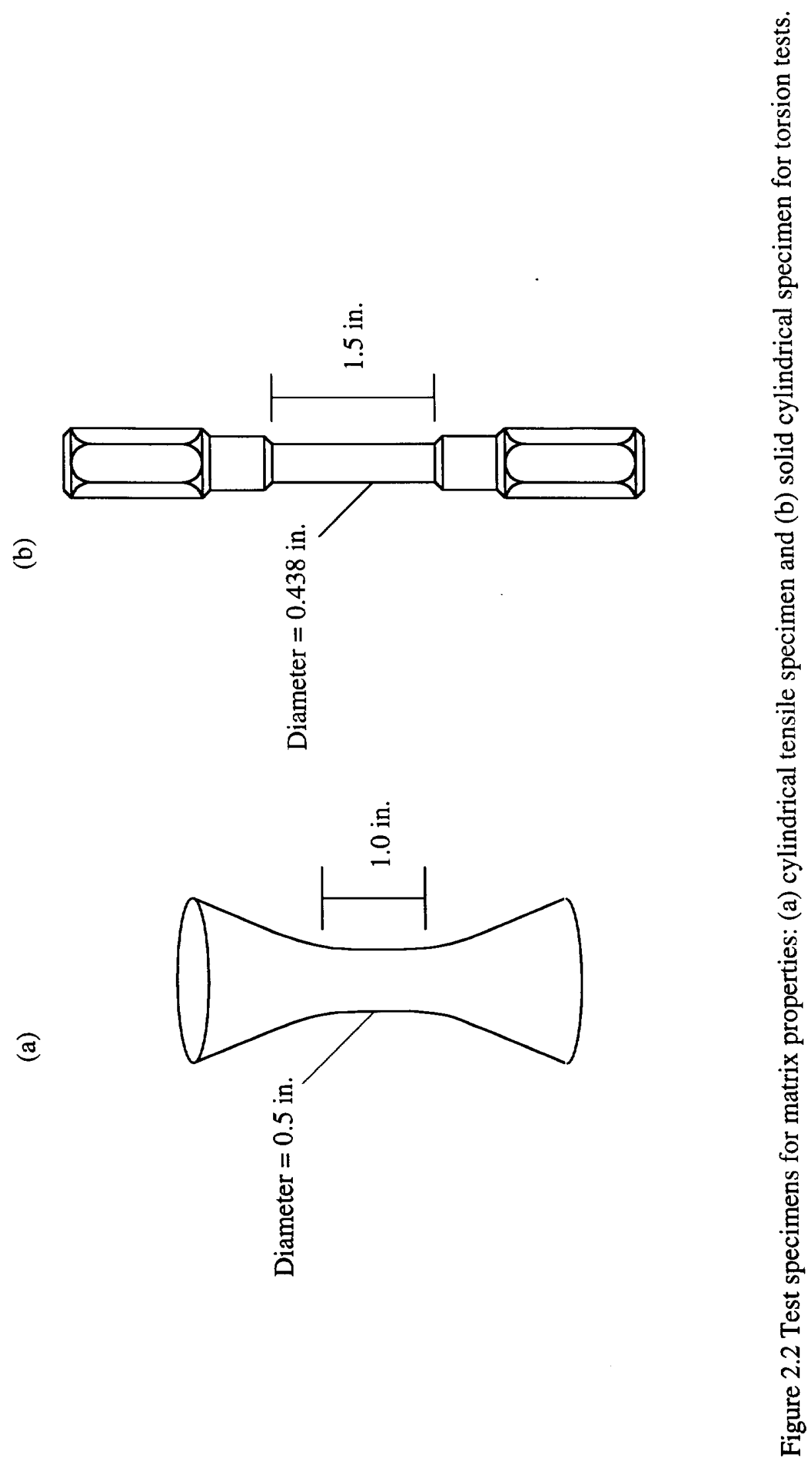


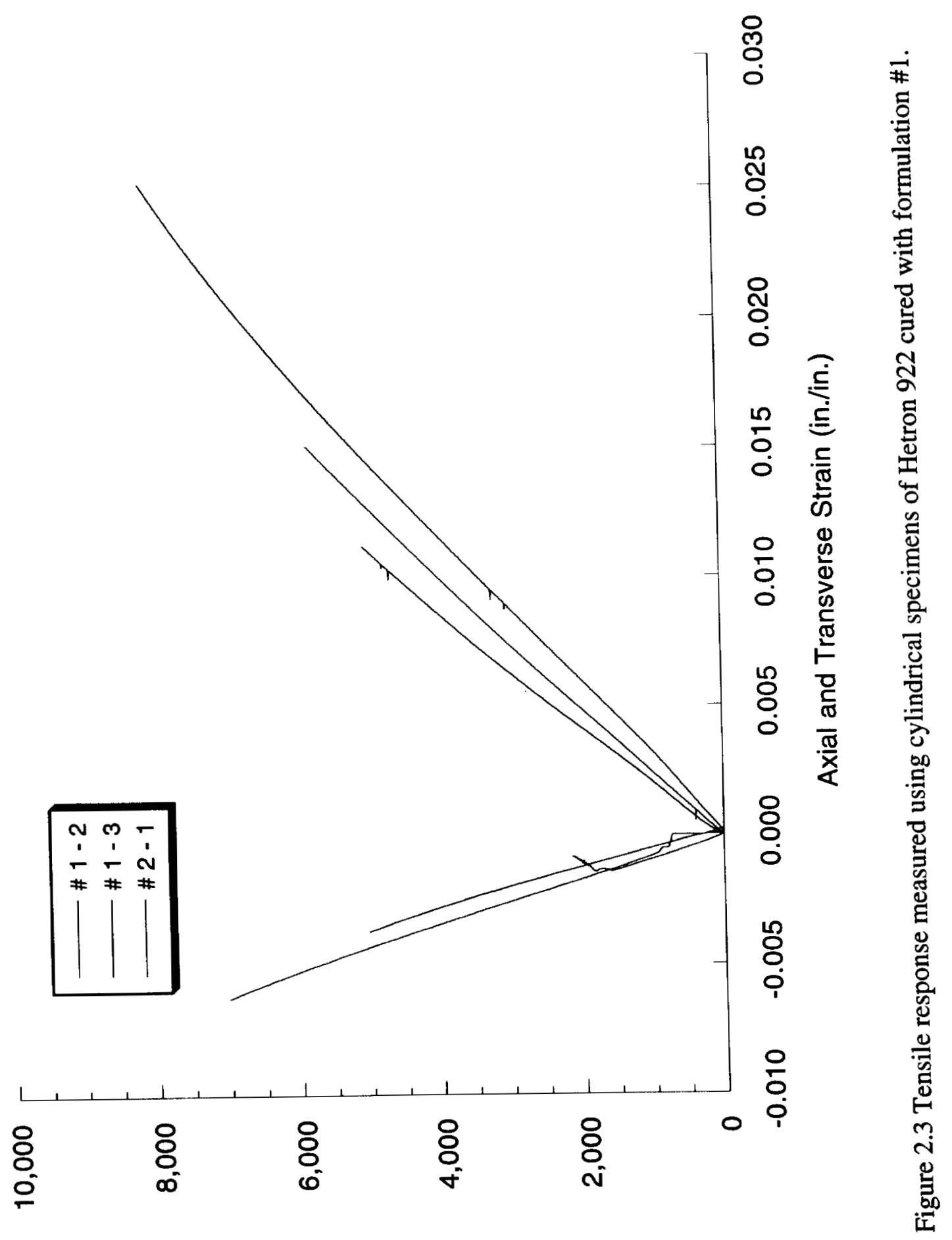

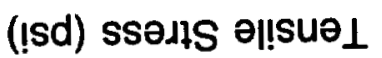



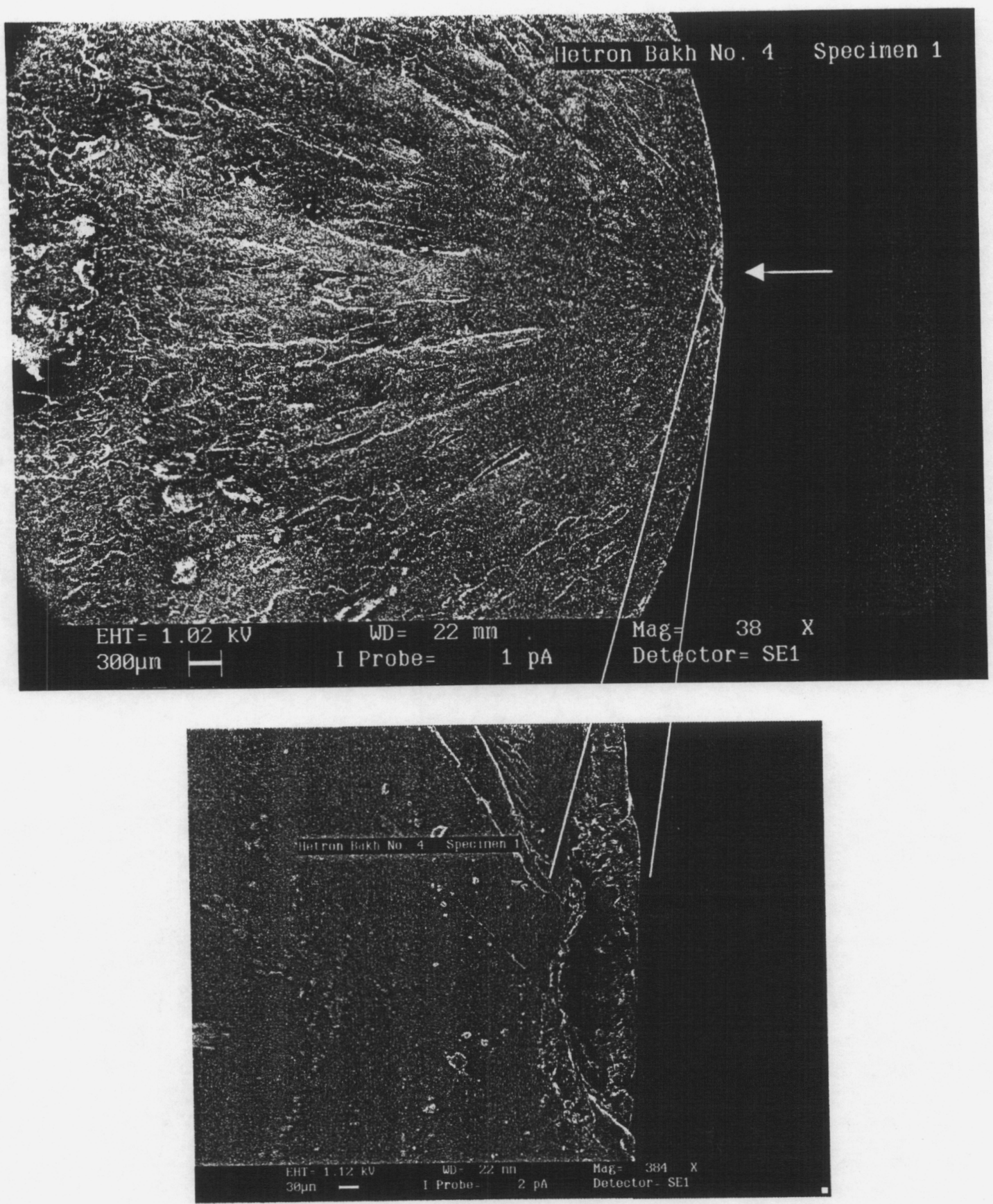

Figure 2.4a Fracture surface of cylindrical tensile specimen of Hetron 922 showing initiation point near surface. 
surface
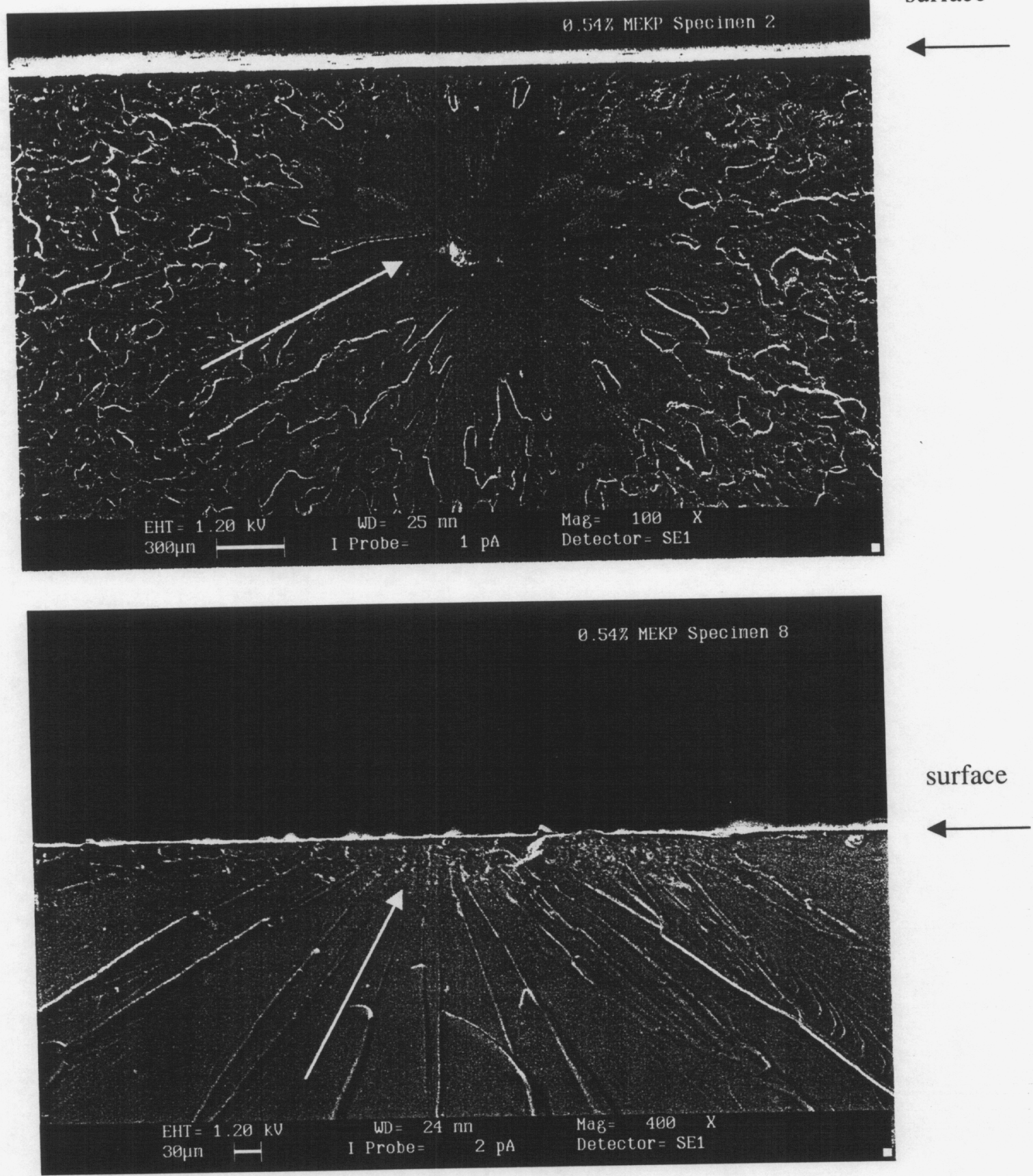

Figure 2.4b Fracture surface of ASTM D-638 tensile specimens of Hetron 922 showing initiation points on inside of one specimen and near the surface of another. 


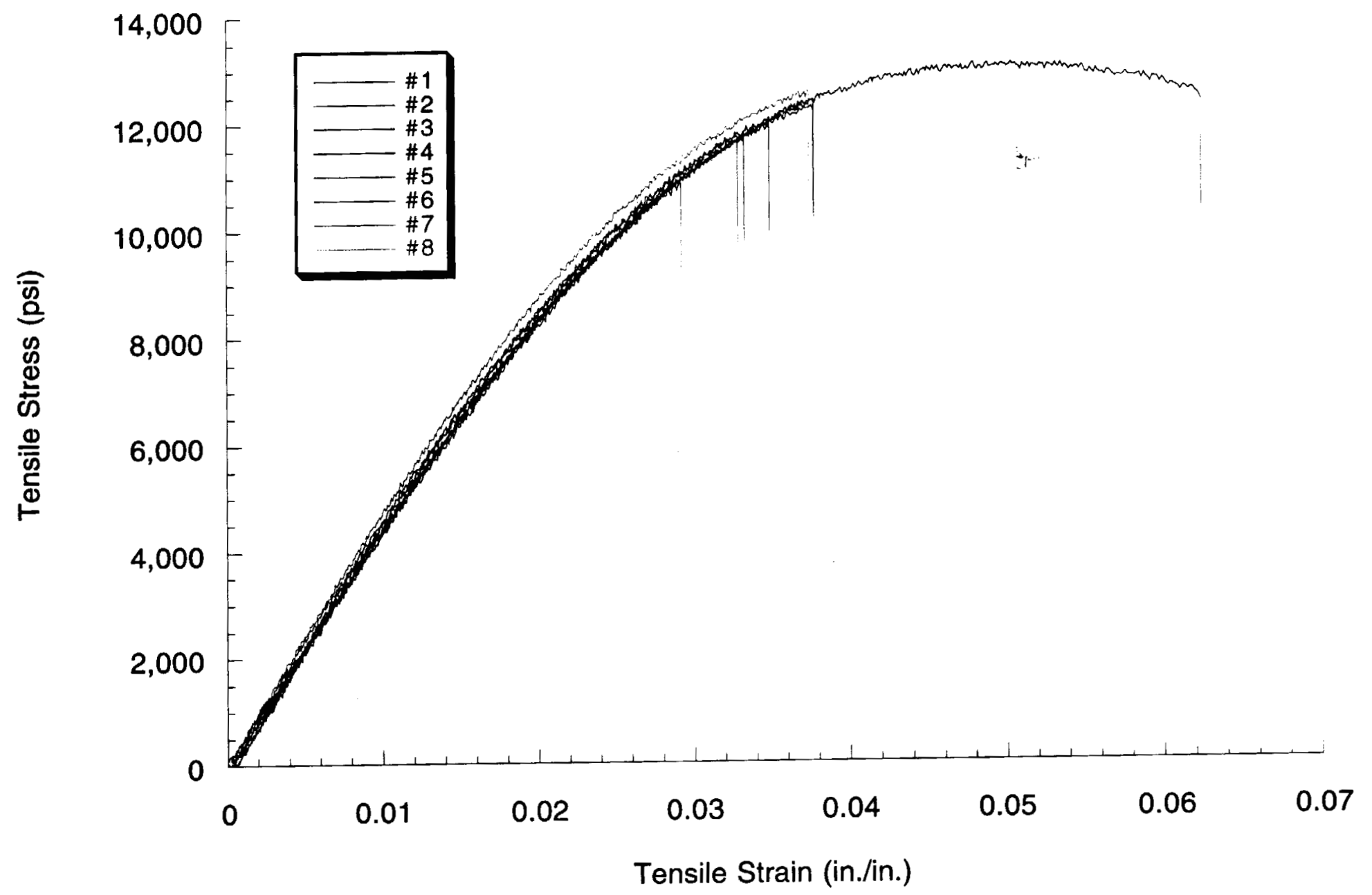

Figure 2.5 Tensile response measured according to ASTM D638 for Hetron 922 cured with formulation \#1. 


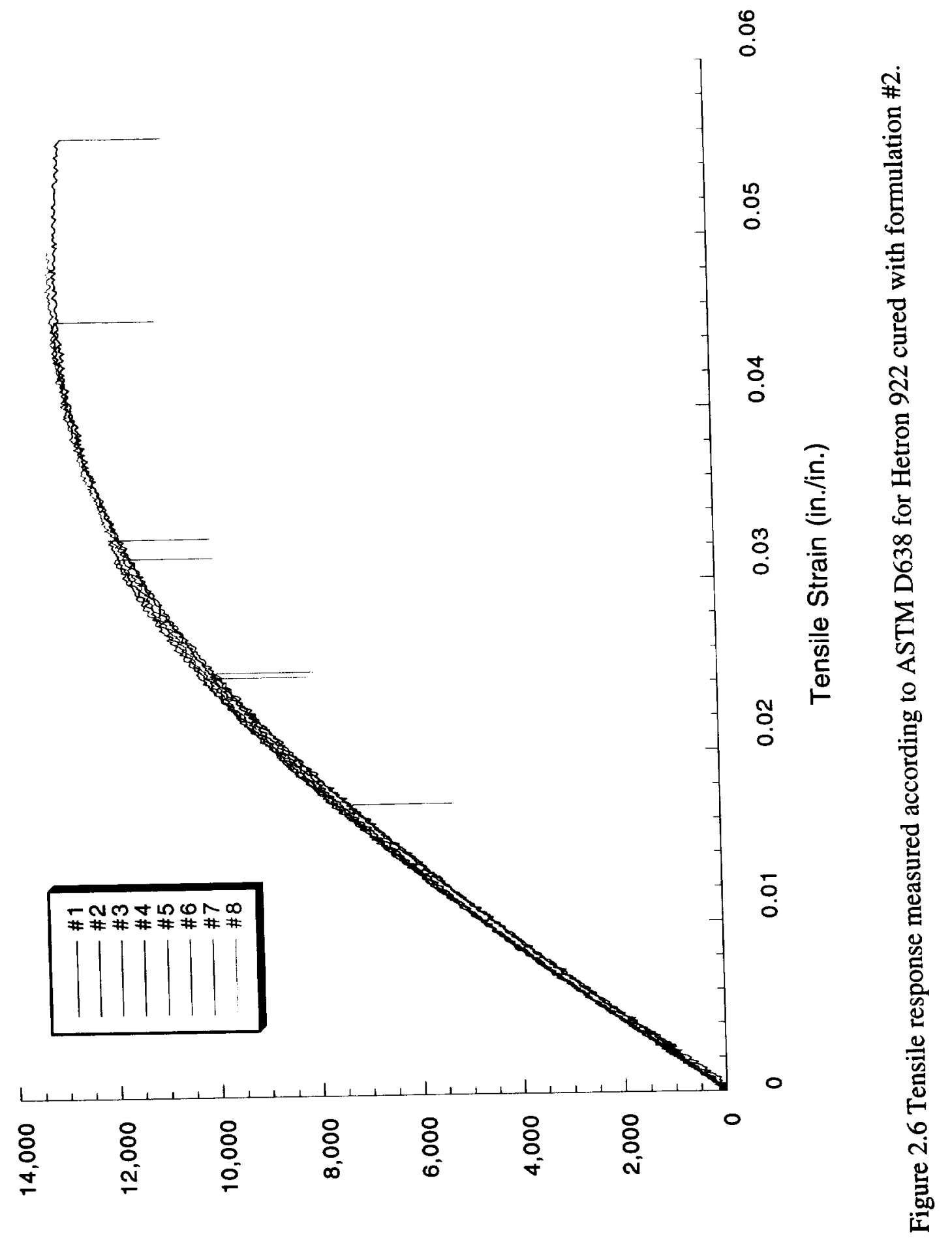

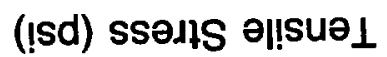




\subsection{Shear Tests}

The shear response of the Hetron resin was measured in torsion tests of solid cylindrical specimens. The specimens were cast in molds that provided hexagonal flats on the ends for gripping as shown schematically in Fig. 2.2b. Only formulation \#1 specimens were prepared and these were allowed to cure for at least $24 \mathrm{hr}$ at room temperature, followed by a post-cure at $138^{\circ} \mathrm{C}\left(280^{\circ} \mathrm{F}\right)$ for $2 \mathrm{hr}$ in an open mold. A biaxial strain gage (Micromeasurements CEA-00-125UT-350, AE-10 epoxy adhesive) was mounted on each specimen at $\pm 45^{\circ}$ to the cylinder axis to determine shear strain. Tests were conducted in a Model 1125 Instron test machine using Jacob's chuck grips. Specimens were deformed at two rotation rates in order to test for strain rate effects.

Data was reduced using an analysis first proposed by Nadai [2] to extract stress-strain response from the torsion of a solid cylinder. Under the assumption that the shear strain remains linearly distributed along the radius of the twisted cylinder, Nadai developed the following relation to calculate shear stress as a function of shear strain from measured torque-twist data

$$
\tau(\gamma)=\frac{3}{2 \pi R^{3}}\left[M+\frac{1}{3} \gamma \frac{\partial M}{\partial \gamma}\right]
$$

where

$$
\begin{aligned}
& \gamma=\text { engineering shear strain } \\
& R=\text { cylinder radius } \\
& M=\text { torque }
\end{aligned}
$$

Nadai proposed the use of this relation only for materials that exhibit a monotonically increasing shear stress-strain response, but more recent work by Lyon [3] claims that (2.1) is applicable for any general response.

Results from the tests of five specimens are shown in Fig. 2.7 and properties calculated from these stress-strain curves are summarized in Table 2.7. The shear moduli are about 15-20\% greater than those measured in DMA tests or calculated from tensile moduli and Poisson's ratio values. The specimens tested at the slower rate $\left(4 \mathrm{E}-5 \mathrm{~s}^{-1}\right)$ exhibited some yield behavior, but those deformed at a 100 times faster rate were relatively brittle. Shear strengths were approximately half of the tensile strengths and fracture surfaces were predominantly helical planes oriented at $45^{\circ}$ to the cylinder axis. This indicates that failure in torsion was due to the principal tensile stress exceeding a maximum value. Several of 
the specimens failed in both the gage and grip sections. For the number of specimens tested and the scatter of the results obtained, no effect of rate on either elastic response or ultimate properties could be discerned. Due to the brittle nature of failure in these torsion tests, further work to characterize the rate effects in shear was abandoned in favor of compression testing, which is described in the next section.

Table 2.7. Shear properties of Hetron 922 resin.

\begin{tabular}{|c|c|c|c|c|}
\hline Specimen & $\begin{array}{c}\text { Strain Rate } \\
\left(\mathbf{s}^{\mathbf{1}}\right)\end{array}$ & $\begin{array}{c}\text { Shear Modulus } \\
(\mathbf{k s i})\end{array}$ & $\begin{array}{c}\text { Shear Strength } \\
(\mathbf{k s i})\end{array}$ & $\begin{array}{c}\text { Shear Strain at } \\
\text { Failure (\%) }\end{array}$ \\
\hline $3-1$ & 4 E-5 & 199 & 5.38 & 13 \\
\hline $3-6$ & “ & 194 & 5.58 & $>5$ \\
\hline $3-2$ & 4 E-3 & 197 & 6.90 & 5 \\
\hline $3-3$ & " & 204 & 4.27 & 2 \\
\hline $3-4$ & " & 199 & 4.33 & 2 \\
\hline
\end{tabular}




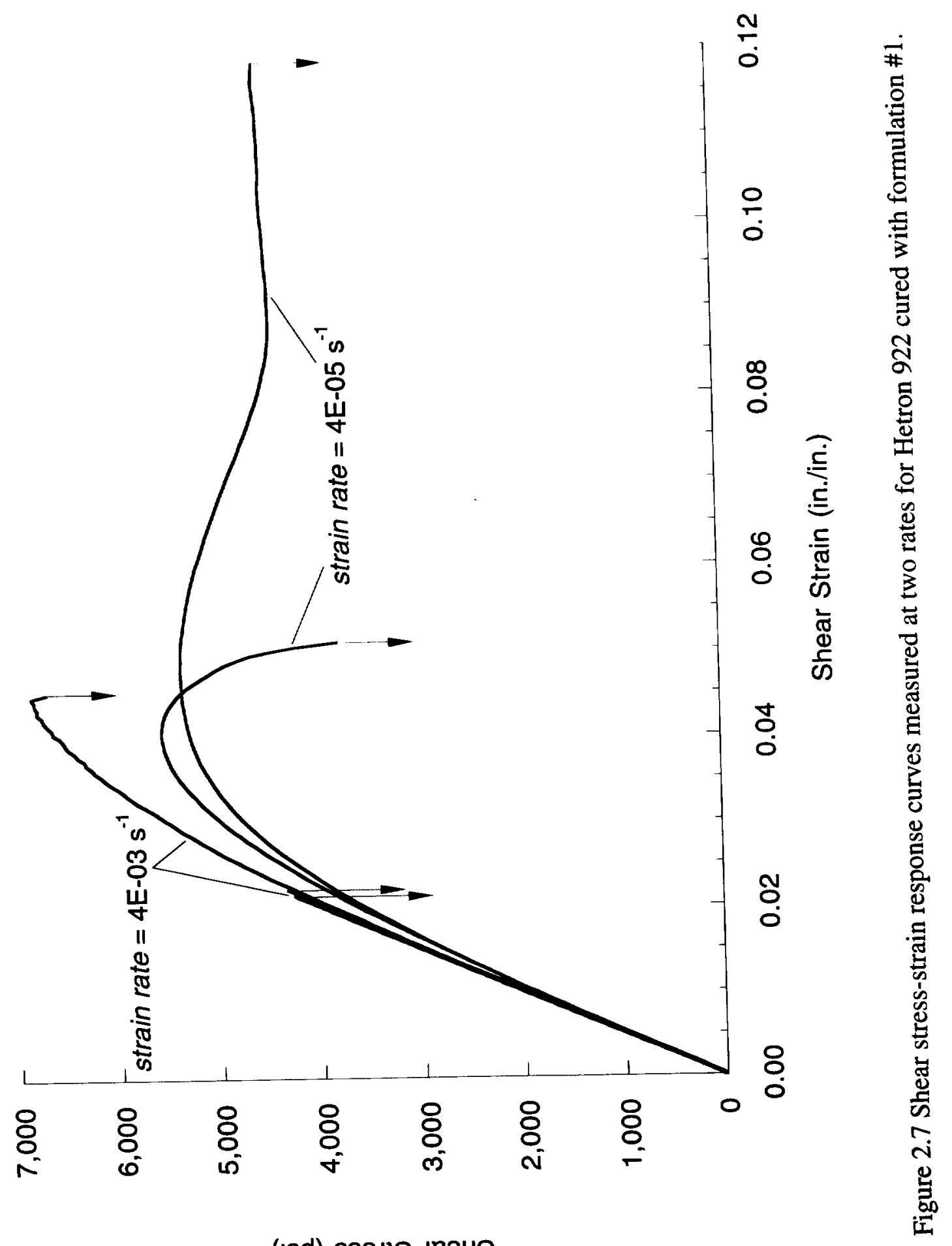

(!sd) ssəגS Jeә4S 


\subsection{Compression Tests and Rate Effects}

The effect of deformation rate on the uniaxial compression behavior of the Hetron 922 resin was characterized for formulation \#1. Cylinders approximately 0.32 in. in diameter were cast using the standard cure cycle ( $24 \mathrm{hr}$ at room temperature followed by $2 \mathrm{hr}$ at $\left.138^{\circ} \mathrm{C}\left(280^{\circ} \mathrm{F}\right)\right)$. Since the intent of these tests was to determine both the compression stress-strain response and the effects of rate on this behavior, most were conducted using a specimen that is amenable to high-rate testing using a split Hopkinson bar apparatus. These tests usually require specimens having an aspect ratio of length to diameter that is close to unity. In contrast, standard uniaxial compression specimens used in quasi-static tests require aspect ratios of 2-4 [4]. We compromised on these dimensions and selected an aspect ratio of 1.25 for all tests. This allowed us to make a comparison of rate effects among all tests. Since this aspect ratio leads to a stress state that is not pure uniaxial, we also conducted some quasi-static tests using an aspect ratio of 2 in order to assess the effect of multiaxial stresses on the yield behavior in compression tests of the 1.25 aspect ratio specimens. The compressive stress-strain response of the longer specimens was identical to that measured using the 1.25 aspect ratio specimen. Therefore it was concluded that the data obtained from the shorter specimen was representative of the uniaxial stress-strain response.

All compression specimens were ground to produce a tolerance on flatness and parallelism between the ends within $\pm 0.000 \mathrm{in}$. Tests at rates from $10^{-4} \mathrm{~s}^{-1}$ to $10^{1} \mathrm{~s}^{-1}$ were conducted using a MTS servohydraulic test machine equipped with precisely aligned steel platens and a 5 kip load cell. The platen displacement was measured using a MTS extensometer and this displacement was used to calculate engineering strain. The split Hopkinson pressure bar apparatus used for high-rate tests consisted of aluminum transmitter and receiver bars and a gas-gun impact system.

Typical stress-strain response curves for all tests up to a strain rate of $10^{1} \mathrm{~s}^{-1}$ are shown in Fig. 2.8. Results were very reproducible and therefore only two repeats were made at any given rate. Properties obtained from these curves are summarized in Table 2.8. Yield strength was defined as the maximum stress value and flow stress was taken as the stress at $15 \%$ engineering strain. Although these specimens were deformed to nearly $20 \%$ strain, all were permanently deformed into "barrel" shapes without fracturing. 
Table 2.8. Compression properties versus strain rate for Hetron 922.

\begin{tabular}{|c|c|c|c|}
\hline Strain Rate $\left(\mathbf{s}^{-1}\right)$ & $\begin{array}{c}\text { Compression } \\
\text { Modulus (ksi) }\end{array}$ & $\begin{array}{c}\text { Yield } \\
\text { Strength } \\
(\mathbf{k s i})\end{array}$ & $\begin{array}{c}\text { Flow Stress } \\
(\mathbf{k s i})\end{array}$ \\
\hline $9.86 \mathrm{E}-5$ & 460 & 15.1 & 13.0 \\
\hline $9.81 \mathrm{E}-4$ & 475 & 16.5 & 14.0 \\
\hline $9.94 \mathrm{E}-3$ & 488 & 17.9 & 14.6 \\
\hline $1.00 \mathrm{E}-1$ & 504 & 19.7 & 15.9 \\
\hline $1.01 \mathrm{E}+0$ & 520 & 21.4 & 17.2 \\
\hline $9.42 \mathrm{E}+0$ & - & 23.1 & 17.8 \\
\hline $9.55 \mathrm{E}+2$ & - & 29.6 & - \\
\hline
\end{tabular}

A typical response curve for compression tests in the split Hopkinson bar apparatus at rates of about $1000 \mathrm{~s}^{-1}$ is shown in Fig. 2.9. Despite the obvious wave effects in the data, the curve is somewhat similar to those measured at the slower rates. Since useful data is only obtained after several stress waves have traversed the specimen, only yield strength data were collected from these tests. These high-rate data are also given in Table 2.8. It is interesting to note that the mode of failure changed when the material was tested at these higher rates. Although the ultimate strain levels achieved in the split Hopkinson bar tests were less than those of the slower rate tests, all specimens fractured when tested at the high rates.

The dependence of elastic and ultimate compression properties of Hetron 922 on strain rate were found to be adequately described by power law behavior of the form

$$
X=X_{0} \dot{\varepsilon}^{m}
$$

where $X$ is the property of interest, $X_{0}$ is the value of that property at a strain rate of $1 \mathrm{~s}^{-1}$, and $m$ is a constant. In addition to the compression moduli obtained from the rate tests, estimates of shear moduli over a wide range of values were determined from DMA at temperatures from $-30^{\circ}$ to $30^{\circ} \mathrm{C}$ and frequencies from 0.1 to $10 \mathrm{rad} / \mathrm{s}$. These data were shifted according to the time-temperature superposition principal [see, for example, J. J. Aklonis and W. J. MacKnight, Introduction to Polymer Viscoelasticity, WileyInterscience, New York, 1983, pp 36-56.] to a single reference temperature of $18^{\circ} \mathrm{C}$ in order to yield a master curve for the effect of strain rate on shear modulus. Normalized values of shear moduli thus obtained and compression moduli measured directly are 
plotted versus strain rate in Fig. 2.10. The lines drawn through these data represent the best fit of the relation (2.2). A similar plot for yield and flow stresses versus strain rate for both the 1.25:1 and 2:1 aspect ratio specimens is given in Fig. 2.11. The parameters obtained from the fit of (2.2) to these data are summarized in Table 2.9.

Table 2.9. Power law fit parameters for the effect of strain rate on mechanical properties of Hetron 922.

\begin{tabular}{|l|c|c|}
\hline \multicolumn{1}{|c|}{ Property } & $\boldsymbol{X}_{\mathbf{0}}(\mathbf{k s i})$ & $\boldsymbol{m}$ \\
\hline Compression modulus & 519.49 & 0.01317 \\
\hline Dynamic shear modulus & 171.99 & 0.00791 \\
\hline Compression yield stress & 21.70 & 0.04090 \\
\hline Compression flow stress & 16.87 & 0.02827 \\
\hline
\end{tabular}

The magnitude of the strain rate effect, as embodied in the parameter $m$, was found to be 2 to 5 times greater for ultimate than for elastic properties. The effect of rate on the compression modulus, which was measured directly, was found to be about twice that determined from DMA and application of the time-temperature superposition principal. In considering the normal inaccuracies of applying this principal to the behavior of polymers at temperatures significantly below the glass transition temperature, we believe the more accurate results are for the effects of rate on compression modulus.

The most significant rate effect was the increase in yield stress. This value increased $10 \%$ for each decade increase in strain rate and this relationship appeared to hold up through the strain rates of nearly $1000 \mathrm{~s}^{-1}$ applied in the split Hopkinson bar tests. The increase in flow stress with rate was somewhat less-about $6.7 \%$ per decade of strain rate. There is less certainty in this value due to the significant shape distortion (barreling) of the specimen that occurs after the yield stress has been reached. 


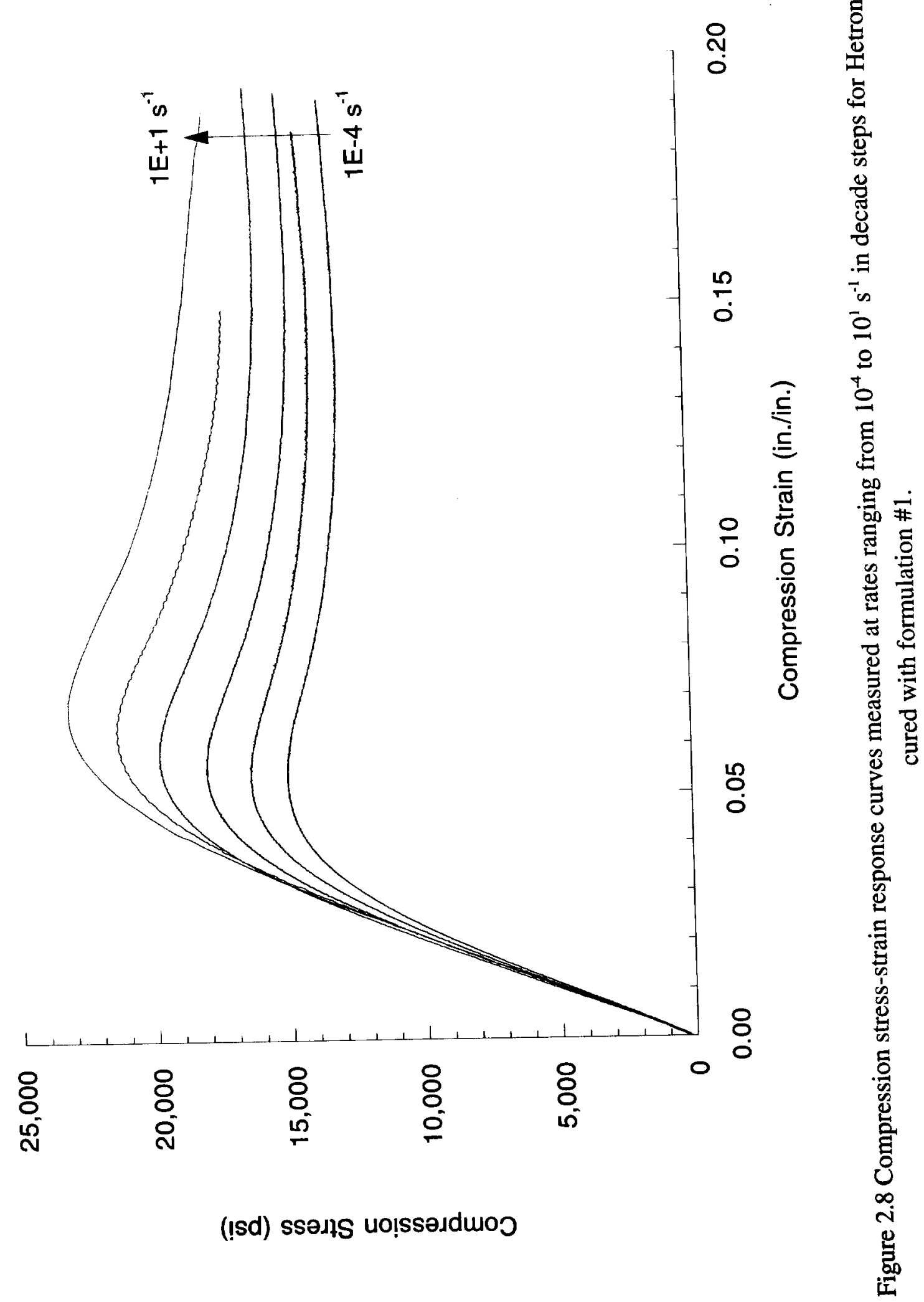

- 


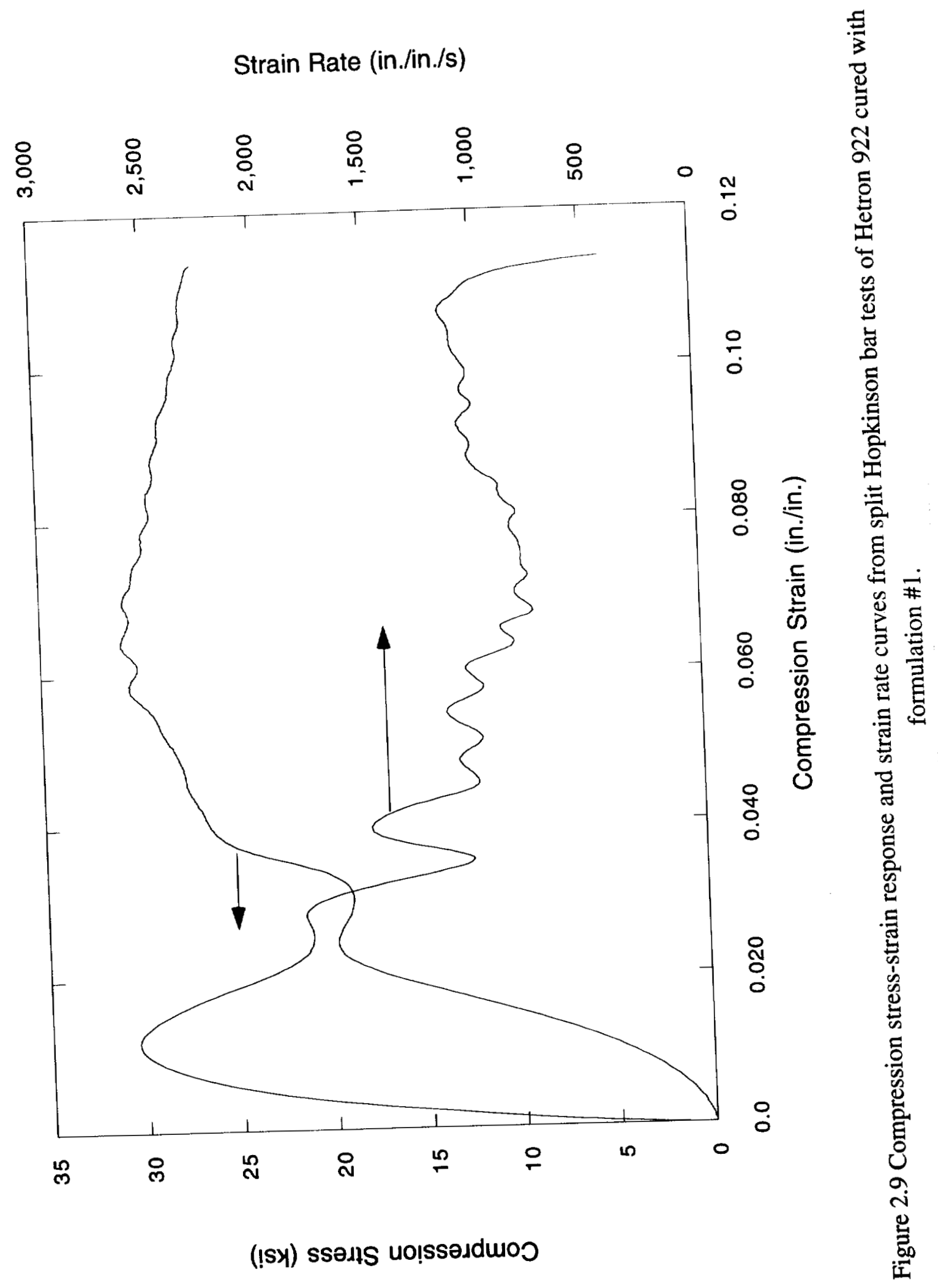




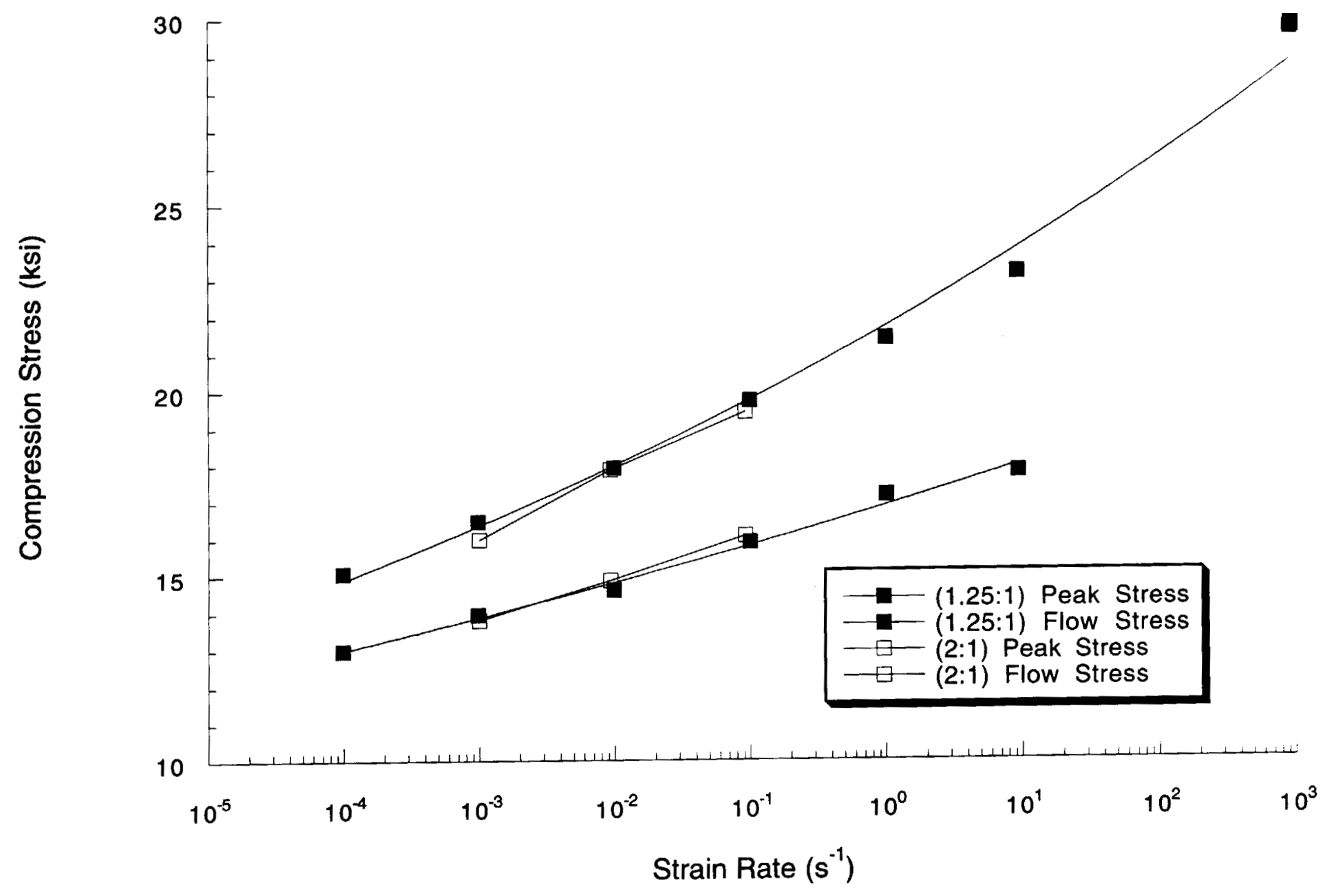

Figure 2.10 Effect of strain rate on compression yield (peak) and flow stresses of Hetron 922 cured with formulation \#1. 


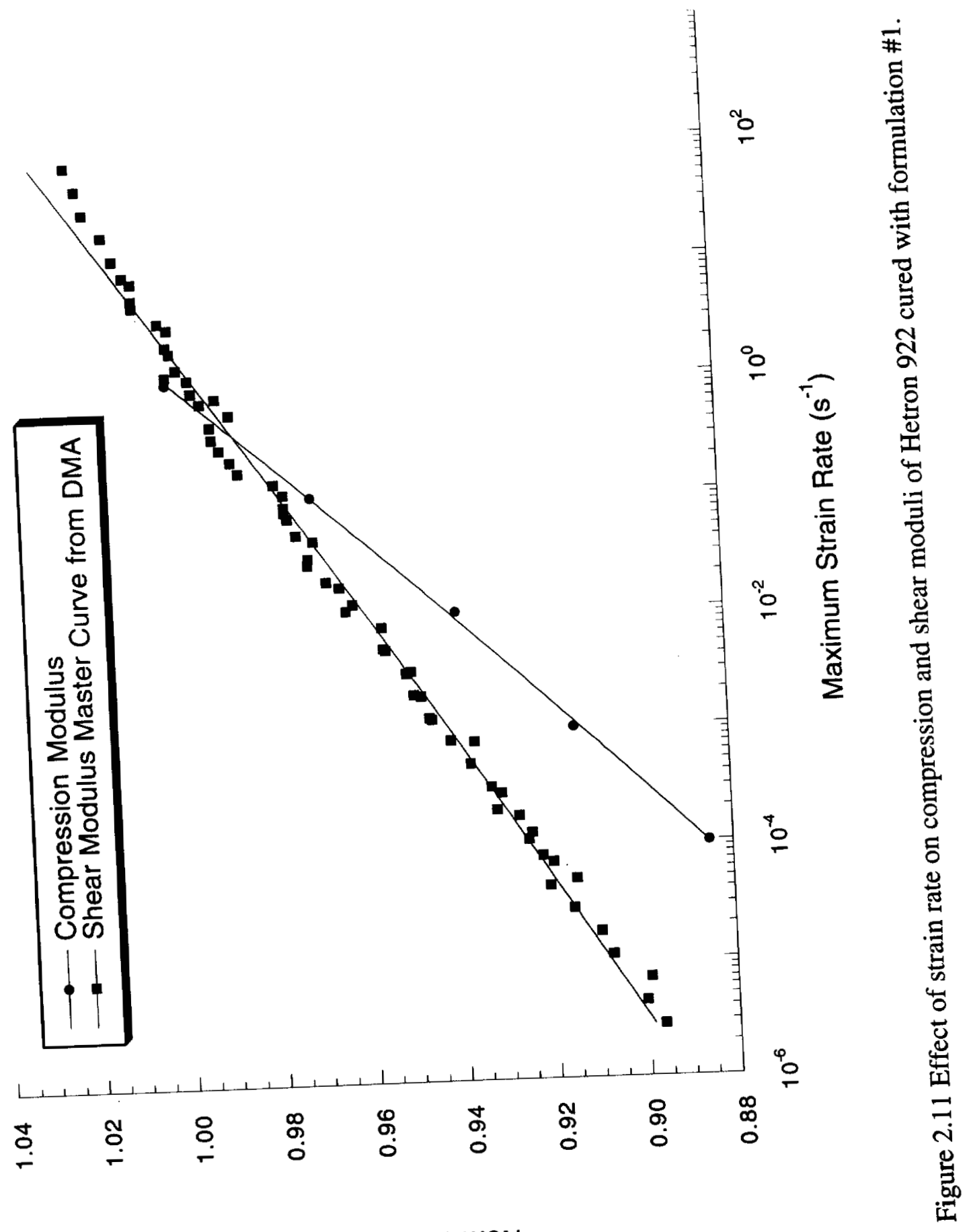

snjnpow pəz!ןeusoN 


\section{Flat Panel Mechanical Testing}

\subsection{Panel Quality}

Materials received from ACC consisted of six flat panels, 26 in. square by ca. 0.12 in. thick, as well as six molded square cross-section tubes. All molded materials were made from Hetron 922 resin and two layers of a $0 / \pm 30$ braid of Fortafil \#556 80k carbon fiber tows (Akzo Nobel). The tows had a yield of $340 \mathrm{ft} / \mathrm{lb}$, filament diameter of $6.2 \mu \mathrm{m}$, and 2.5 wt. \% of a sizing that is compatible with vinyl ester resins. The braid was fabricated using 60 carriers each for the three tow directions at a density of 2.5 tows per inch. Data provided by ACC showed that the panels contained 58 wt. \% (45 vol. \%) fiber and 3.7 vol. $\%$ voids. The properties provided by the manufacturer for the carbon fiber are listed in Table 3.1

Table 3.1. Properties of Fortafil 80k carbon fiber.

\begin{tabular}{|l|c|}
\hline \multicolumn{1}{|c|}{ Property } & Value \\
\hline Tensile Strength (ksi) & 550 \\
\hline Tensile Modulus (Msi) & 33.5 \\
\hline Ultimate Elongation (\%) & 1.64 \\
\hline Density $(\mathrm{g} / \mathrm{cc})$ & 1.8 \\
\hline Filament Diameter $(\mu \mathrm{m})$ & 6 \\
\hline Yield for $80 \mathrm{k}$ Tow $(\mathrm{ft} / \mathrm{lb})$ & 340 \\
\hline Sizing Content $(\mathrm{wt} . \%)$ & 2.5 \\
\hline
\end{tabular}

All flat panels were warped and had surface bumps. There were obvious resin-rich regions that allowed light to pass through the thickness of the panel. Approximately 2-3 in. of the edges were poor quality material that had poor tow distribution and alignment and contained masking tape (presumably the tape was used to anchor the braid during mold fill). The panels appeared to have been center-injected and a resin-rich circular step was molded at the center where the port had been located. Only the central portion of a panel was used to manufacture test specimens, but even this region exhibited some nonuniform microstructure. The tow paths and spacings for the $0^{\circ}$ and $30^{\circ}$ tows of a typical panel were traced within the central 22 by 17 in. section. The resulting patterns are shown in Figs. 3.1 and 3.2. The $0^{\circ}$ tows were oriented at about $5^{\circ}$ away from the edge of the panel. The maximum deviation of the tow path from a mean $0^{\circ}$ value was about $\pm 4^{\circ}$. Tow spacing was 
also nonuniform and ranged from 0.30 to $0.60 \mathrm{in}$. for the $0^{\circ}$ tows. The off-axis $\pm 30^{\circ}$ fiber tows exhibited more noticeable misalignment and nonuniform spacing as shown in Fig. 3.2. In this figure, only the path of every fourth tow is traced for clarity. The lines in this figure are the actual lengths of "exposed" braid tows on the surface of the panels, which is indicative of the spacing between tows. Tow orientation was measured with respect to the reference line for the $0^{\circ}$ tows and was found to range from $19^{\circ}$ to $36^{\circ}$. The nonuniform tow distribution is also evident by the numerous resin-rich spots seen in all panels. A backlit photograph of a panel given in Fig. 3.3 shows these resin-rich areas. Their presence indicates that in some regions of the panel the two braided layers are lying directly on top of each other rather than in a nested fashion.

Every panel was marked with a reference line for an average $0^{\circ}$ tow orientation and mechanical test specimens having different orientations were machined relative to this reference. Most tests were conducted using 1.5 in. wide specimens, which gave an average of 6-8 $0^{\circ}$ tows per specimen. Slightly narrower specimens having $1.0 \mathrm{in}$. of width were used for examining the effects of rate on mechanical properties. This was necessary in order to use existing lightweight grips, which were required to achieve the desired strain rate. The first specimens tested were machined from a panel using a numerically -controlled milling machine equipped with a small diameter two-flute carbide end mill to produce an oversize specimen that would be brought to final dimensions using a surface grinder. The milling operation left a rectangular hole in the panel, which allowed us to track the origin of a specimen. It was during the milling step that we first noticed the dry and poorly bonded nature of the composite. Edges of milled pieces had significant amounts of "fuzzy" carbon fiber that appeared to have little or no matrix material. An example of this milled surface is shown in Fig. 3.4. After several tests, we found no direct relationship between properties and panel location of the specimen. We then decided to abandon the milling step in favor of machining the specimens using a diamond cut-off saw. All machining operations were conducted using flood coolant to minimize detrimental frictional heating effects. All specimens were tested without tabbing. 
9I-0I [auted yV

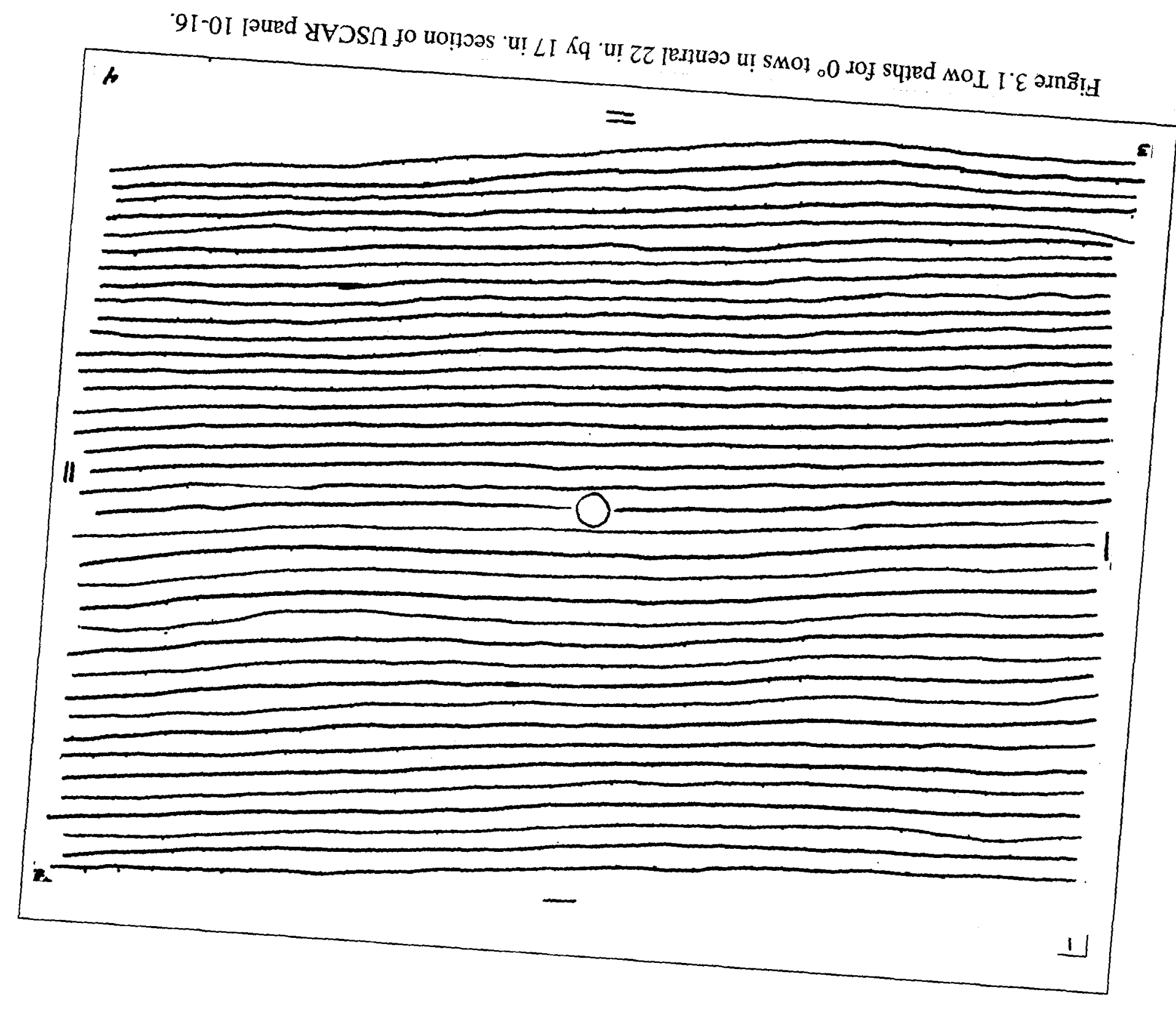




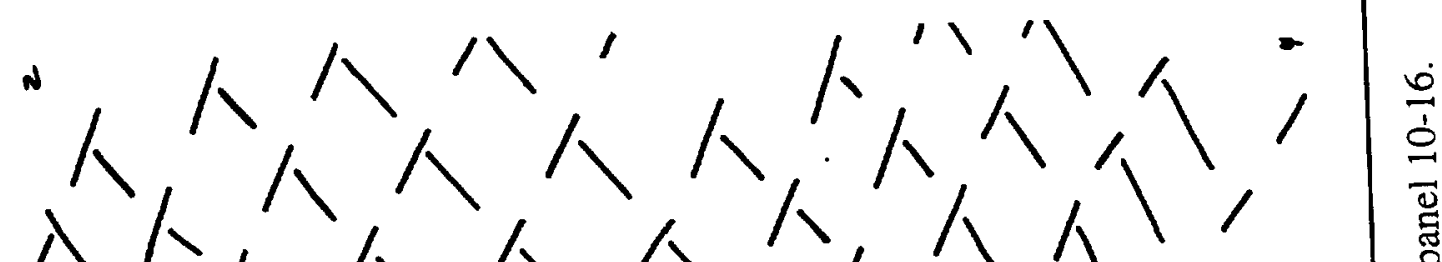

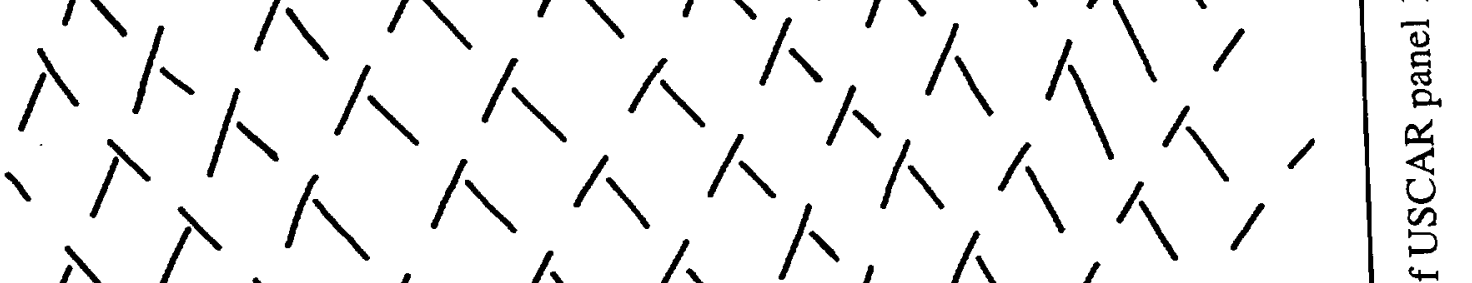
八入入人人久人人久人'

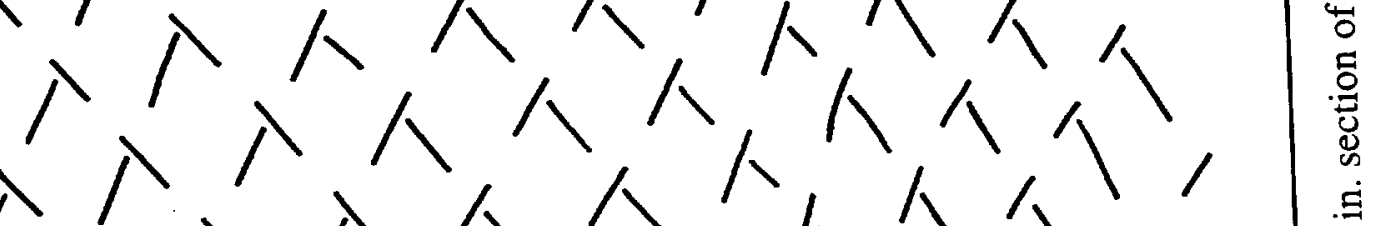
$\lambda 入 \lambda \lambda \wedge \wedge \wedge \Lambda 八 1$

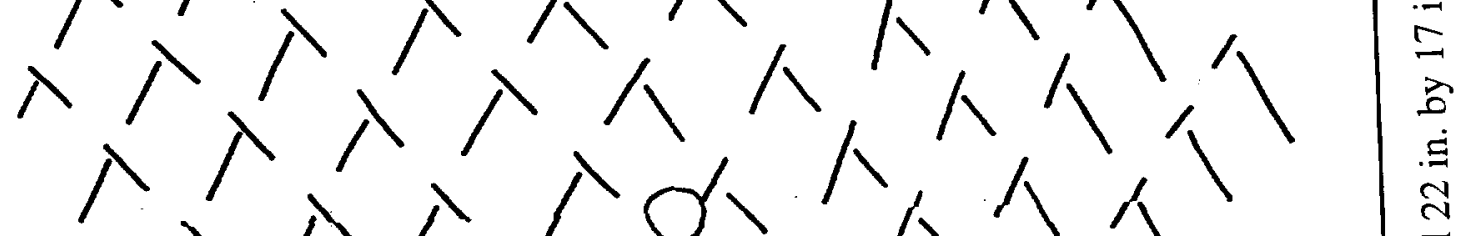
$\lambda \lambda \lambda^{\lambda} \lambda \lambda \wedge \lambda \wedge \lambda 入$ $\lambda \lambda \lambda \lambda \lambda \lambda$ 人久久

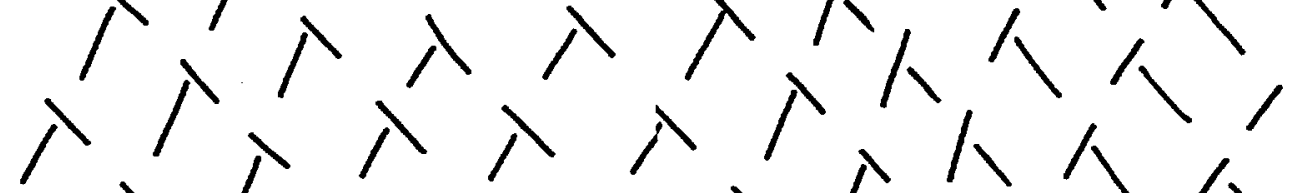
$\lambda>\lambda \lambda \lambda \lambda \wedge \Lambda \Lambda \wedge$ $\lambda \lambda \lambda \lambda \lambda \lambda \lambda \lambda \wedge \Lambda$, $\lambda \lambda \lambda \lambda \lambda \lambda \lambda \lambda \wedge \lambda \wedge$

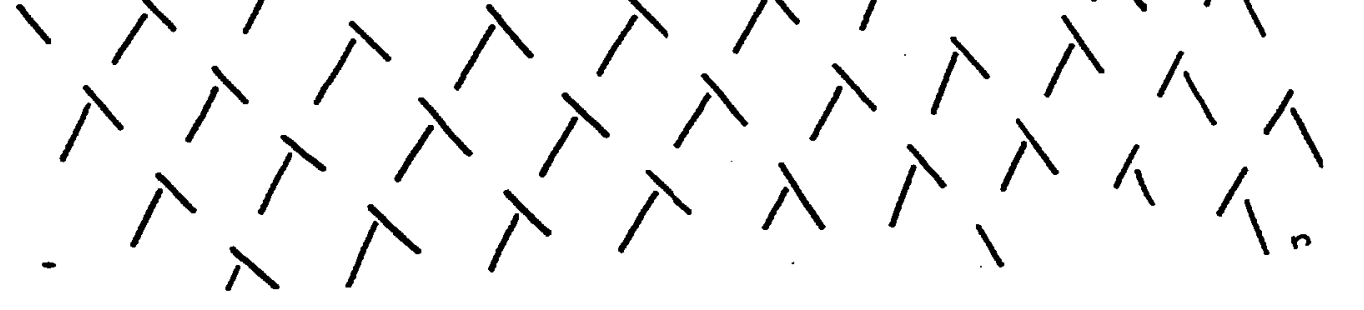




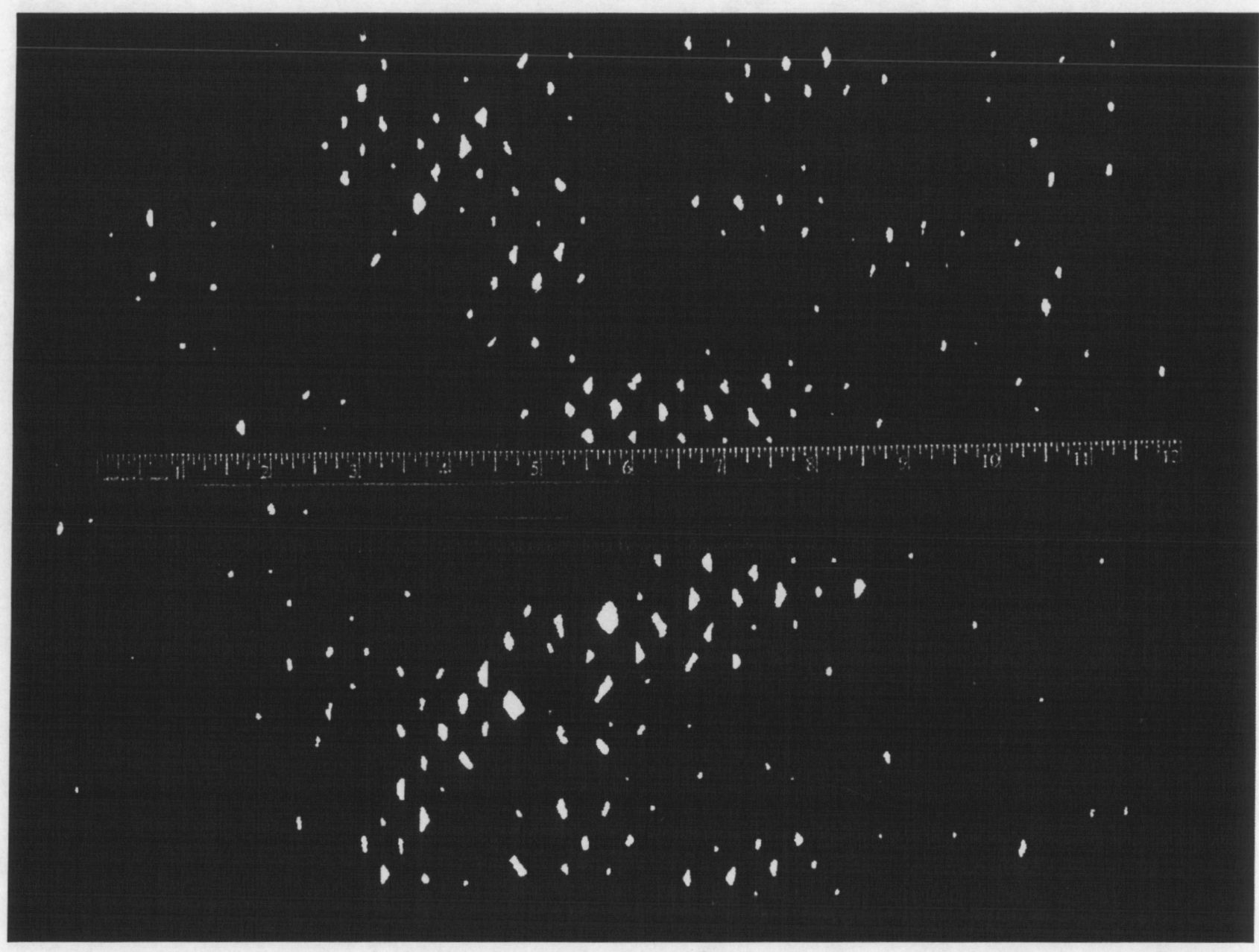

Figure 3.3 Backlit USCAR panel 10-10 showing nonuniform fiber distribution and resin-rich areas over 12 in. by 10 in. section. 


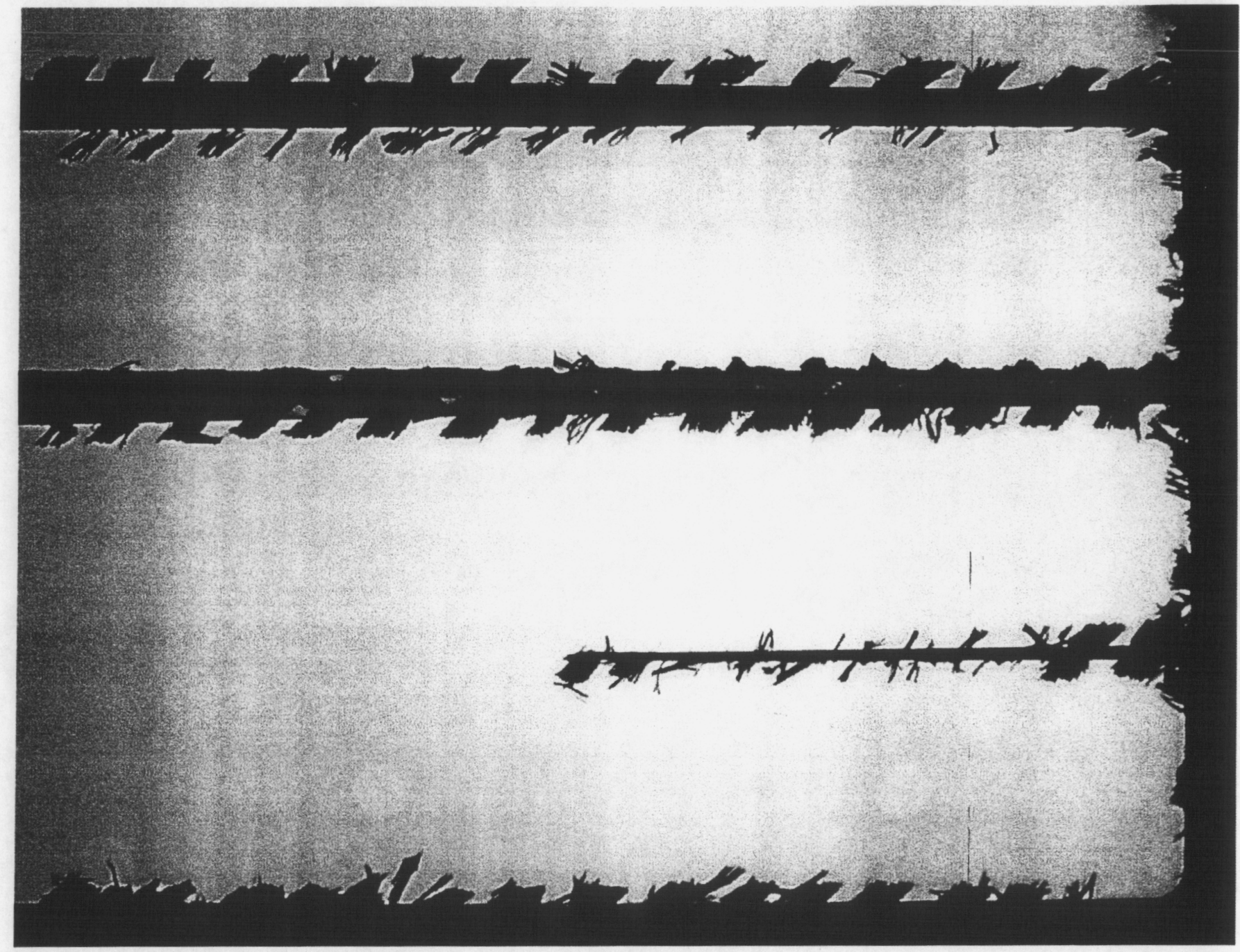

Figure 3.4 Machined USCAR panel 10-13 showing dry fiber exposed by carbide end mill. 


\subsection{Flexural Versus Tensile $0^{\circ}$ Moduli}

Due to the coarse structure of the braided panel (only two layers of braided large tow carbon fiber), the distribution of fiber both within the plane of the panel and through the thickness is not very uniform. This nonhomogeneous microstructure can lead to differences in elastic constants measured in flexure versus in-plane deformation. A micromechanics-based model for this effect has been proposed by Zywicz and Nguyen [5]. In order to characterize the magnitude of the effect in the two-layer braided panel, a series of tests for the $0^{\circ}$ elastic stress-strain response in uniaxial tension versus flexure were conducted. Specimens were subjected to multiple cycles of flexural and tensile loading to a maximum strain level of $0.5 \%$. Loading was reversed when any gage attained a strain magnitude of $0.5 \%$. For these braided $0 / \pm 30$ laminates, the longitudinal Poisson's ratio is greater than one and in most tests it was found that the transverse strain reached the maximum value first.

Specimens were fitted on each face with an axial and transverse strain gage. Due to the coarse microstructure of the composite, large, 1 in. foil gages (Micro-Measurements N2A00-10CBE-350 gages bonded with AE-10 epoxy adhesive, Measurements Group Inc, Raleigh, NC) were used in an attempt to obtain an average strain measurement. Both flexural and tensile tests were conducted using Model 1125 Instron test machines. For flexural tests, a four-point bending fixture set to a major span length of $7.5 \mathrm{in}$. and a minor span of 2.5 in. The uniaxial tensile tests were conducted using hydraulic grips equipped with surfalloy wedges (MTS, MN).

Test results showed that the strain response in both flexure and tension was nonuniform. Relatively large disparities between strain signals measured from the two faces were found for several specimens. These differences can be attributed to a number of factors including the initial curvature in the panel and the unsymmetrical distribution of fiber. Typical stressstrain responses that show these strain differences are given in Figs. 3.5 and 3.6 for tension and flexural tests, respectively. To obtain average flexural moduli, specimens were tested twice to load each side in compression and tension. Hysteresis of the stress-strain response was seen in the flexural tests. Although no obvious visual signs of damage were observed, some cracking noises were heard during loading. Considering the poor quality of the fiber/matrix adhesion in these panels, it is likely that some of this damage in the flexural tests was due to either fiber compression (buckling) or failure by interlaminar shear stresses.

In order to compare these results with theoretical predictions that do not account for asymmetry, the strain signals were averaged to calculate elastic constants. Additionally, an 
average flexural modulus was determined using the strain calculated from the displacement of the minor loading points and the relation:

$$
\varepsilon_{f}=\frac{5.41 d t}{L^{2}}
$$

where

$$
\begin{aligned}
& d=\text { deflection of minor load points } \\
& t=\text { beam thickness } \\
& L=\text { major span length }
\end{aligned}
$$

Average values for elastic constants obtained from several cycles of loading are summarized in Table 3.2. The relatively large scatter in values was disconcerting and prompted a closer look at the microstructure. Due to the relatively nonuniform distribution of the tows, it was considered that each 1.5 in. wide specimen may contain different amounts of the $0^{\circ}$ tows. Because these tows are the predominant load-bearing material in $0^{\circ}$ specimens, it is necessary to normalize to the number of these tows for comparison with theoretical predictions. In order to count these tows, especially those that were parted by the machining process, it was necessary to remove the Hetron 922 matrix material. Standard acid digestion techniques [6] were considered because these procedures have minimal effect on the fiber. However, due to the mixing that occurs in these procedures, it is difficult to keep track of individual tows in the original specimen. A simple resin burnout technique does maintain the fiber tows in a pattern that makes it easy to identify their orientation, but also results in oxidation and weight loss of fiber. This technique was used after establishing the minimum conditions of time and temperature to burn off the resin. Control specimens of dry fiber tows pulled from a braided tube were used to determine these conditions. It was assumed that the fiber weight loss was the same for both composite and dry tow specimens so that the recovered weight of $0^{\circ}$ tows could be adjusted to give the original weight in the composite. The effective number of $0^{\circ}$ tows determined in this manner is listed in Table 3.2.

The results given in Table 3.2 show the strong dependence of modulus on the number of $0^{\circ}$ tows. Meaningful data can only be obtained by accounting for the specific number of tows in a test specimen. Beyond this correction it can be seen that the flexural moduli are, on average, about $25 \%$ less than tensile moduli. This is the effect of the coarse braid structure and nonuniform fiber distribution where the stiffer $0^{\circ}$ tows are located away from the surface where they contribute less to the flexural modulus than the tensile modulus. Flexural moduli calculated using average strain gage data and displacement data are in 
relatively good agreement. Poisson's ratios from both types of tests are somewhat scattered, but also in fairly good agreement.

Table 3.2. Tensile and flexural $0^{\circ}$ elastic properties.

\begin{tabular}{|c|c|c|c|c|c|c|}
\hline \multirow[t]{2}{*}{ Specimen } & \multirow{2}{*}{$\begin{array}{l}\text { No. } 0^{\circ} \\
\text { Tows }\end{array}$} & \multicolumn{3}{|c|}{ Flexural Properties } & \multicolumn{2}{|c|}{ Tensile Properties } \\
\hline & & $\begin{array}{c}0^{\circ} \text { Modulus }^{a} \\
\text { (ksi) }\end{array}$ & $\begin{array}{c}0^{\circ} \text { Modulus }^{\mathrm{b}} \\
(\mathrm{ksi})\end{array}$ & $\begin{array}{c}\text { Poisson's } \\
\text { Ratio } \\
\end{array}$ & $\begin{array}{c}0^{\circ} \text { Modulus } \\
(\mathrm{ksi})\end{array}$ & $\begin{array}{c}\text { Poisson's } \\
\text { Ratio } \\
\end{array}$ \\
\hline 1 & 7.0 & 5.50 & 5.16 & 1.19 & 7.57 & 1.08 \\
\hline 2 & 7.8 & 5.80 & 5.73 & 1.33 & 7.30 & 1.20 \\
\hline 3 & 7.1 & 4.34 & 4.33 & 1.48 & 5.67 & 1.07 \\
\hline 4 & 4.1 & 3.43 & 3.44 & 1.54 & 5.20 & 1.13 \\
\hline 5 & 4.3 & 4.32 & 4.15 & 1.07 & 5.13 & 1.21 \\
\hline
\end{tabular}

a. Determined from strain gage measurements

b. Determined from displacement of minor loading points. 


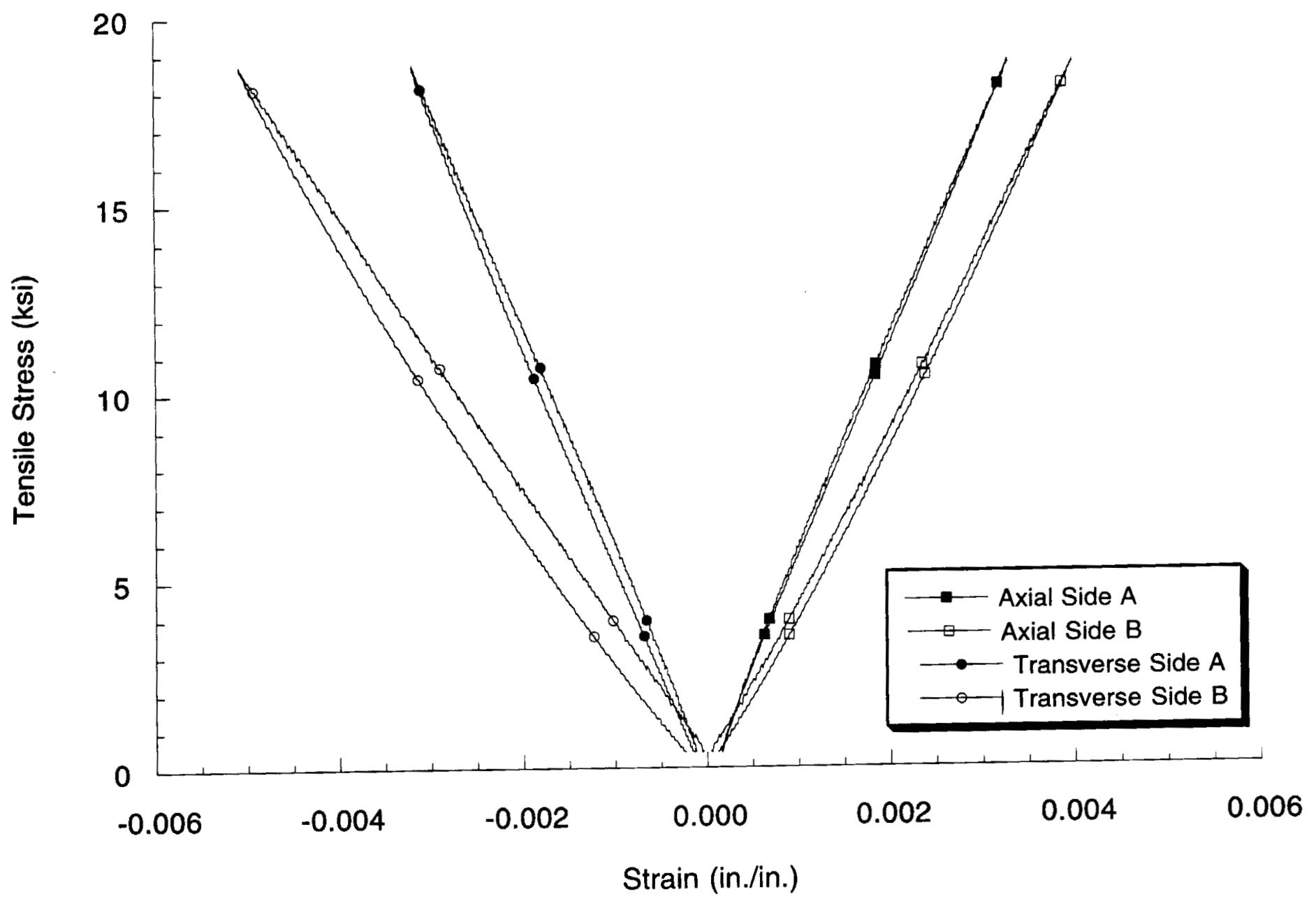

Figure 3.5 Cyclic stress-strain response of $0^{\circ}$ specimen in uniaxial tension. 


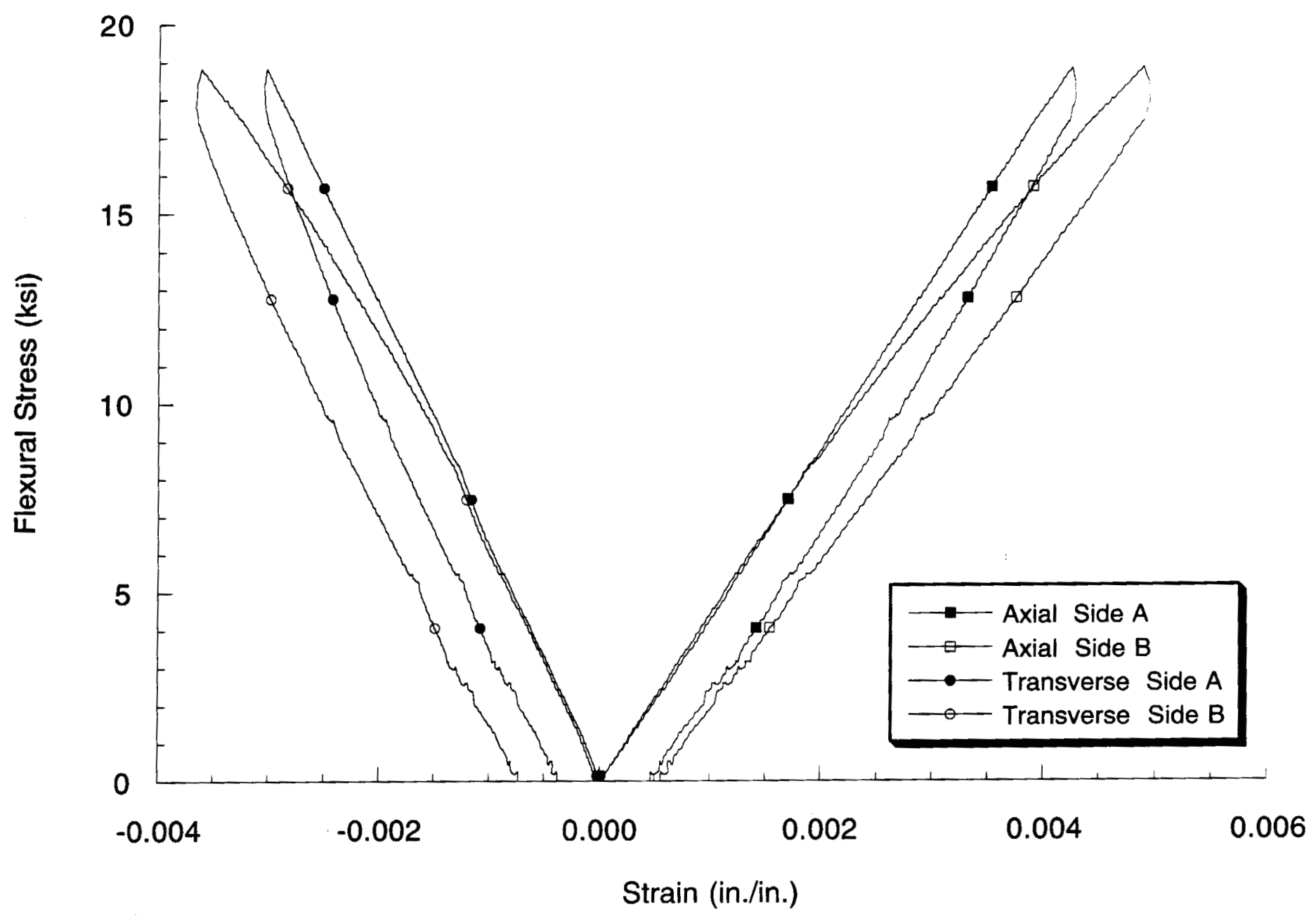

Figure 3.6 Cyclic stress-strain response of $0^{\circ}$ specimen in flexure. 


\subsection{Quasi-Static Tensile Tests}

Specimens used to determine $0^{\circ}$ elastic constants were also loaded to failure in axial tension. Additionally, specimens having $30^{\circ}, 60^{\circ}$, and $90^{\circ}$ orientations were also loaded at quasi-static rates to failure. Although the $30^{\circ}$ and $60^{\circ}$ specimens are anisotropic and should exhibit shear coupling, no effort was made to allow these specimens to twist freely during tensile loading. Thus these specimens were not tested under pure uniaxial stress conditions. All specimens were moumted with the large foil strain gages in the axial and transverse directions as described in the previous section. However, data for transverse strains could only be obtained from the $0^{\circ}$ and $90^{\circ}$ specimens. The transverse gages on the off-axis specimens all failed at the onset of loading. In addition to the strain gages, an extensometer was used to measure axial strain. Specimens having $0^{\circ}$ orientation were also taken from one of the molded tubes and were tested to compare with the panel results. Specimens were tested with a gage length of $6.4 \mathrm{in}$. at a nominal strain rate of $1 \mathrm{E}-4 \mathrm{~s}^{-1}$ using the same test set-up described in the previous section. Stress-strain response curves up to peak loads are shown in Figs. 3.7-3.10 for $0^{\circ}, 30^{\circ}, 60^{\circ}$ and $90^{\circ}$ directions, respectively. Data for the $0^{\circ}$ specimens extracted from the tubes are shown in Fig. 3.11. In all of these figures, the strain data shown was that obtained from the strain gages.

For purposes of examining large deformation damage and failure mechanisms, some specimens of each type were pulled until complete failure (zero load) was attained. The results from these tests are shown in Figs. 3.12-3.15. Only one large deformation test for the $90^{\circ}$ direction is shown in Fig. 3.15, but several others will be described in a later section on rate effects. In these response curves an apparent strain was calculated from the machine displacement and the gage length of the specimen. Attempts to use either foil strain gages or extensometers to measure strains past the peak load were uniformly unsuccessful. Since the machine displacement includes the motions of the test hardware, the apparent strain is always greater than the actual specimen strain. The elastic constant and strength data collected from all of these tests is summarized in Table 3.3. The modulus is an average obtained from the strain gage and extensometer readings and strength is defined as the peak stress. Note that the tensile moduli for $0^{\circ}$ specimens \#1-5 are not exactly the same as those listed in Table 3.1 because the former are taken from the final test to failure and the latter are the average of several cyclic tests to a maximum strain of $0.5 \%$.

The data for tensile properties show a relatively large scatter, especially for the $0^{\circ}$ and $90^{\circ}$ orientations. The variability in the ultimate properties of the $0^{\circ}$ specimens is undoubtedly due in large part to the concentration of $0^{\circ}$ tows in the specimens. Both the strength and modulus appear to correlate with the number of these tows (see Table 3.2). The scatter in 
the results for the $90^{\circ}$ tests could be attributed to both the inhomogeneous microstructure (fiber-rich versus resin-rich regions) and the apparently poor fiber-matrix adhesion and wetting that was observed during machining of the specimens.

The strain at the peak stress level could not always be accurately measured with either foil strain gages or extensometers due to the onset of damage prior to attaining this maximum stress. Data collected up to the initiation of this damage and estimates of strain from the machine displacement show that significant damage and peak stresses occurred at less than $1 \%$ strain. For the fiber-dominated $0^{\circ}$ and $30^{\circ}$ orientations, this indicates that the ultimate fiber tensile properties are not attained in these braided composites. This poor strength translation could be due to either poor wetting of the fiber by the resin or to misalignment of the tow. In both cases strength would be reduced because the $0^{\circ}$ tows and the filaments within these tows would not be uniformly loaded. Although the tensile moduli in the $0^{\circ}$ and $30^{\circ}$ directions are similar, the peak stresses of the $0^{\circ}$ laminates are about $40 \%$ greater than $30^{\circ}$ laminates. Furthermore, the $0^{\circ}$ laminates underwent a gradual softening up to the peak stress while the $30^{\circ}$ laminates exhibited more severe load drops throughout the response curve.

Fracture of the $0^{\circ}$ specimens was by a combination of failure between the $30^{\circ}$ braider tows and filament fracture of the axial tows as shown in Fig. 3.16. The braider tows failed predominantly by fracture between tows and most are seen to remain relatively intact with little evidence of fiber failure. The failure between the braider tows is mostly in-plane cracking and except for areas where the axial tow has been pulled out, the braider tows remain relatively well-bonded in the thickness direction (not "delaminated"). The failure of the axial tows occurred with longitudinal splitting and pull-out over relatively long lengths (Fig. 3.16b). Damage along the edges was seen for lengths of 2-3 in. In all cases the primary damage zone followed one or both of the braider tows.

Fracture of the $30^{\circ}$ specimens showed much more extensive damage than in the $0^{\circ}$ specimens as shown in Fig. 3.17. The primary damage zone tended to follow the axial tows, which were oriented $30^{\circ}$ to the load axis. Although the fracture followed these tows, they exhibited little evidence of fiber failure. Damage at the edges of the specimen was seen over lengths from 3 in. to the entire gage length. The most noteworthy difference between the $0^{\circ}$ and $30^{\circ}$ specimens was the large-scale through-thickness separation (delamination) of the tows. In some cases the separation was so severe that it caused outof-plane bending failure of the braider tow oriented at $60^{\circ}$ to the load axis. The most likely cause for this severe out-of-plane failure is the stresses generated when the undulating braider tow that is aligned in the load direction is pulled in tension. Under tension, this tow will try to straighten but can only do so by displacing the neighboring off-axis tows. The 
result is large-scale separation of tows by in-plane cracking and delamination. With severe delamination the off-axis tows become ineffective in supporting stress. The failure of the primary load-bearing braider tows (oriented in the load direction) seemed to occur at the cross-over points of the braid where it had been most severely curved. The curvature at these points was nonuniform and in some places very small. Considering the different states of combined stress at these points of varying fiber misalignment, it is possible that the tows failed in a sequential manner. The sequential failure of axially aligned braider tows and the severe delamination of the off-axis tows could explain the more noticeable load drops seen in the $30^{\circ}$ tensile tests (see Fig. 3.13) as well as the lower strength of these specimens when compared to the $0^{\circ}$ tensile tests (Fig. 3.12, Table 3.3).

Both the $60^{\circ}$ and $90^{\circ}$ laminates exhibited nonlinear behavior at relatively small strains, which is typical for matrix-dominated behavior of polymer matrix fiber composites. The peak stresses were only about $1 / 3$ to $1 / 2$ the tensile strength of the pure Hetron resin and this low strength suggests either poor fiber wetting or poor fiber/matrix adhesion. After the peak stress, both of these laminates maintained a plateau stress that was approximately $1 / 3$ to $1 / 2$ of the peak value. This stress most likely corresponded to the deformation of the offaxis tows.

The failure of the $90^{\circ}$ specimens was due to fracture between the axial and braider tows, and shear buckling and splitting of the braider tows as shown in Fig. 3.18. The damage region was oriented at $90^{\circ}$ to the load axis (parallel to the axial tow). Failure was over a smaller area compared with the fiber-dominated $0^{\circ}$ and $30^{\circ}$ specimens and very little outof-plane (delamination) failure was observed. The plateau stress was due to the load borne by the braider tows that bridged the fracture zone. The bridging tows underwent severe internal splitting, but no fiber failure.

The $60^{\circ}$ specimens failed in a manner that was similar to the $90^{\circ}$ specimens, except that the damage region followed either the braider or axial tow and was thus oriented at $30^{\circ}$ or $60^{\circ}$ to the load axis. In this specimen the plateau stress was due to bridging afforded by the axial tow and the braider tow oriented at $30^{\circ}$ to the load axis. 
Table 3.3. Tensile properties of panel specimens tested along different directions.

\begin{tabular}{|c|c|c|c|c|}
\hline Orientation & $\begin{array}{l}\text { Specimen } \\
\text { Number }\end{array}$ & $\begin{array}{c}\text { Initial Modulus } \\
\text { (Msi) }\end{array}$ & $\begin{array}{l}\text { Poisson's } \\
\text { Ratio }\end{array}$ & $\begin{array}{l}\text { Strength" } \\
\text { (ksi) }\end{array}$ \\
\hline $0^{\circ}$ & 1 & 7.28 & 1.06 & 51.9 \\
\hline $0^{\circ}$ & 2 & 7.14 & 1.21 & 52.6 \\
\hline $0^{\circ}$ & 3 & 5.37 & 1.10 & 38.0 \\
\hline $0^{\circ}$ & 4 & 5.10 & 1.17 & 40.5 \\
\hline $0^{\circ}$ & 5 & 4.80 & 1.25 & 41.9 \\
\hline $0^{\circ}$ & 7 & 5.18 & 1.09 & 29.6 \\
\hline \multirow[t]{2}{*}{$0^{\circ}$} & 12 & 7.18 & - & 49.1 \\
\hline & $\begin{array}{r}\begin{array}{r}\text { Average: } \\
(\mathrm{SD}):\end{array} \\
\end{array}$ & $\begin{array}{l}6.01 \\
(1.13) \\
\end{array}$ & $\begin{array}{l}1.15 \\
(.075) \\
\end{array}$ & $\begin{array}{r}43.4 \\
(8.36) \\
\end{array}$ \\
\hline $0^{\circ}$ & Tube Strip \#I & 5.40 & 1.23 & 37.2 \\
\hline $0^{\circ}$ & Tube Strip \#2 & 6.43 & 1.25 & 41.3 \\
\hline $30^{\circ}$ & 7 & 6.11 & & 31.5 \\
\hline $30^{\circ}$ & 8 & 6.38 & & 33.9 \\
\hline $30^{\circ}$ & 9 & 5.11 & & 33.0 \\
\hline $30^{\circ}$ & 10 & 5.78 & & 26.7 \\
\hline \multirow[t]{2}{*}{$30^{\circ}$} & 13 & $6.88^{\mathrm{b}}$ & & 29.8 \\
\hline & $\begin{array}{r}\text { Average: } \\
(\mathrm{SD}): \\
\end{array}$ & $\begin{array}{r}6.05 \\
(0.66) \\
\end{array}$ & & $\begin{array}{r}31.0 \\
(2.85) \\
\end{array}$ \\
\hline $60^{\circ}$ & 14 & 2.1 & & 4.87 \\
\hline $60^{\circ}$ & 15 & 1.9 & & 4.96 \\
\hline $60^{\circ}$ & 16 & 2.1 & & 5.07 \\
\hline $60^{\circ}$ & 17 & 1.9 & & 4.20 \\
\hline \multirow[t]{2}{*}{$60^{\circ}$} & 20 & 2.0 & & 4.09 \\
\hline & $\begin{array}{r}\text { Average: } \\
(S D): \\
\end{array}$ & $\begin{array}{r}2.0 \\
(0.1) \\
\end{array}$ & & $\begin{array}{r}4.64 \\
(0.46) \\
\end{array}$ \\
\hline $90^{\circ}$ & 1 & 0.94 & .203 & 2.87 \\
\hline $90^{\circ}$ & 2 & 0.95 & .198 & 3.05 \\
\hline $90^{\circ}$ & 3 & 1.15 & .215 & 4.00 \\
\hline $90^{\circ}$ & 4 & 1.16 & .211 & 4.38 \\
\hline $90^{\circ}$ & 5 & 1.06 & .203 & 4.16 \\
\hline \multirow[t]{2}{*}{$90^{\circ}$} & 14 & 0.83 & - & 2.55 \\
\hline & $\begin{array}{r}\text { Average: } \\
(\mathrm{SD}):\end{array}$ & $\begin{array}{r}1.02 \\
(0.13) \\
\end{array}$ & $\begin{array}{r}.206 \\
(0.007) \\
\end{array}$ & $\begin{array}{l}3.50 \\
(0.77) \\
\end{array}$ \\
\hline
\end{tabular}

a. Peak stress.

b. Measured using only an extensometer. 


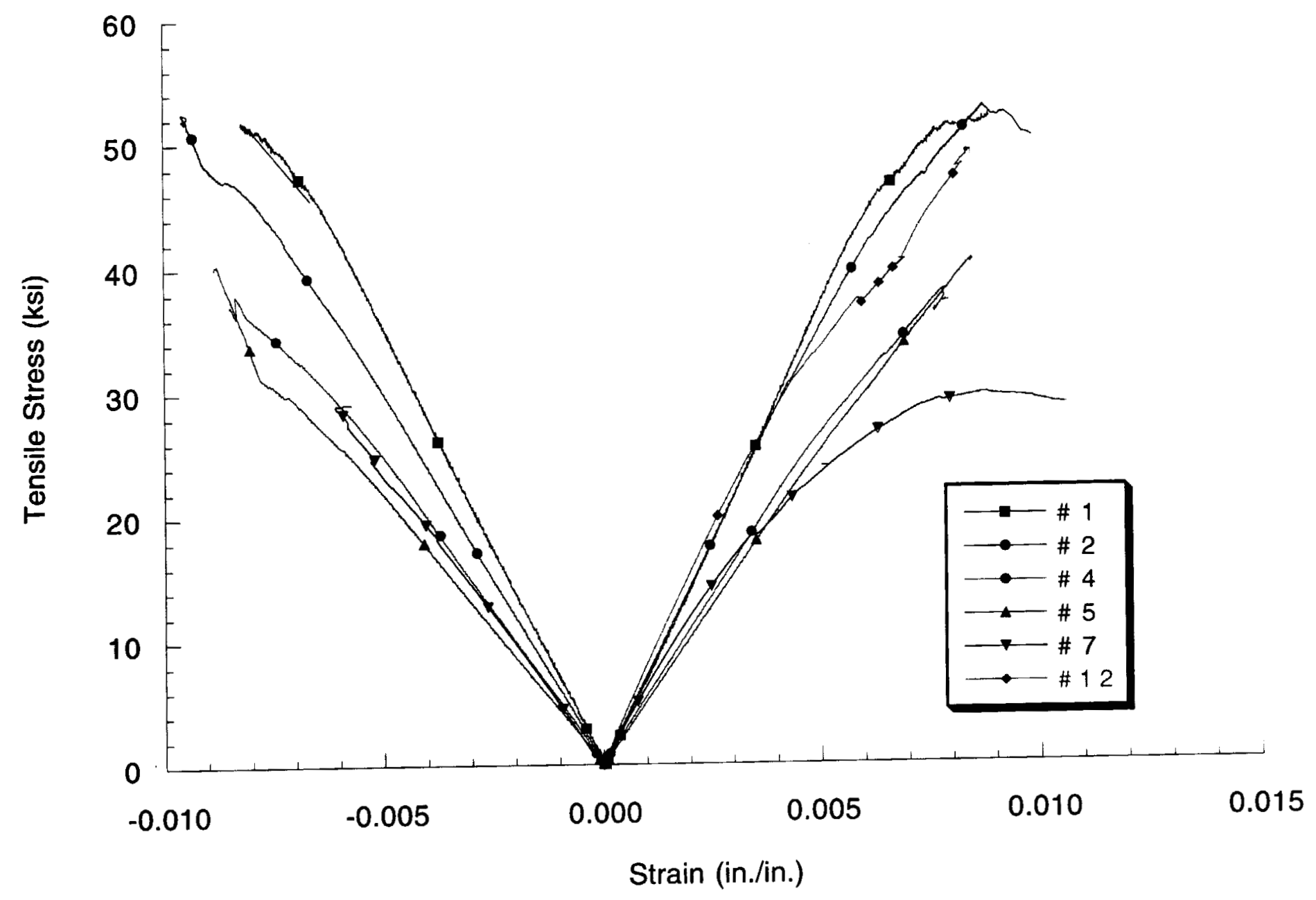

Figure 3.7 Initial tensile stress-strain response in $0^{\circ}$ direction. 


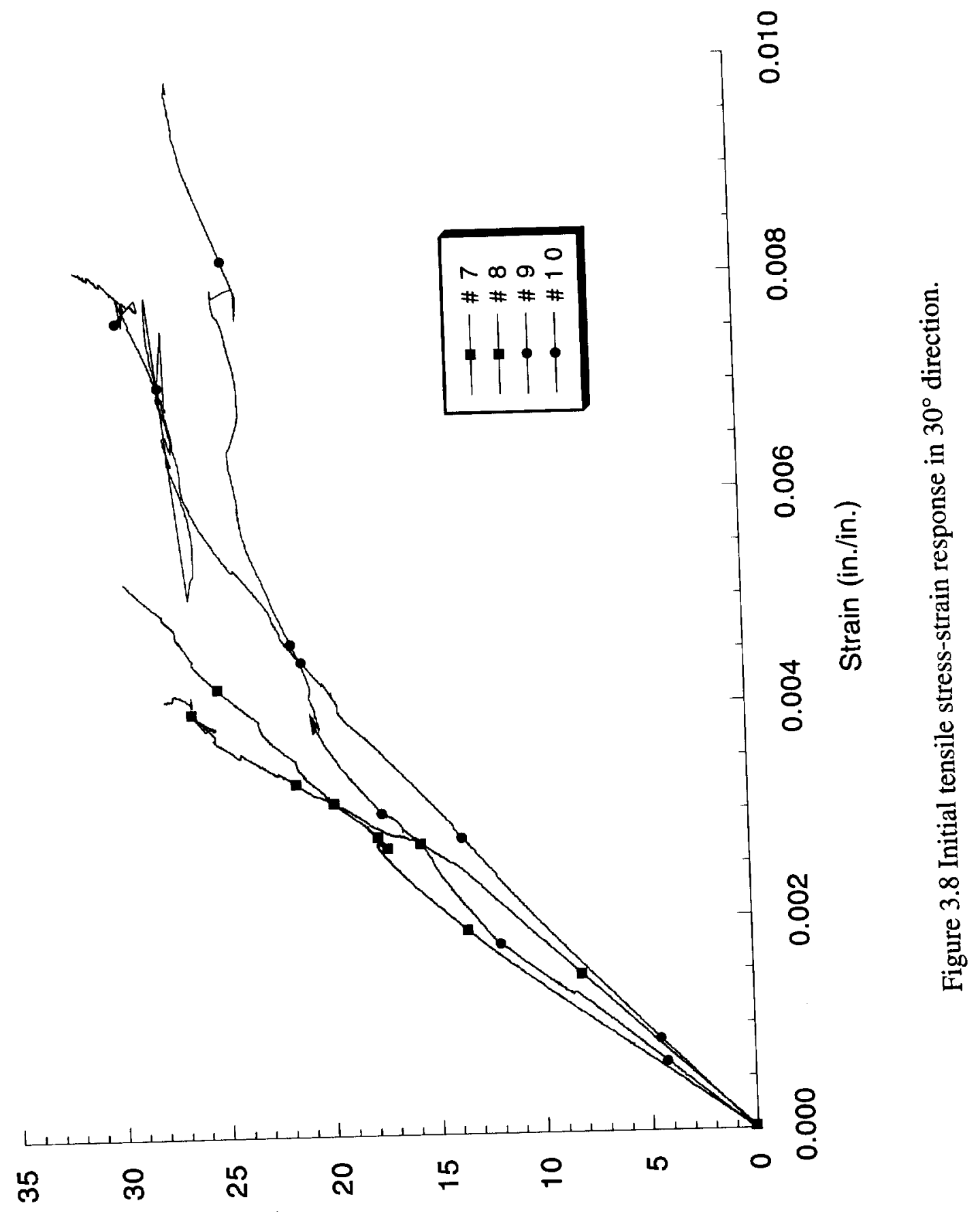

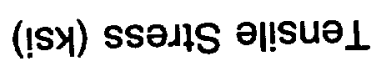




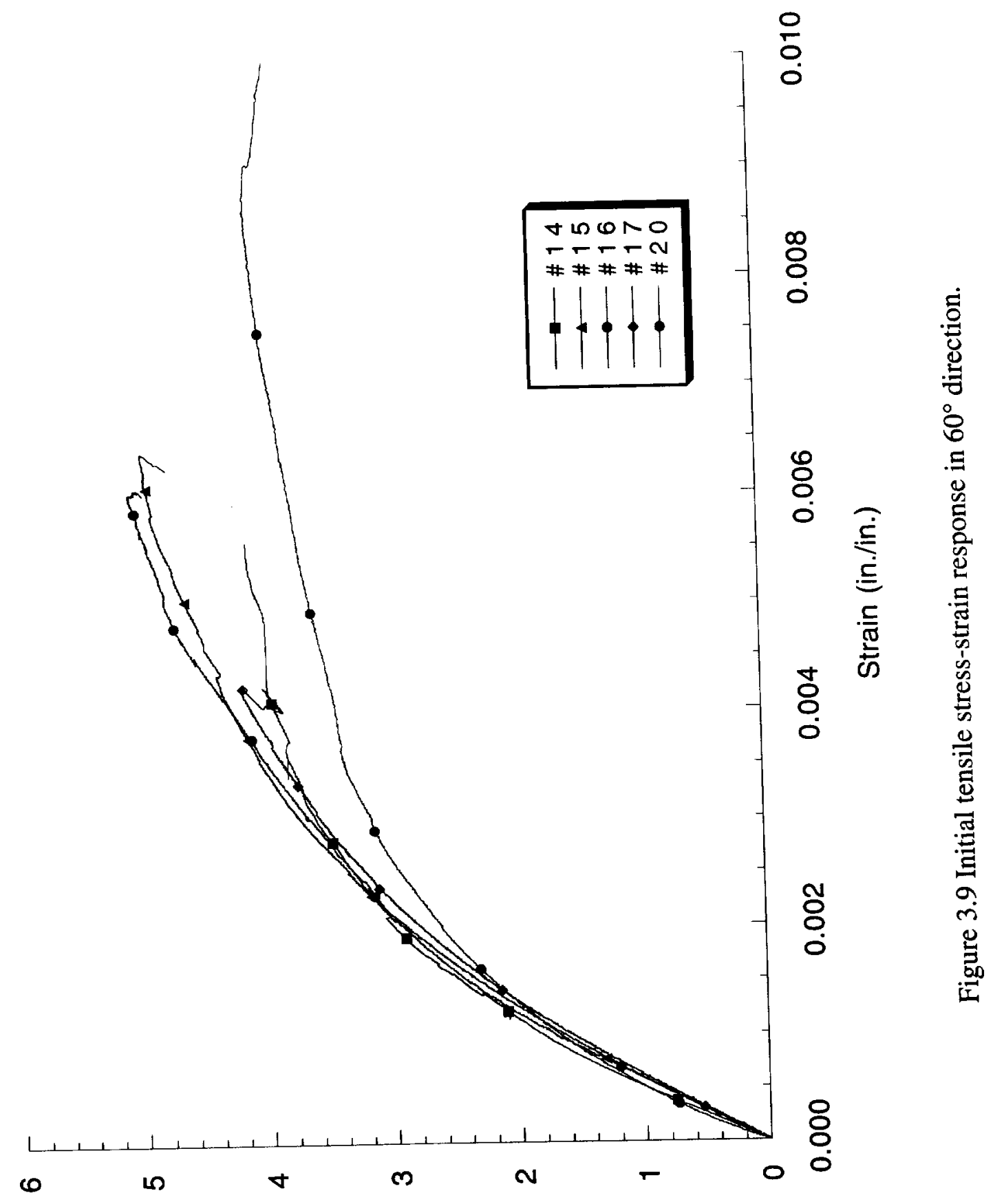

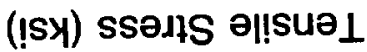




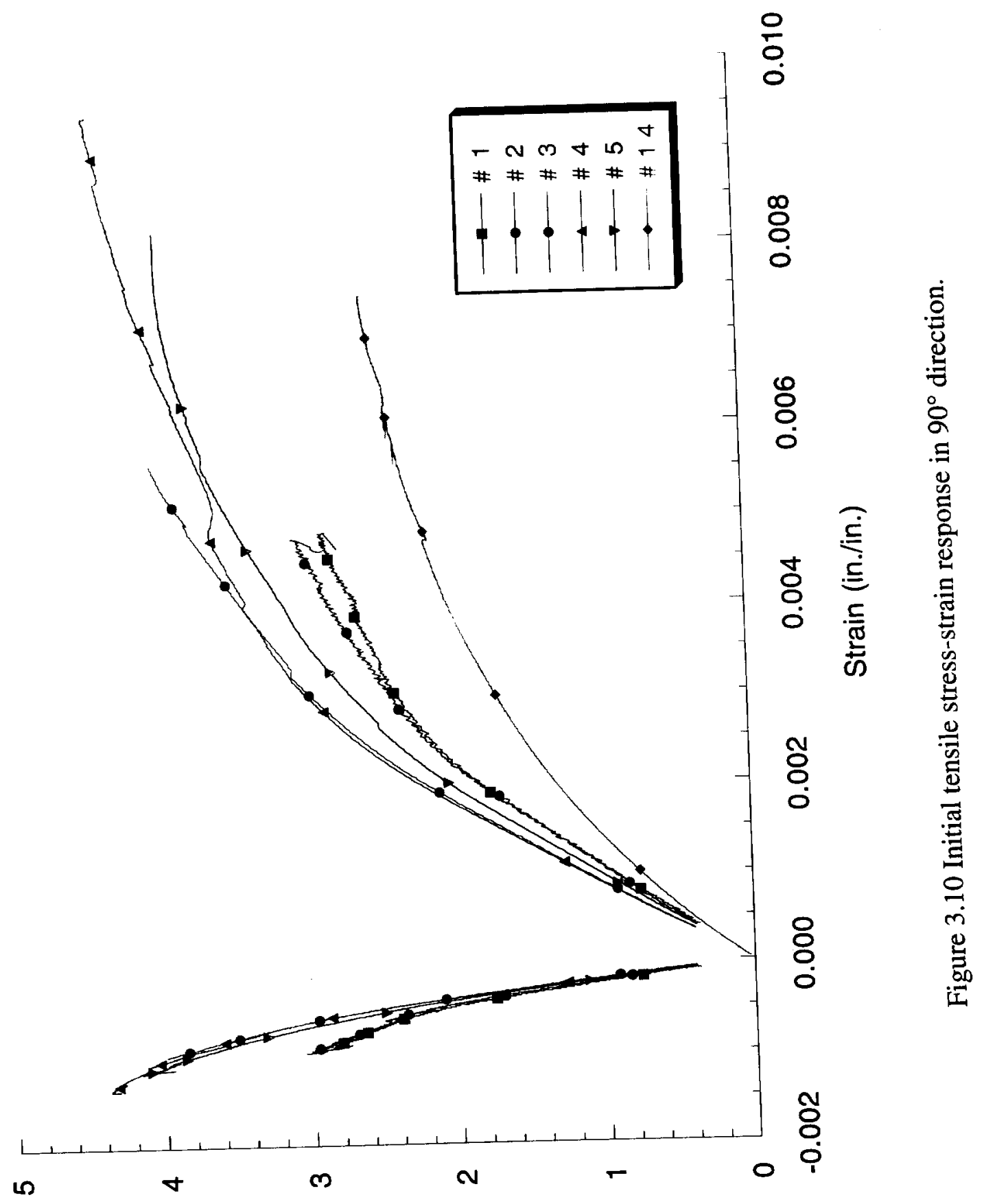

(!sy) ssəג 


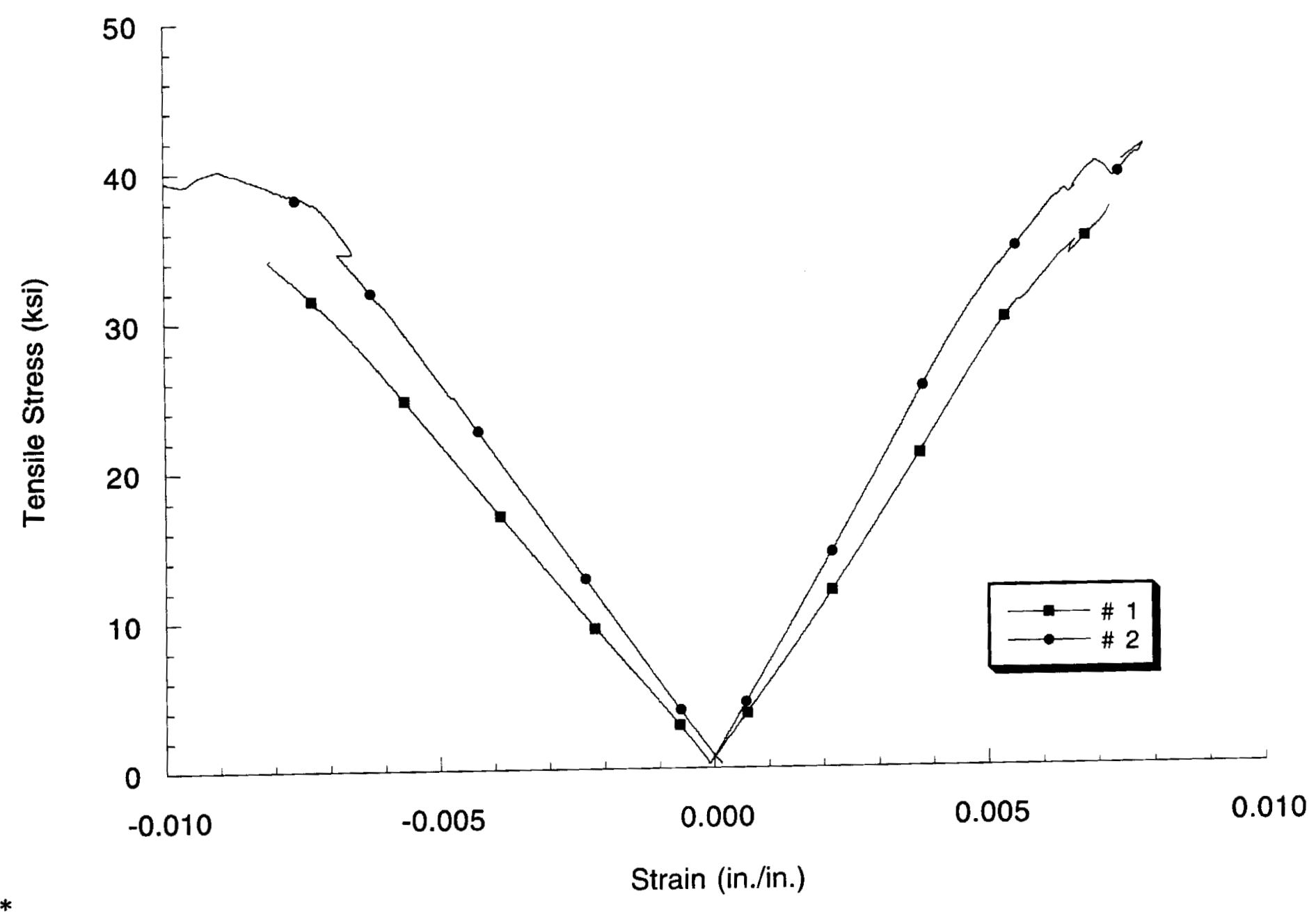

Figure 3.11 Initial tensile stress-strain response of tube specimen in $0^{\circ}$ direction. 


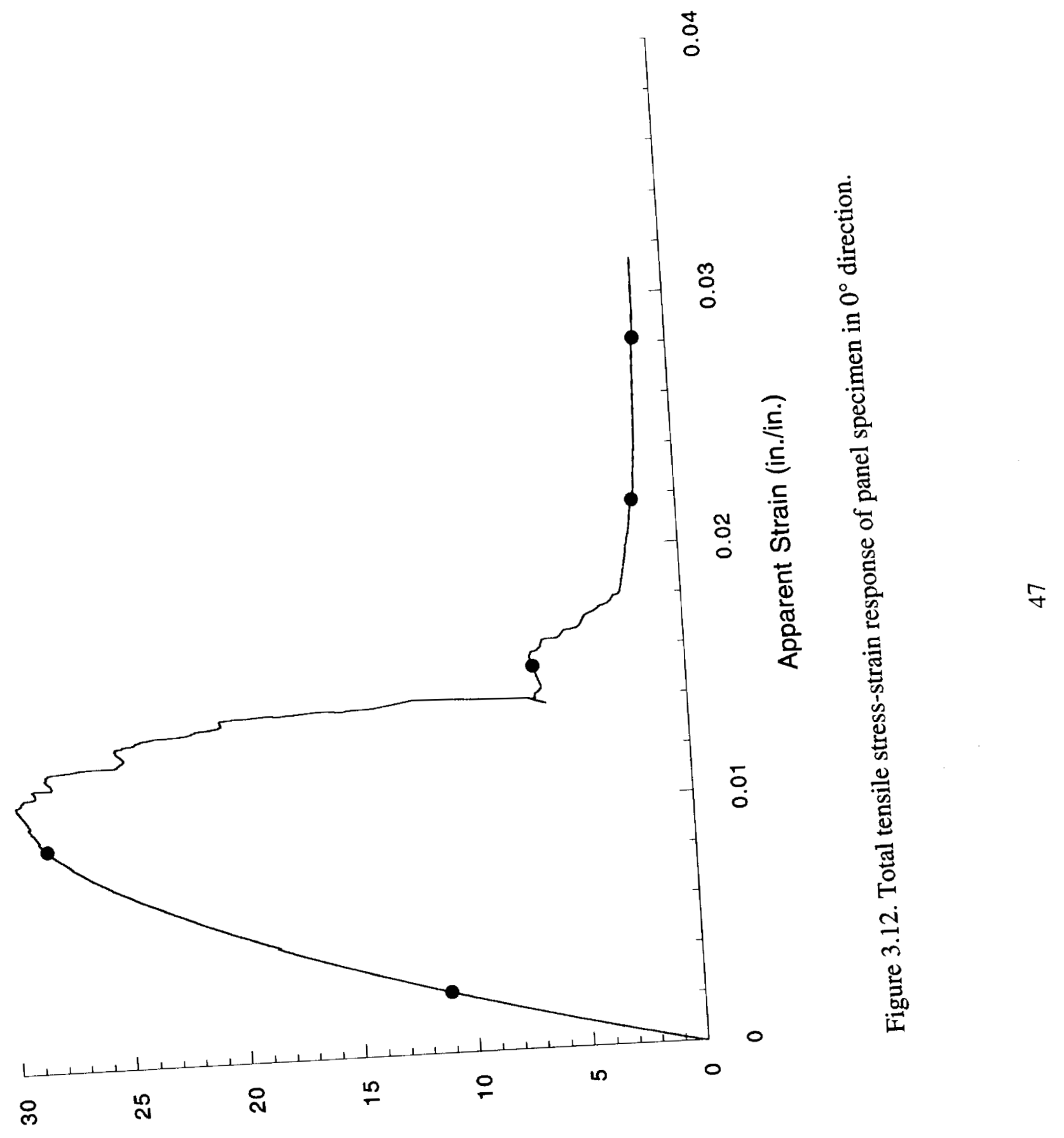

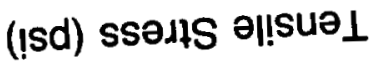




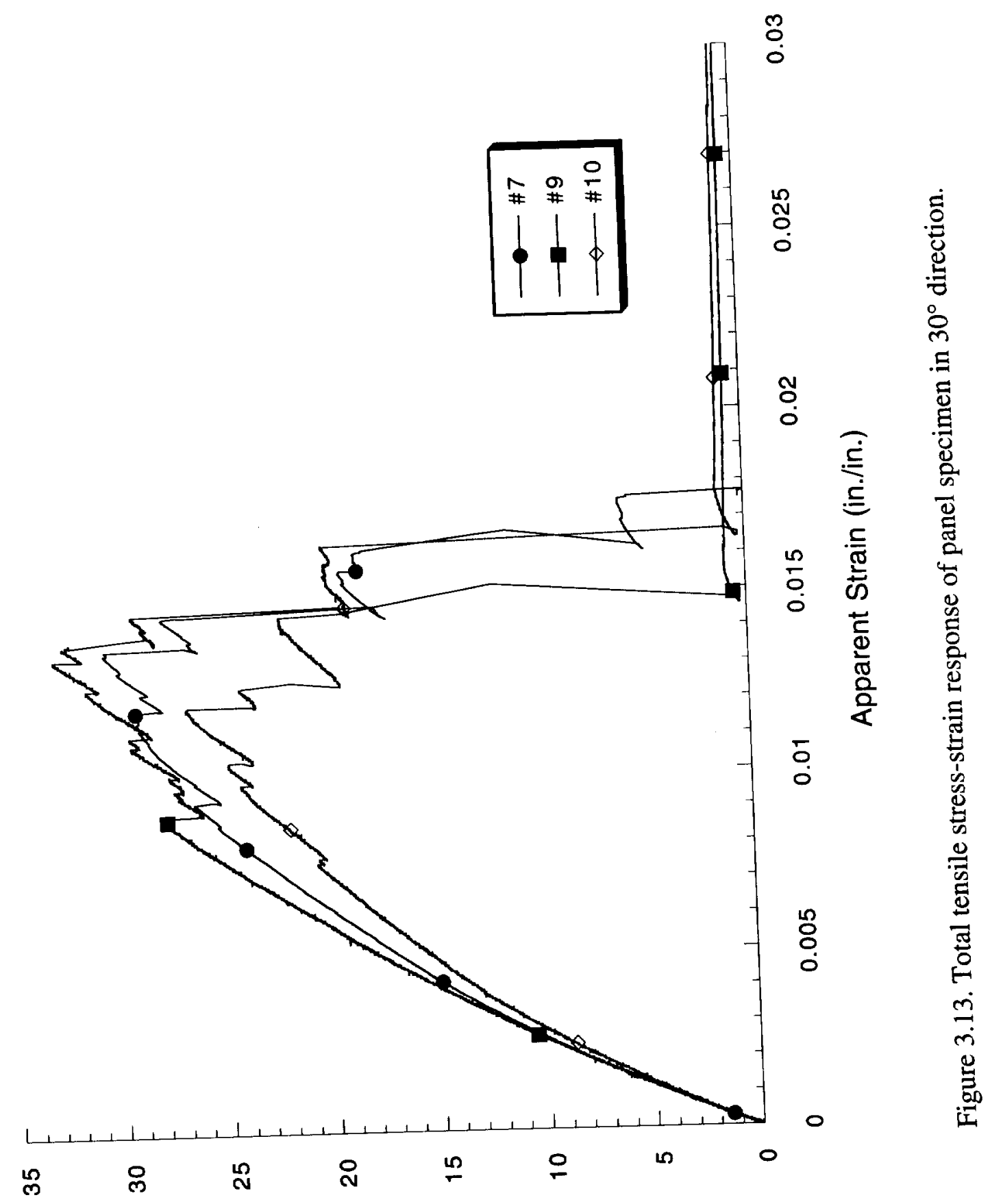

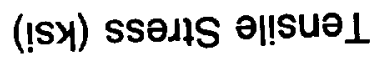




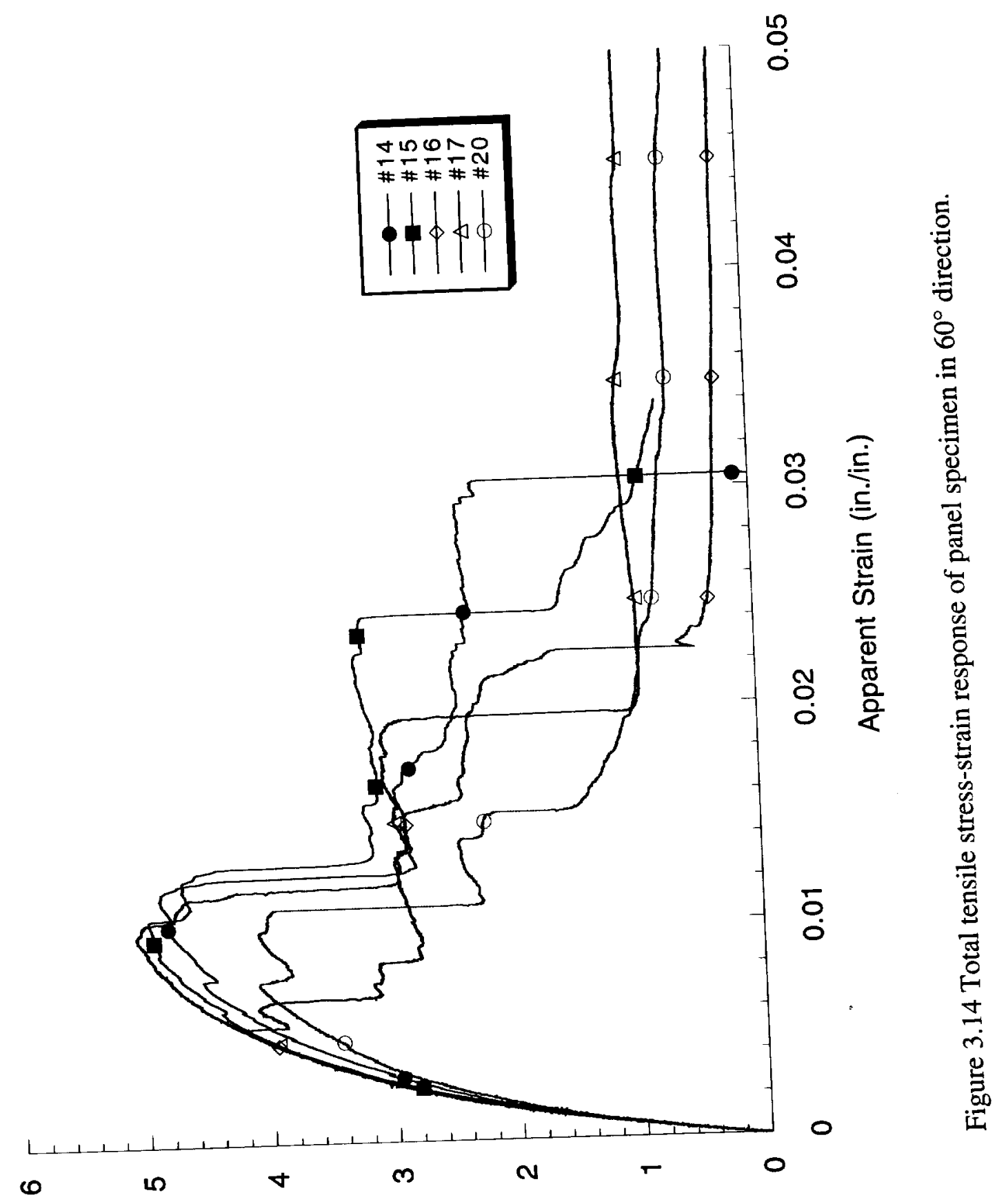

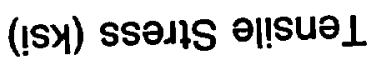




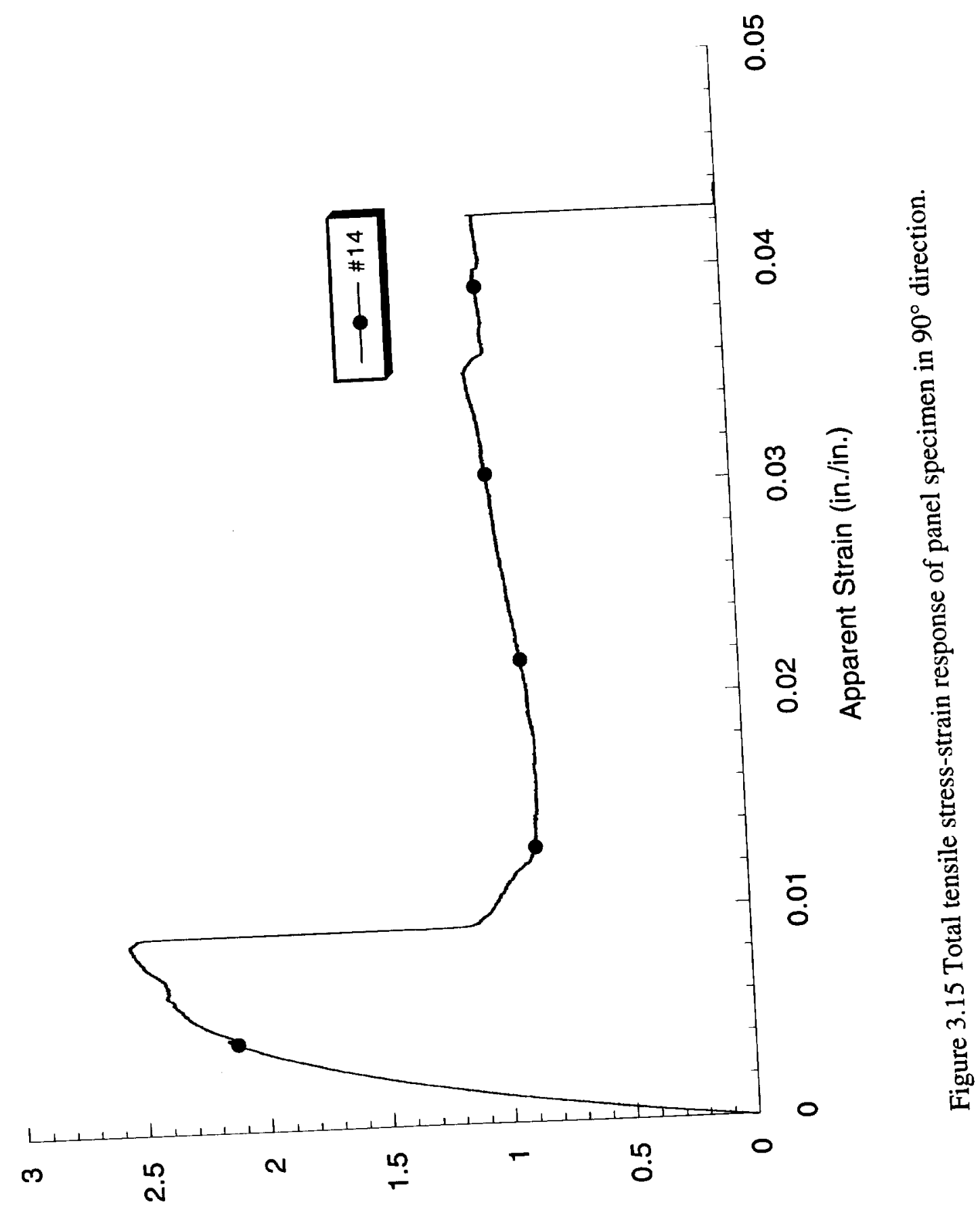

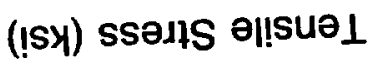




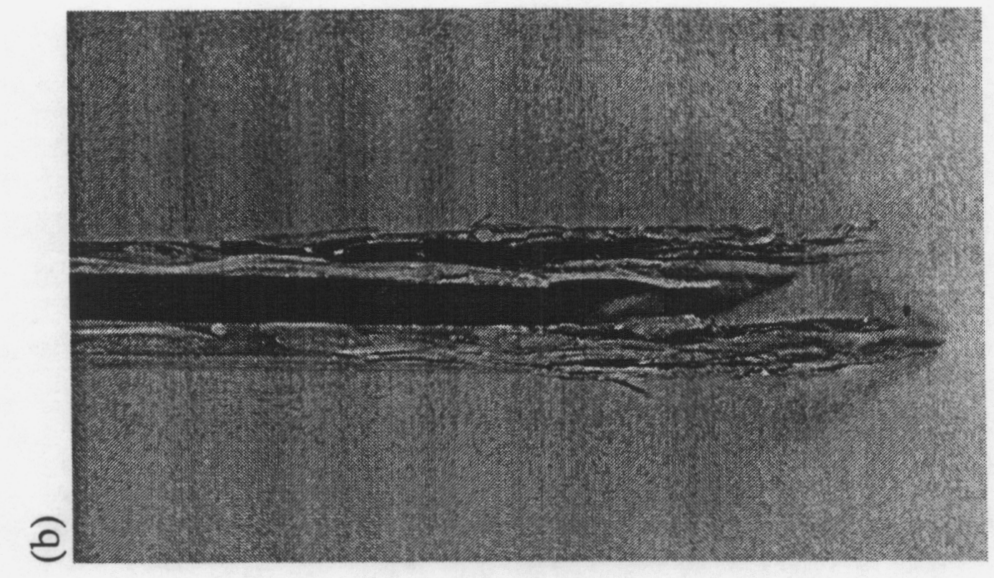

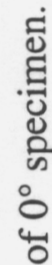

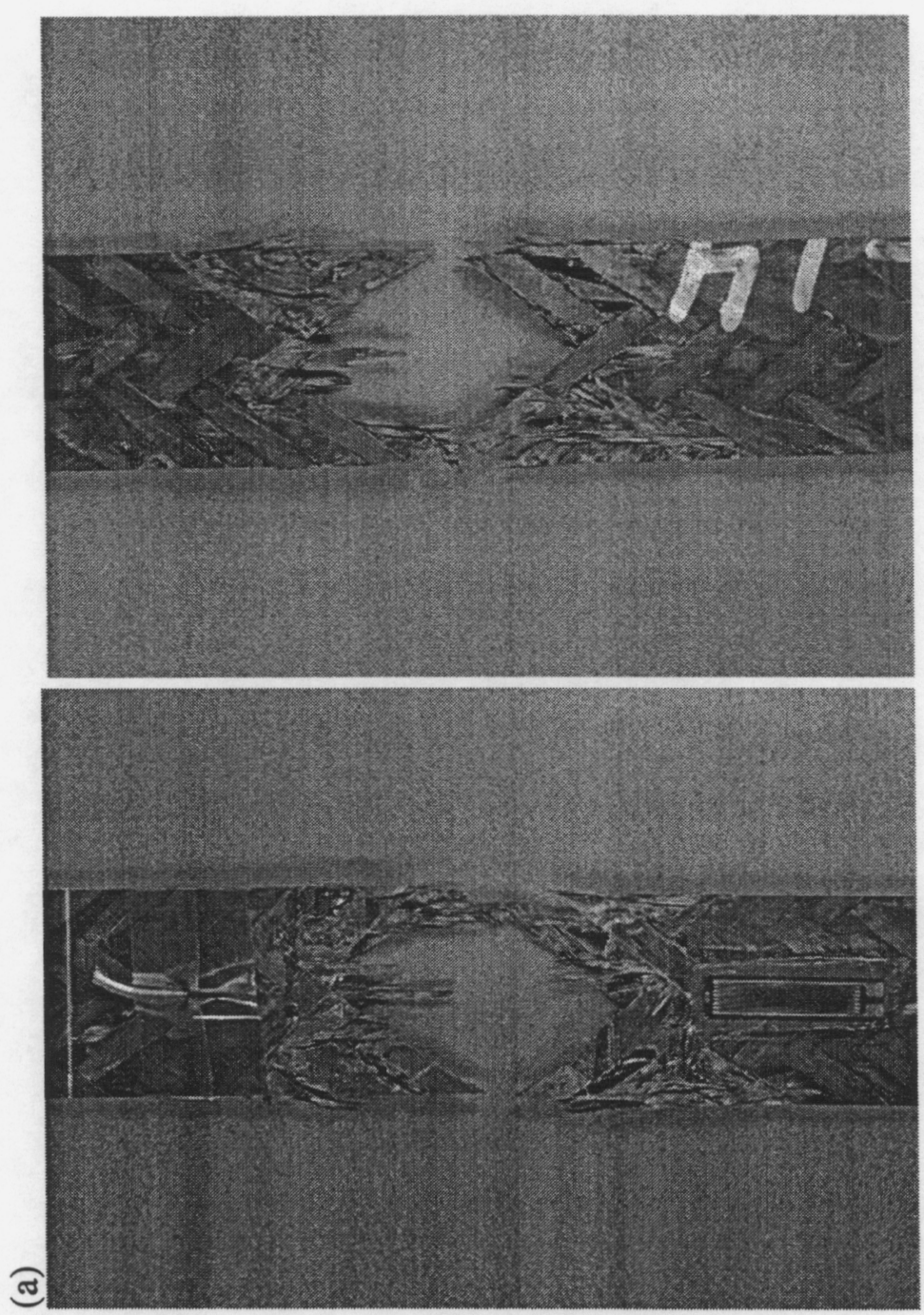

ఫ్ర

อ

등

.

ป్

(ิ)

6

范 

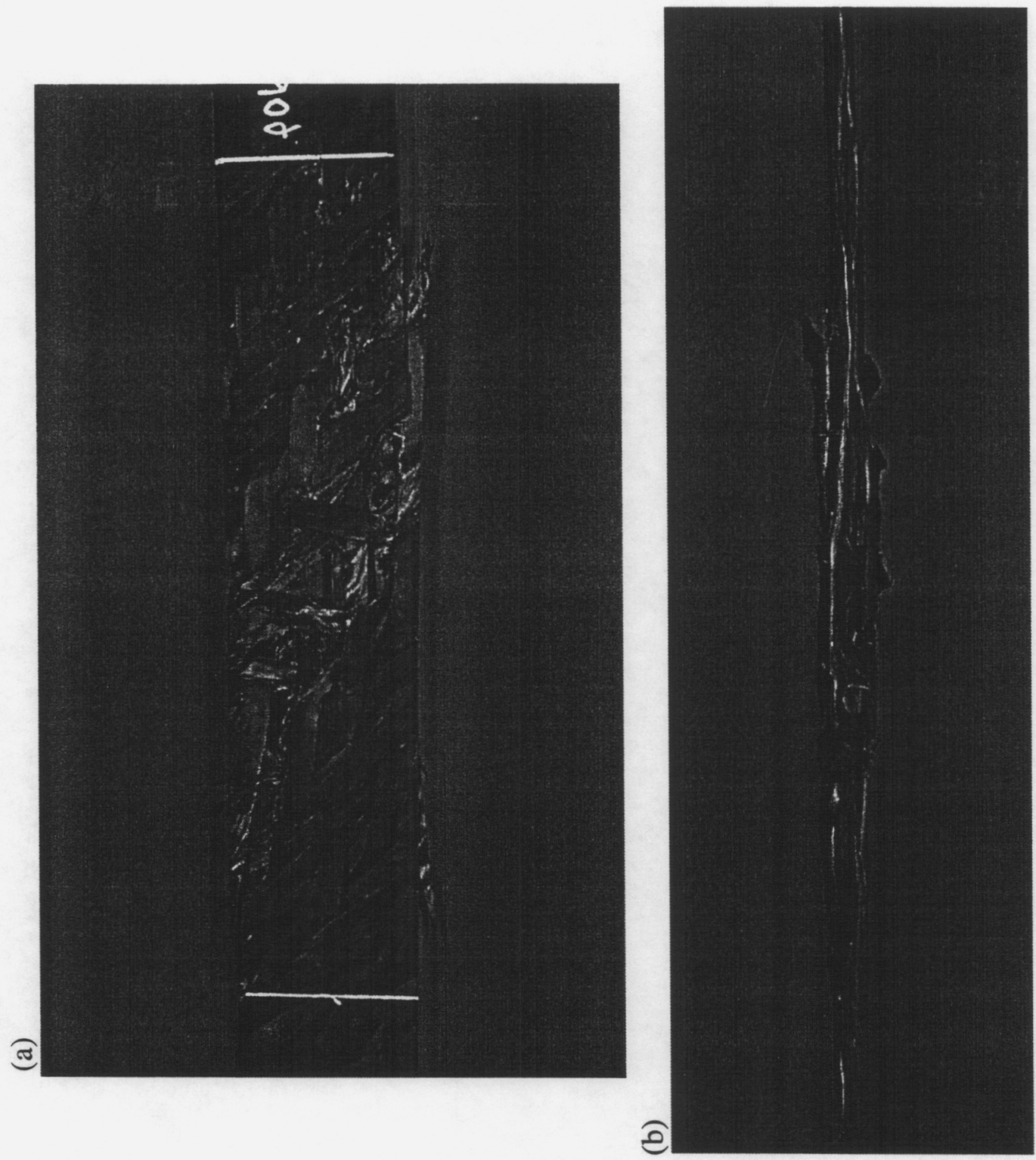

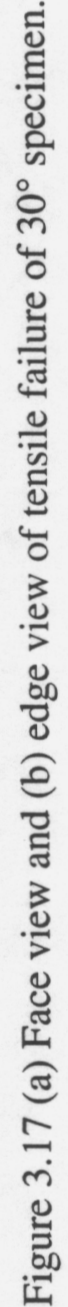

ก 

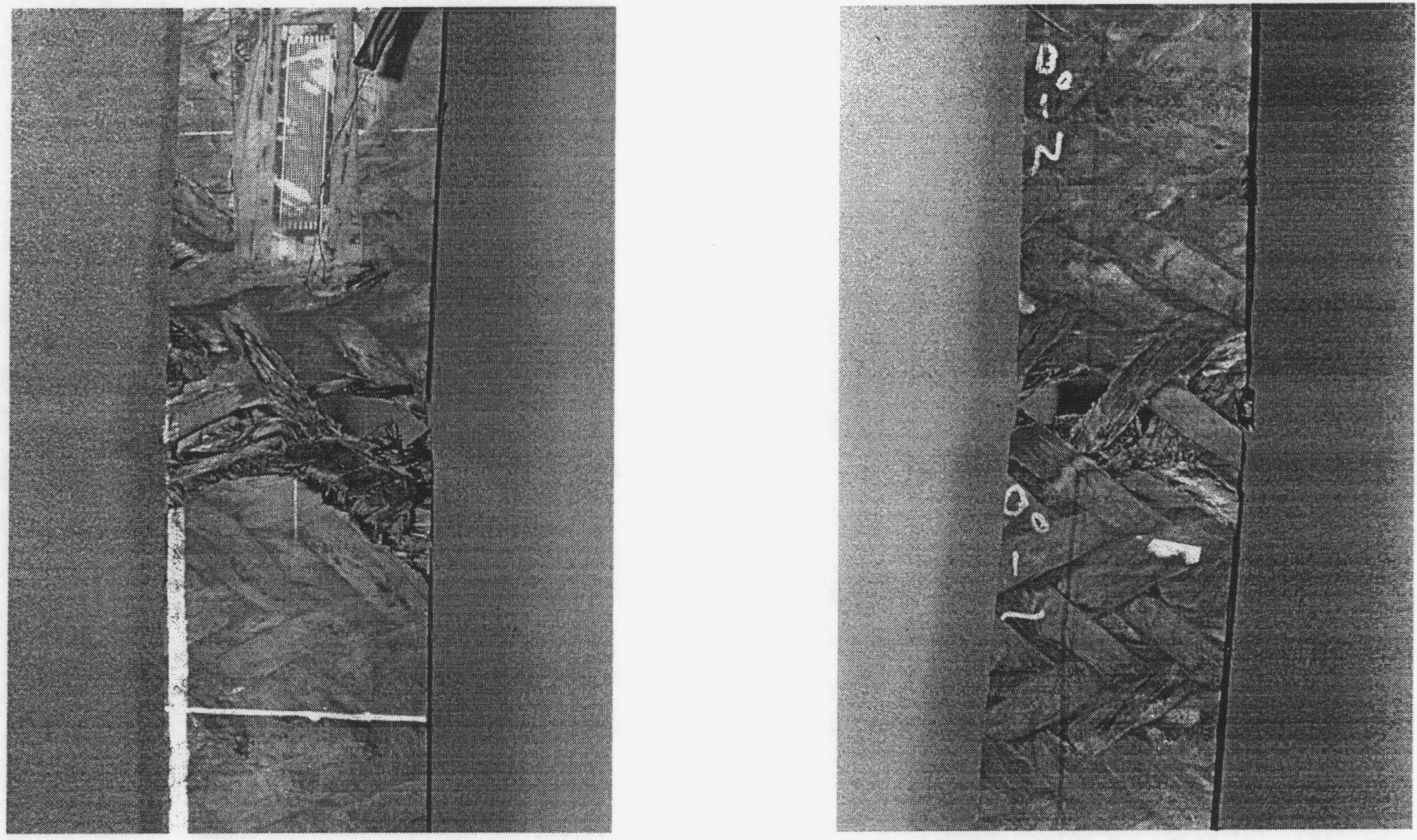

Figure 3.18 Face views of tensile failure of $90^{\circ}$ specimen. 


\subsection{Quasi-Static Compression Tests}

Quasi-static compression tests of panel specimens were conducted along the same four directions used in tensile testing. Rather than use a standard tabbed test specimen and a compression fixture for fiber composites, untabbed specimens were tested in a servohydraulic test machine equipped with hydraulic grips and surfalloy wedges. This method allowed testing of the full 1.5 in. wide specimen that was used for all the previous tensile tests. Preliminary tests of $0^{\circ}$ specimens at different gage lengths were used to determine that a gage length of $0.86 \mathrm{in}$. was suitable for achieving axial compression failure as opposed to Euler buckling. It is believed that acceptable compression failures were possible without a special compression fixture because of both the precise alignment of the grips and the relatively low strength of the composites in all directions. The short gage length prohibited the accurate measurement of strain using either foil strain gages or extensometers. Therefore, all strain data reported for the compression tests is an apparent strain that was calculated from the machine displacement and the specimen gage length. A machine displacement was chosen to yield an estimated effective strain rate of $1 \mathrm{E}-3 \mathrm{~s}^{-1}$. As with the tensile tests, the anisotropic $30^{\circ}$ and $60^{\circ}$ laminates were fixed against any twisting due to shear-coupling effects.

The compression stress-apparent strain response curves for the four specimen orientations are given in Figs. 3.19-3.22. The strength data from these tests are summarized in Table 3.4. The compression response of all laminates is generally similar. A peak stress is reached at approximately $1 \%$ strain, which is followed by a relatively stable plateau stress that is about half the peak value. The peak stresses are not very different despite the difference in fiber orientation. The strengths of fiber-dominated laminates $\left(0^{\circ}\right.$ and $\left.30^{\circ}\right)$ are only about $75 \%$ greater than the strengths of the matrix-dominated $60^{\circ}$ and $90^{\circ}$ laminates. Comparison of the data in Table 3.4 and Figs. 3.19-3.22 with that measured for the pure resin and summarized in Table 2.7 shows that in all directions, the composite is weaker in compression than the resin. This is true for both peak and plateau stresses and is suggestive of poor composite quality. Well-made fiber composites typically exhibit fiber- and matrixdominated compression strengths that are greater than that of the resin material.

Failure of the fiber-dominated $0^{\circ}$ and $30^{\circ}$ specimens occurred by buckling of the surface braider tows and underlying axial tows as shown in Fig. 3.23 for a $0^{\circ}$ specimen. The specimen in Fig. 3.23a was tested to just beyond the maximum stress and shows the incipient buckling of the surface braider tows. The specimen in Fig. 3.23b had been subjected to much more compressive deformation and exhibits more massive buckling of all the tows in the gage section. It was difficult to assess how much fiber damage occurred during this severe buckling, but tensile tests of previously compressed specimens as 
described in the next section demonstrated that there was significant fiber failure during compression. Both $60^{\circ}$ and $90^{\circ}$ specimens failed by buckling of the surface tows and through-thickness shear failure as shown in Fig. 3.24 for a $90^{\circ}$ specimen.

Table 3.4. Compression strengths of panel specimens tested along different directions.

\begin{tabular}{|c|c|c|}
\hline Orientation & Specimen & $\begin{array}{c}\text { Strength } \\
\text { (ksi) }\end{array}$ \\
\hline $0^{\circ}$ & $10-1$ & 10.3 \\
\hline $0^{\circ}$ & $10-2$ & 14.5 \\
\hline $0^{\circ}$ & $11-1$ & 15.9 \\
\hline \multirow[t]{2}{*}{$0^{\circ}$} & $11-2$ & 13.5 \\
\hline & $\begin{array}{r}\text { Average: } \\
\text { (SD): } \\
\end{array}$ & $\begin{array}{l}13.6 \\
(2.4) \\
\end{array}$ \\
\hline $30^{\circ}$ & $11-1$ & 15.4 \\
\hline $30^{\circ}$ & $11-2$ & 14.8 \\
\hline $30^{\circ}$ & $12-1$ & 12.0 \\
\hline \multirow[t]{2}{*}{$30^{\circ}$} & $12-2$ & 15.9 \\
\hline & 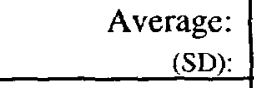 & $\begin{array}{l}14.5 \\
(1.7) \\
\end{array}$ \\
\hline $60^{\circ}$ & $18-1$ & 7.07 \\
\hline $60^{\circ}$ & $18-2$ & 9.31 \\
\hline $60^{\circ}$ & $19-1$ & 5.98 \\
\hline \multirow[t]{2}{*}{$60^{\circ}$} & $19-2$ & 9.01 \\
\hline & $\begin{array}{r}\text { Average: } \\
(\mathrm{SD}): \\
\end{array}$ & $\begin{array}{r}7.84 \\
(1.59) \\
\end{array}$ \\
\hline $90^{\circ}$ & 17 & 7.56 \\
\hline $90^{\circ}$ & 18 & 6.37 \\
\hline $90^{\circ}$ & 20 & 7.40 \\
\hline \multirow[t]{2}{*}{$90^{\circ}$} & 21 & 11.7 \\
\hline & $\begin{array}{r}\text { Average: } \\
\text { (SD): }\end{array}$ & $\begin{array}{r}8.26 \\
(2.35) \\
\end{array}$ \\
\hline
\end{tabular}

a. Peak stress. 


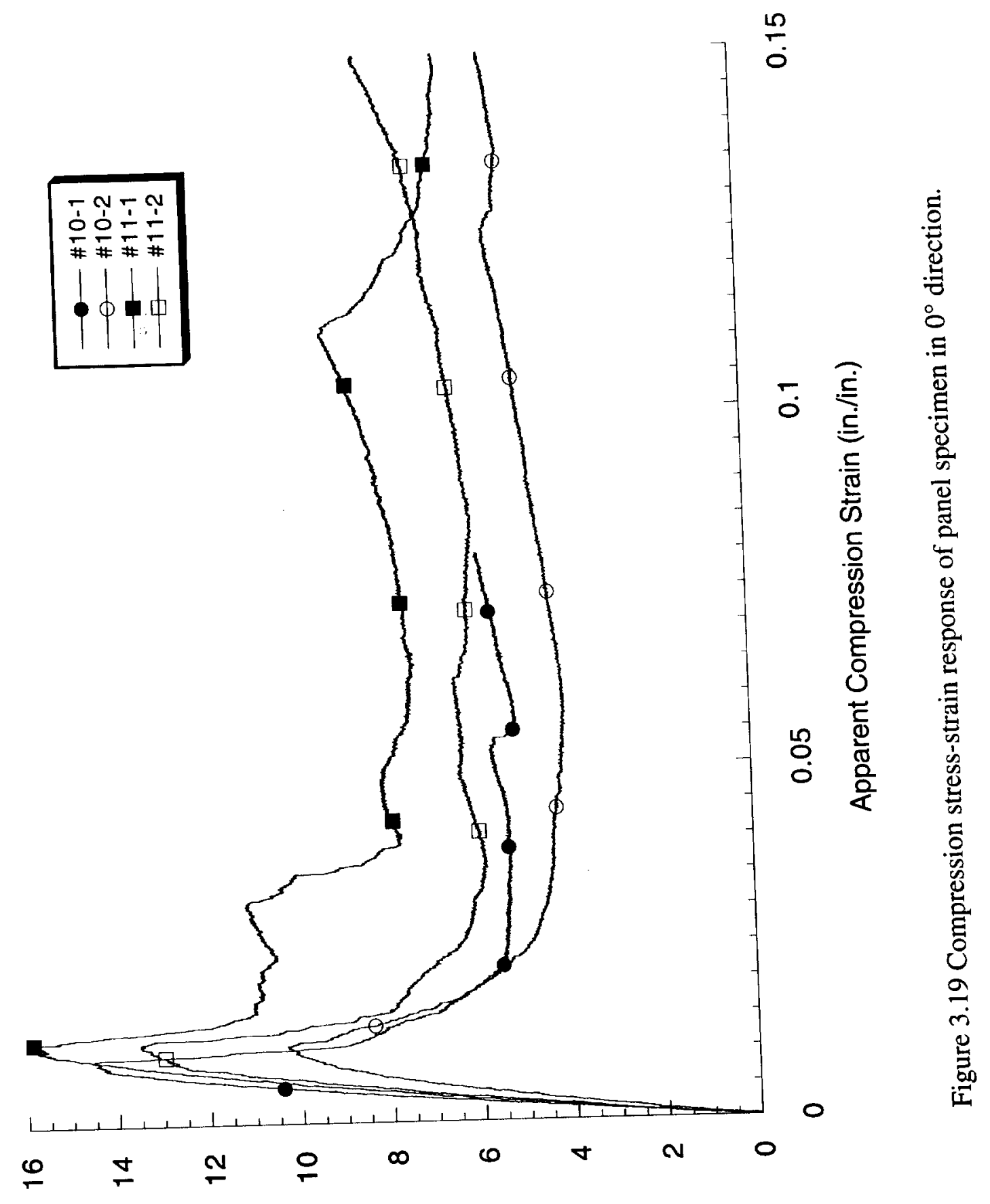

(!sy) ssans uolssadduoo 


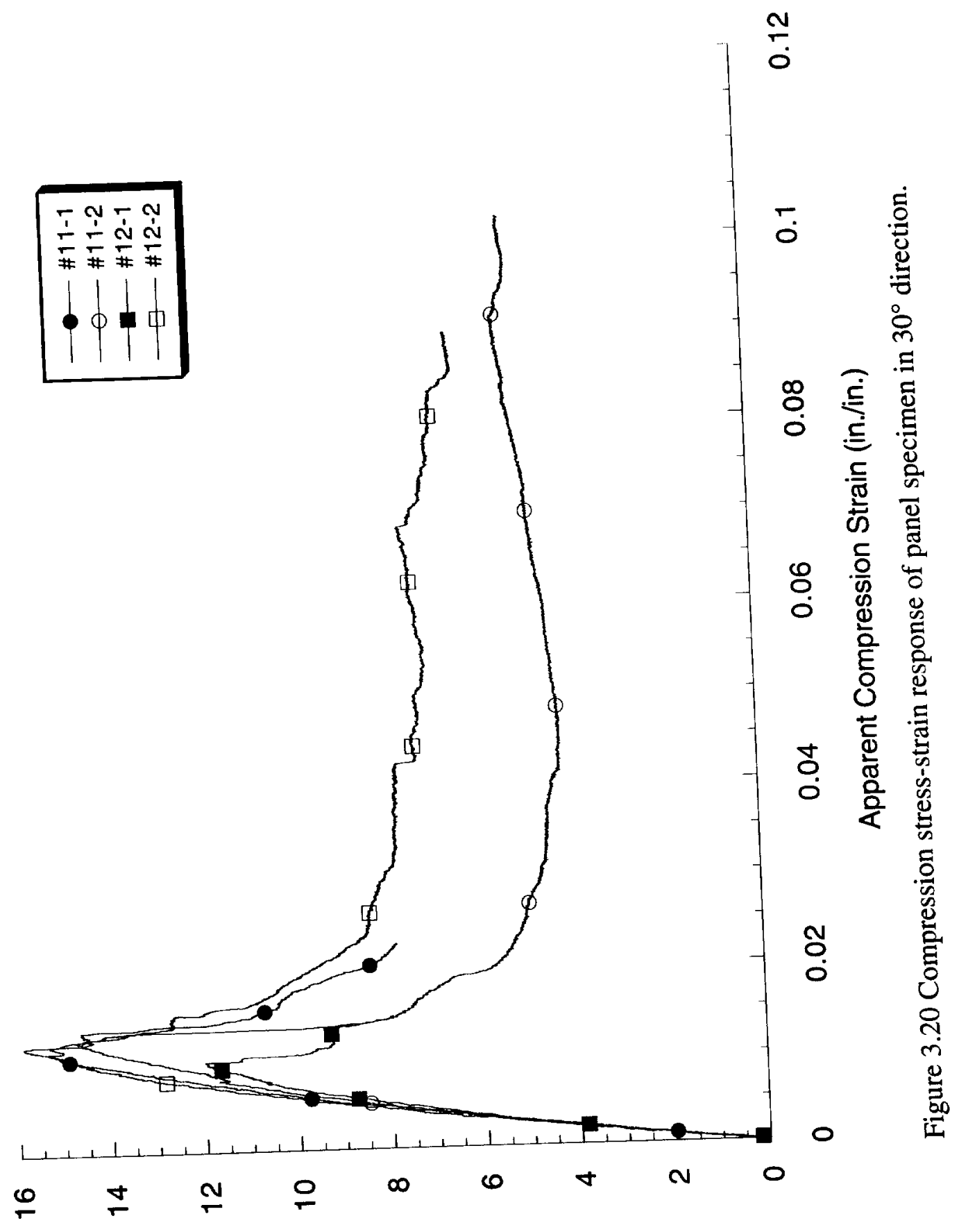

(ISy) ssants uo!ssaddwoo 


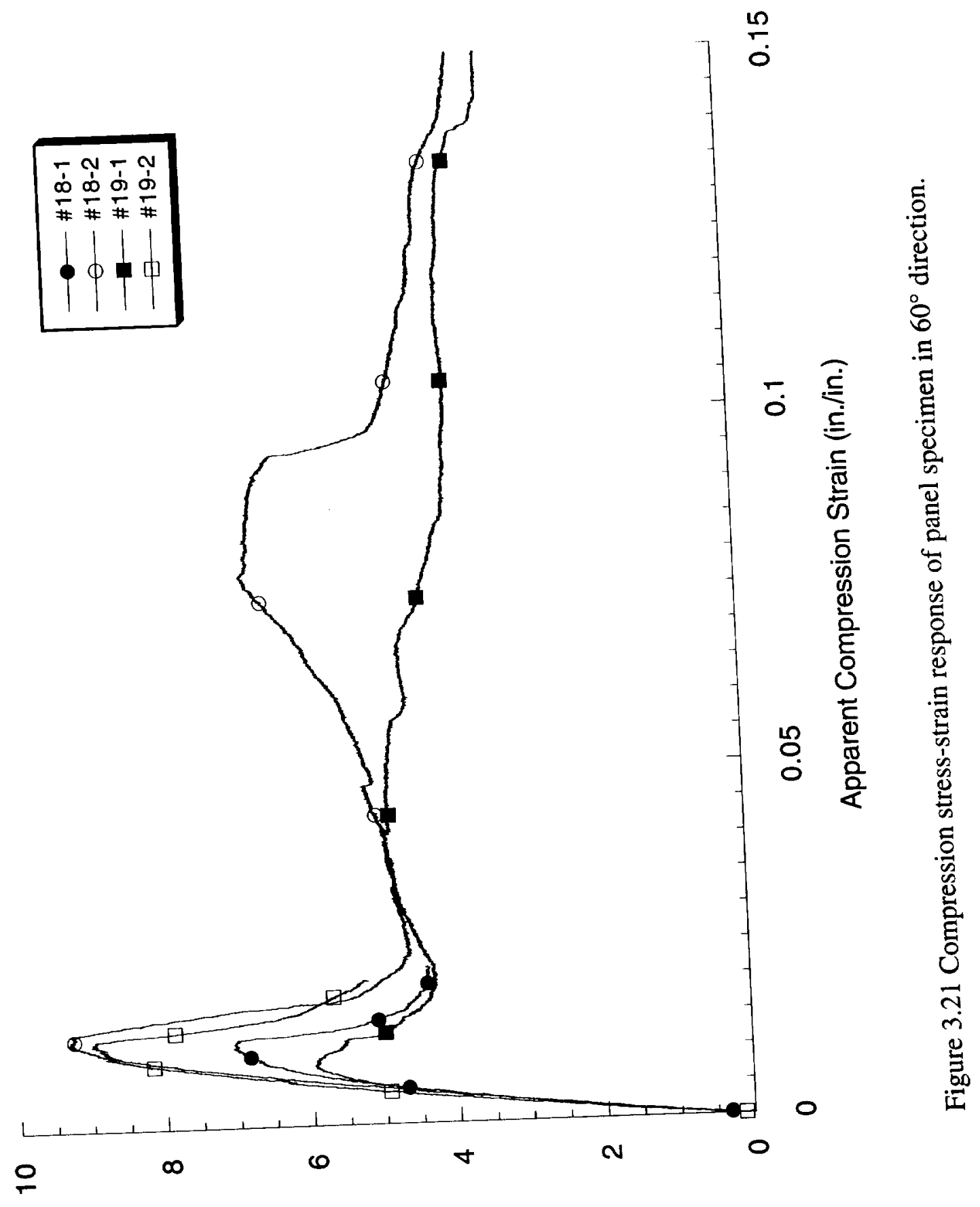

(!Sy) ssaגs uo!ssəıdwoo 


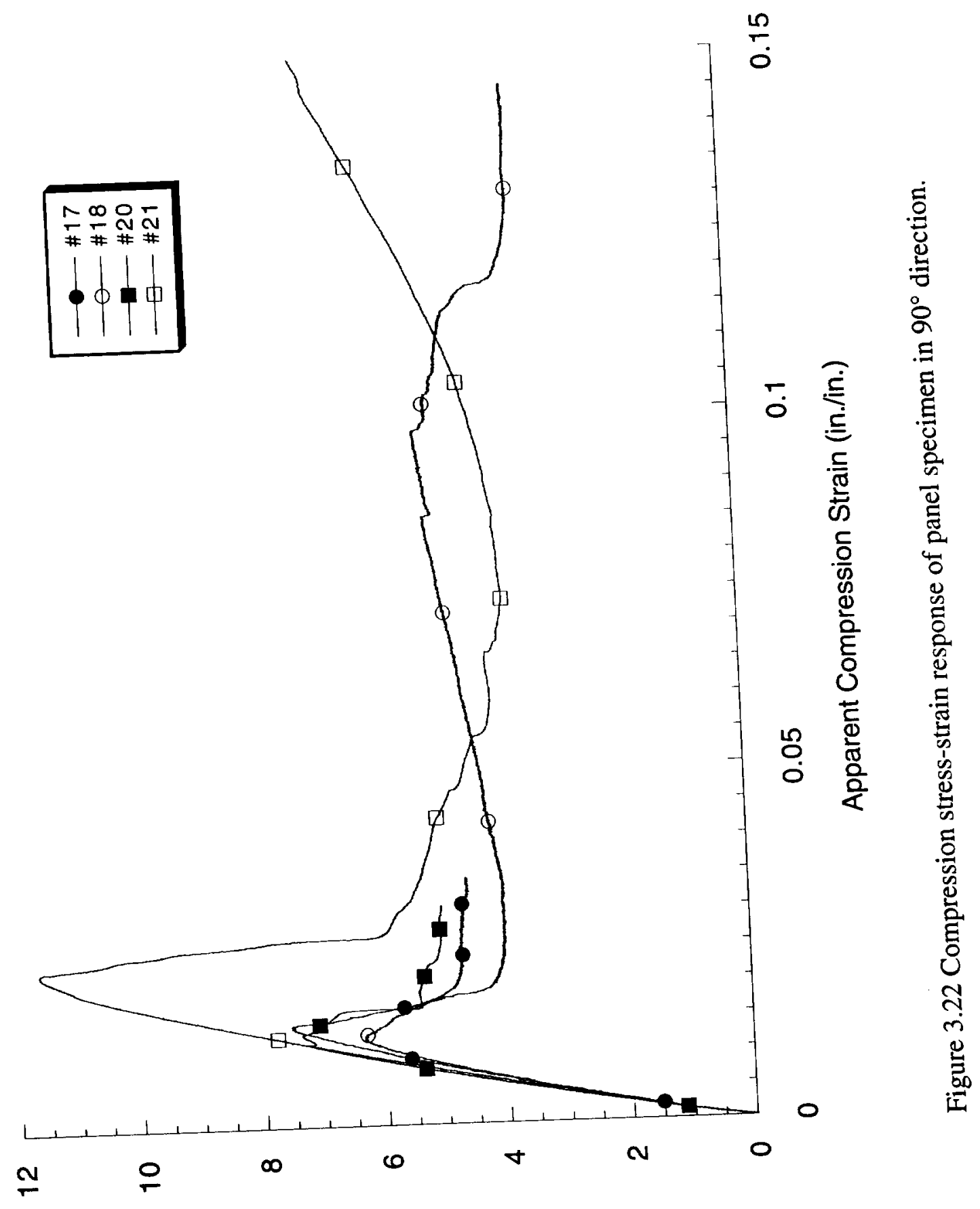

(!sx) ssans uo!ssaıdwoo 


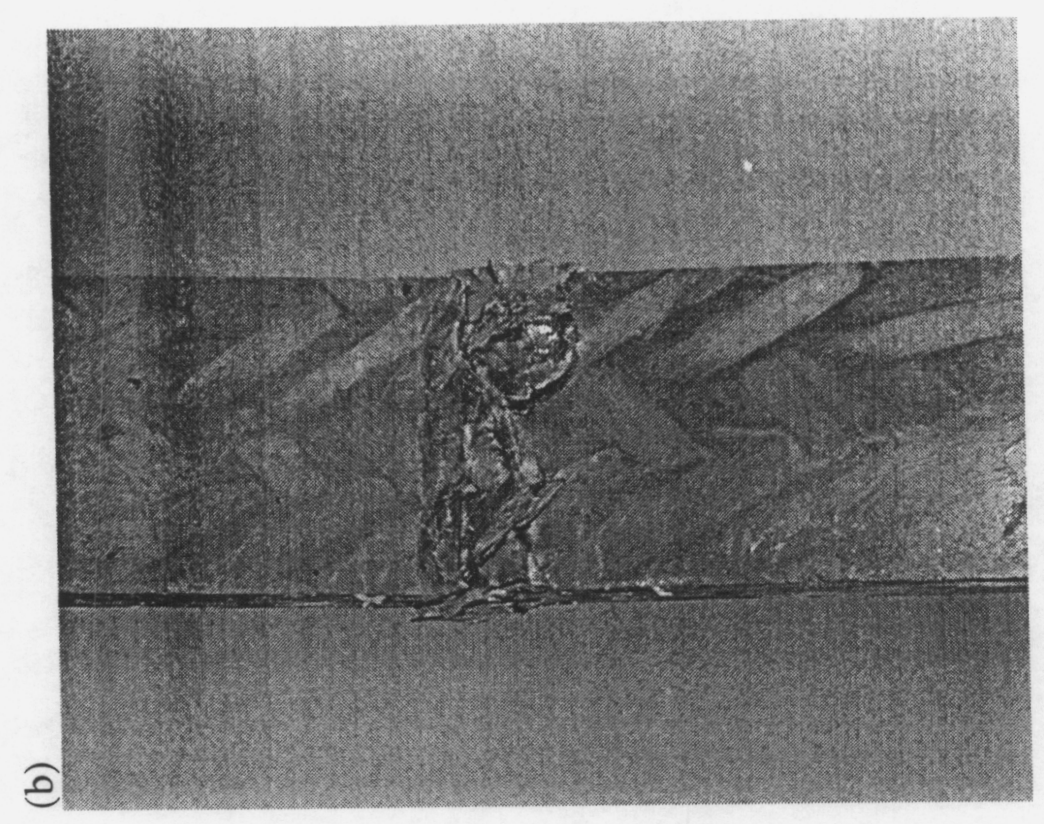

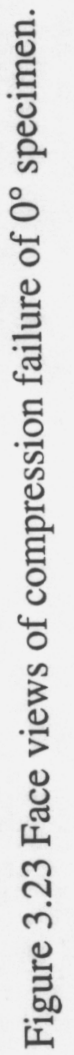

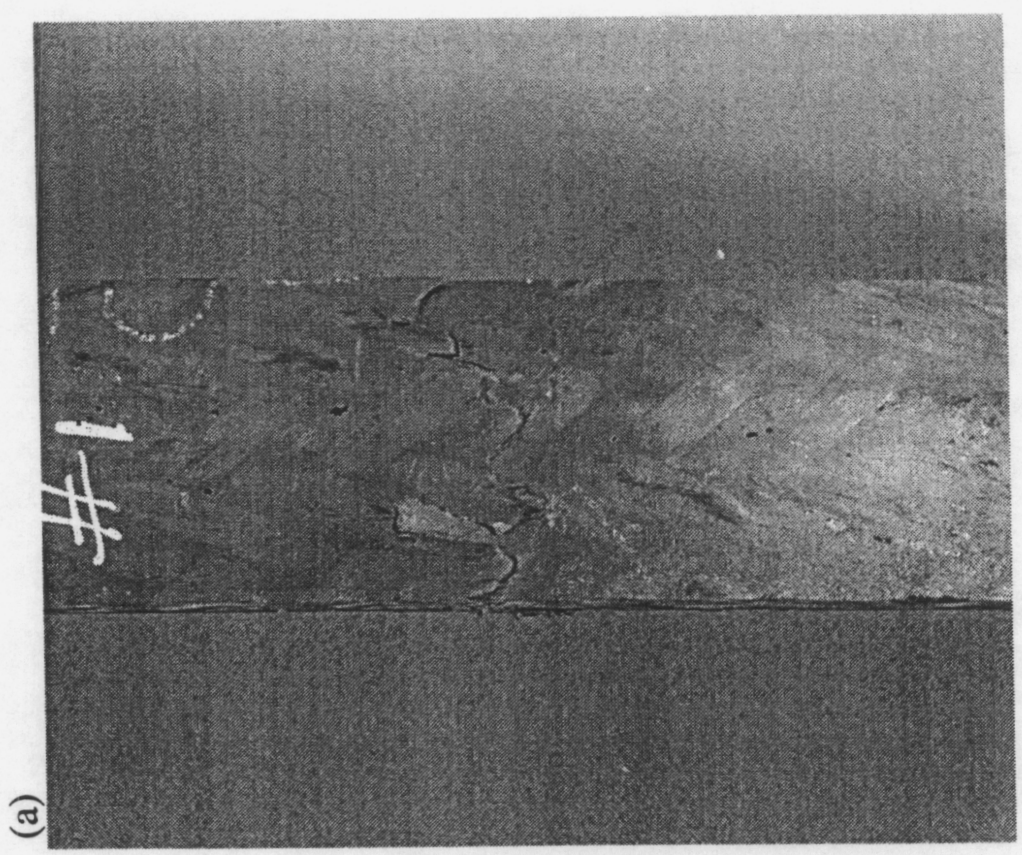




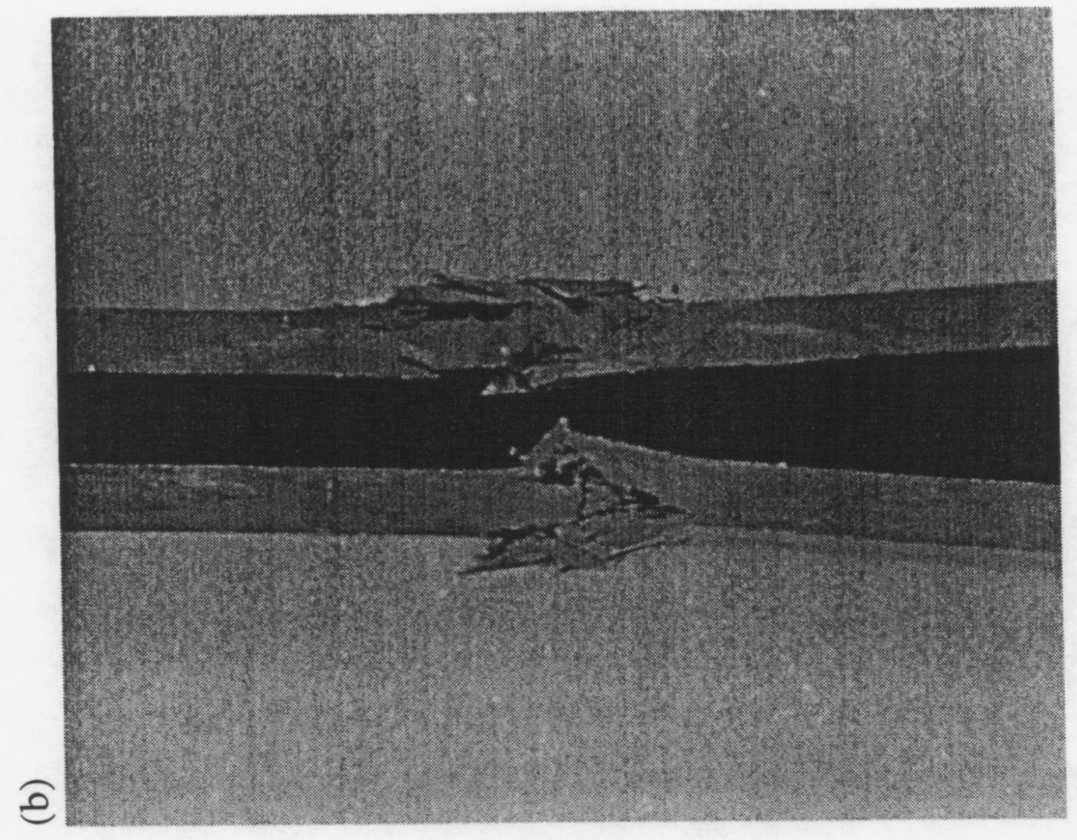

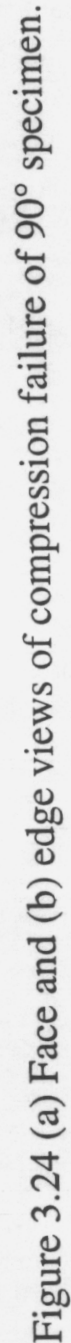

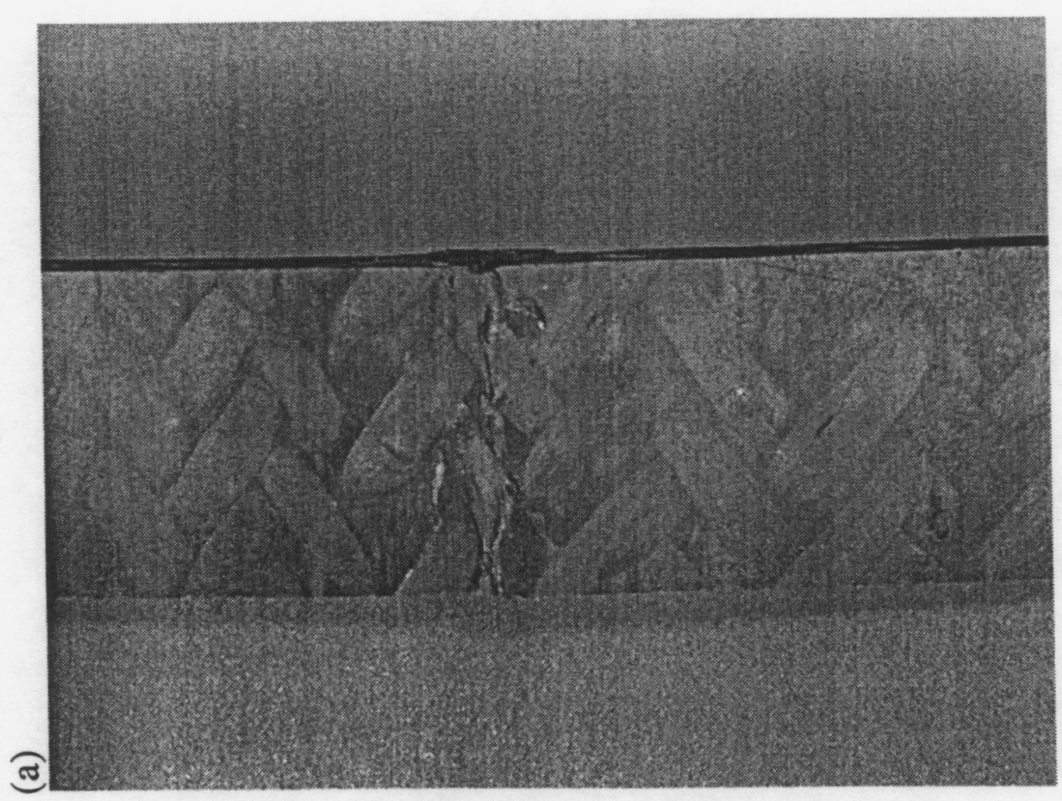




\subsection{Tension After Compression Tests}

To assess state of damage and elucidate failure mechanisms under compression, specimens that were previously tested in uniaxial compression to various strain levels were subsequently pulled in uniaxial tension to failure. The same compression specimens that were described in the previous section were used for these tests. The combined compression and tension response curves for four specimens are shown in Figs. 3.25-3.28. For the first two specimens tested (\#10 and \#11), the compression and subsequent tension loading were done separately and no data was recorded during the unloading from the compression cycle. The last two tests (\#7 and \#8) were run so that the entire loading from compression to tension was performed as a single test. After compression past the peak stress value, the composite is permanently deformed with buckled $30^{\circ}$ tows on the surface and presumably buckled $0^{\circ}$ inside. When a compressed specimen is then pulled in tension, no appreciable stress is generated until the buckled fiber is straightened. The results given in Figs. 3.27 and 3.28 show that nearly all the permanent compressive deformation must be recovered before the material stiffens and sustains a tensile stress.

The data for compression strength and subsequent maximum tensile stress are summarized in Table 3.5. The maximum tensile stresses reached after compression are about an order of magnitude less than the $0^{\circ}$ tensile strength of the laminate (Table 3.3). Specimen \#7 was compressed to a smaller maximum deformation level, which resulted in a greater retention of tensile strength. The loss in tensile strength indicates that significant damage has occurred to the tension load-bearing fiber during compression, but this damage isn't necessarily due to fiber breakage alone. The much-reduced tensile stress response could also be the result of matrix failure and loss of bonding between carbon filaments. In the extreme case of completely dry or unbonded tow, there is no mechanism to transfer stress across the broken ends of filaments and the maximum tensile stress is greatly reduced. It should be noted that specimens \#7 and \#8, which were taken from a different panel, have much higher compression strength than specimens \#10 and \#11 as well as all other specimens tested (Table 3.4 ).

The tensile fracture of specimens that had been previously compressed was different from the normal tensile fracture of a $0^{\circ}$ laminate. The fracture zone was confined to a much narrower region as shown in Fig. 3.29, which corresponded to the material damaged in compression. This behavior is further evidence for the failure of the load-bearing fiber and the matrix surrounding it. 
Table 3.5. Maximum stress levels in compression followed by tension tests.

\begin{tabular}{|c|c|c|c|}
\hline Specimen & $\begin{array}{c}\text { Peak Compression } \\
\text { Stress (ksi) }\end{array}$ & $\begin{array}{c}\text { Maximum } \\
\text { Compression } \\
\text { Deformation (in.) }\end{array}$ & $\begin{array}{c}\text { Peak Tensile Stress } \\
\text { (ksi) }\end{array}$ \\
\hline$\# 10$ & 10.33 & 0.15 & 4.78 \\
\hline$\# 11$ & 13.51 & 0.15 & 3.93 \\
\hline$\# 7$ & 19.68 & 0.05 & 7.80 \\
\hline$\# 8$ & 20.78 & 0.15 & 2.20 \\
\hline
\end{tabular}




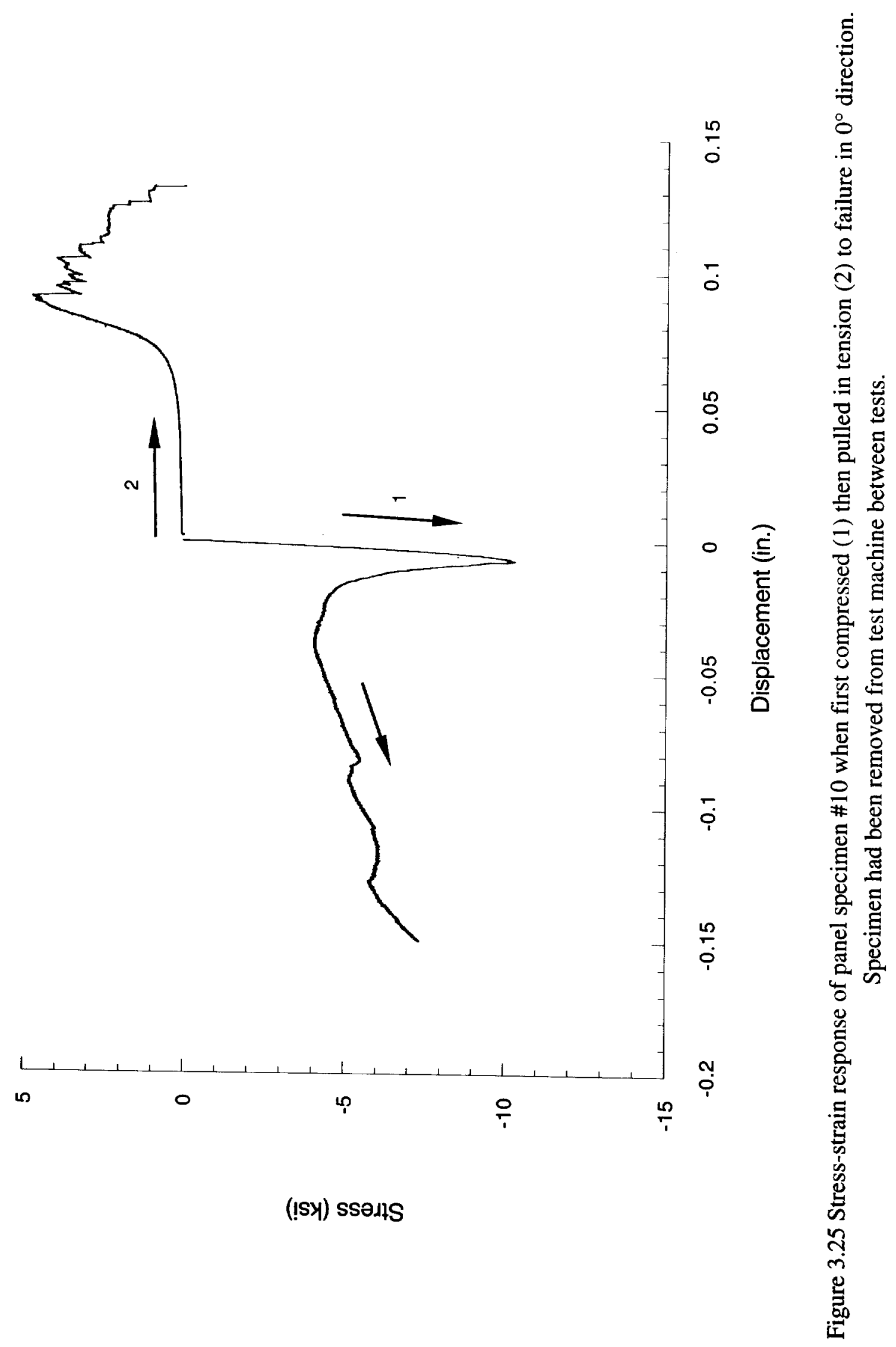




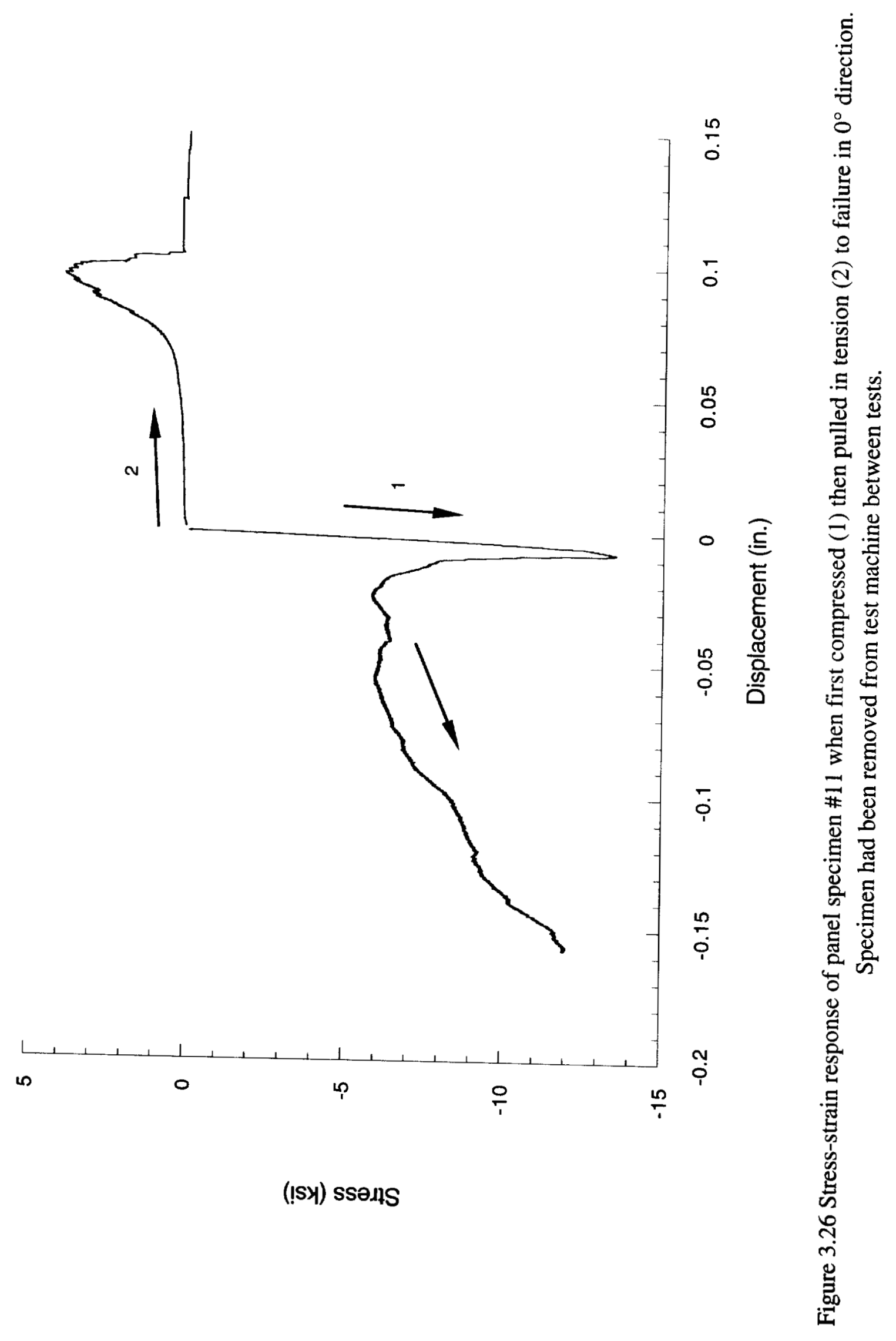




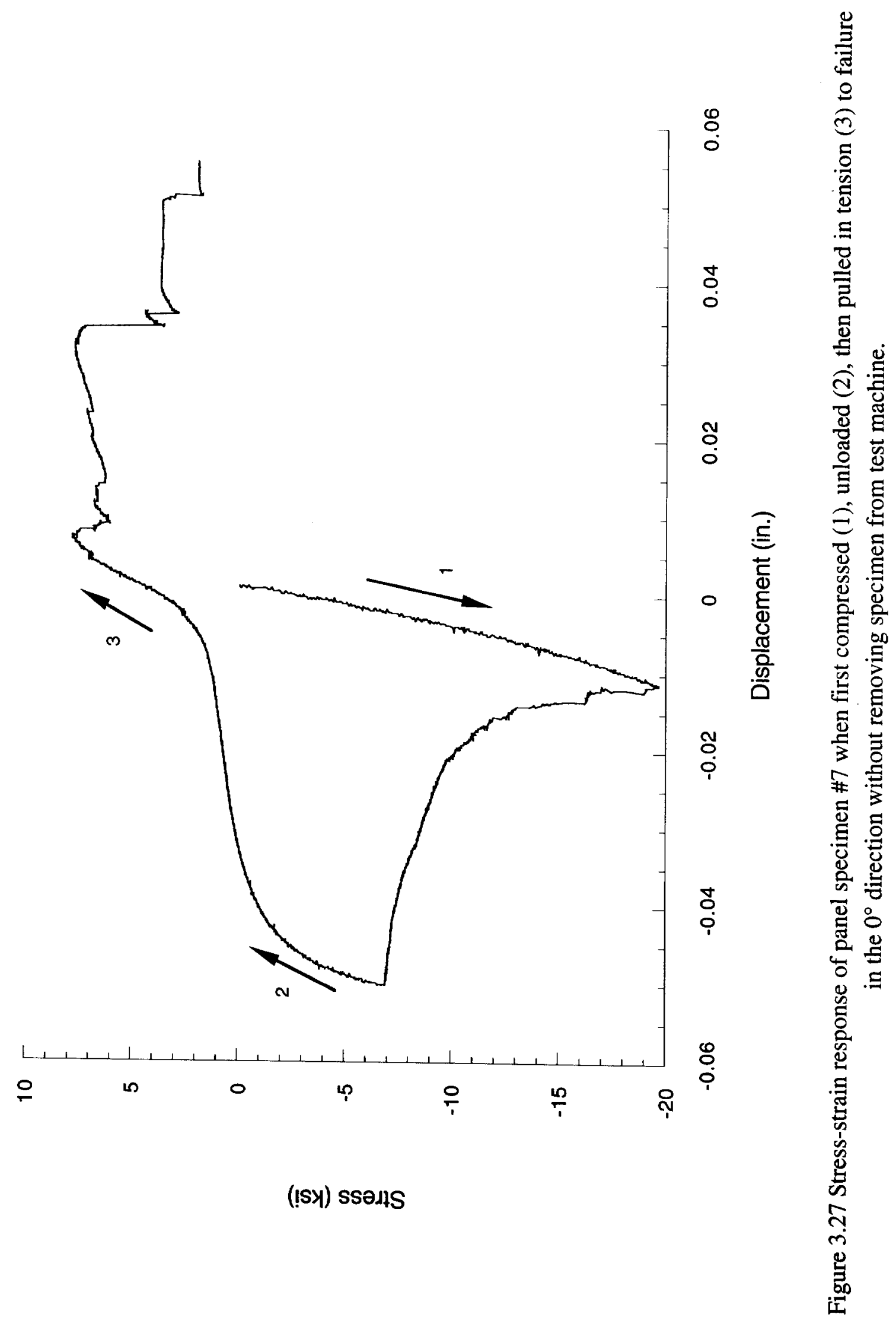




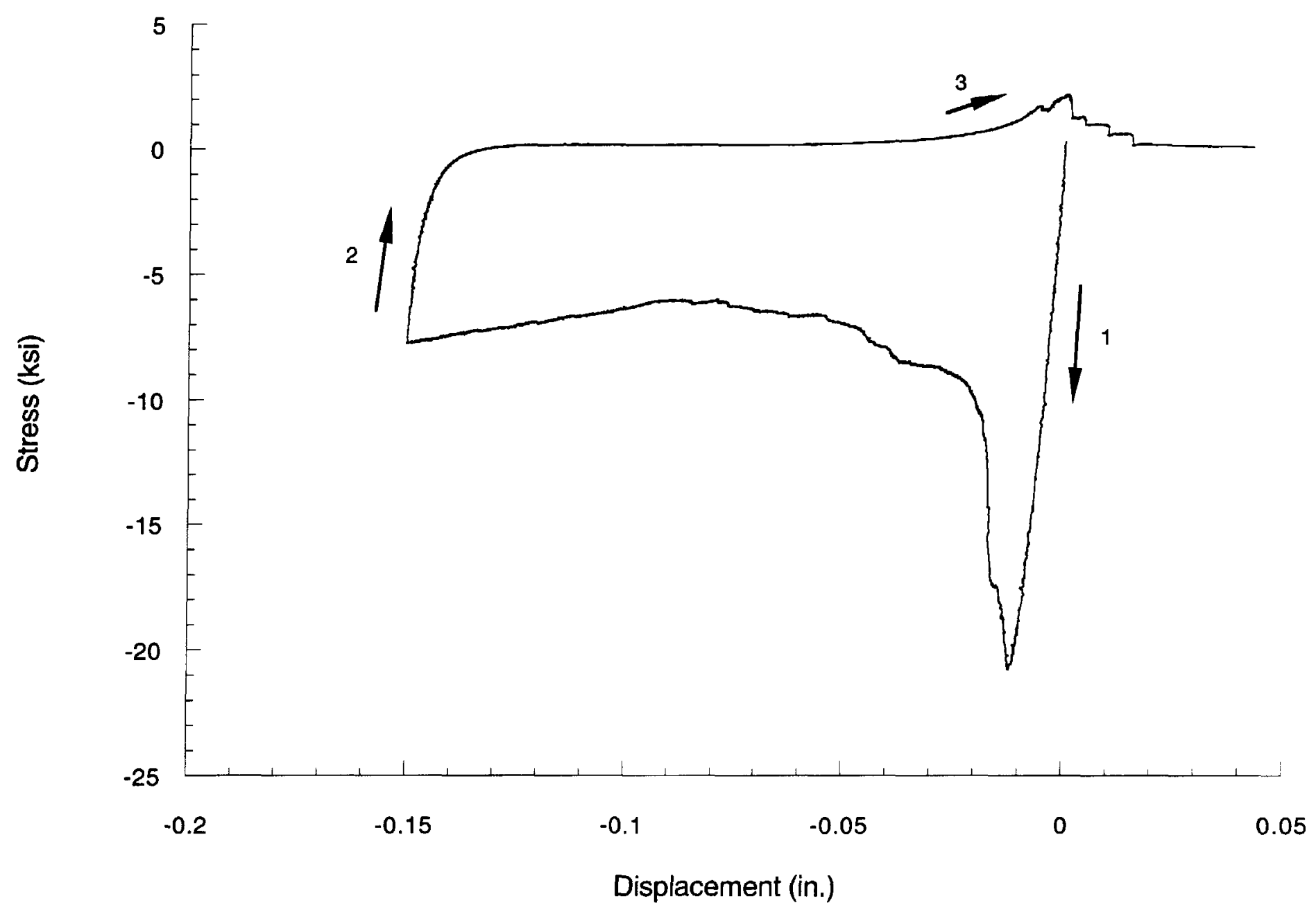

Figure 3.28 Stress-strain response of panel specimen \#8 when first compressed (1), unloaded (2), then pulled in tension (3) to failure in the $0^{\circ}$ direction without removing specimen from test machine. 
(a)

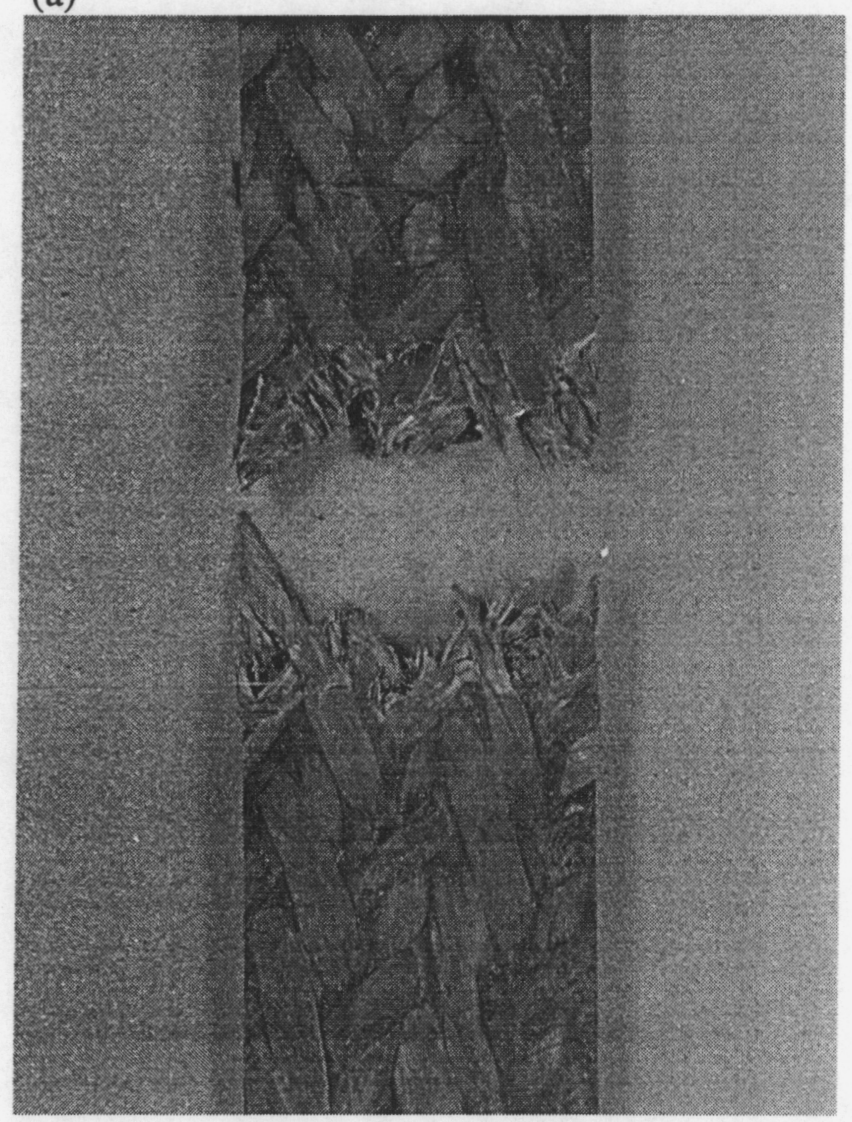

(b)

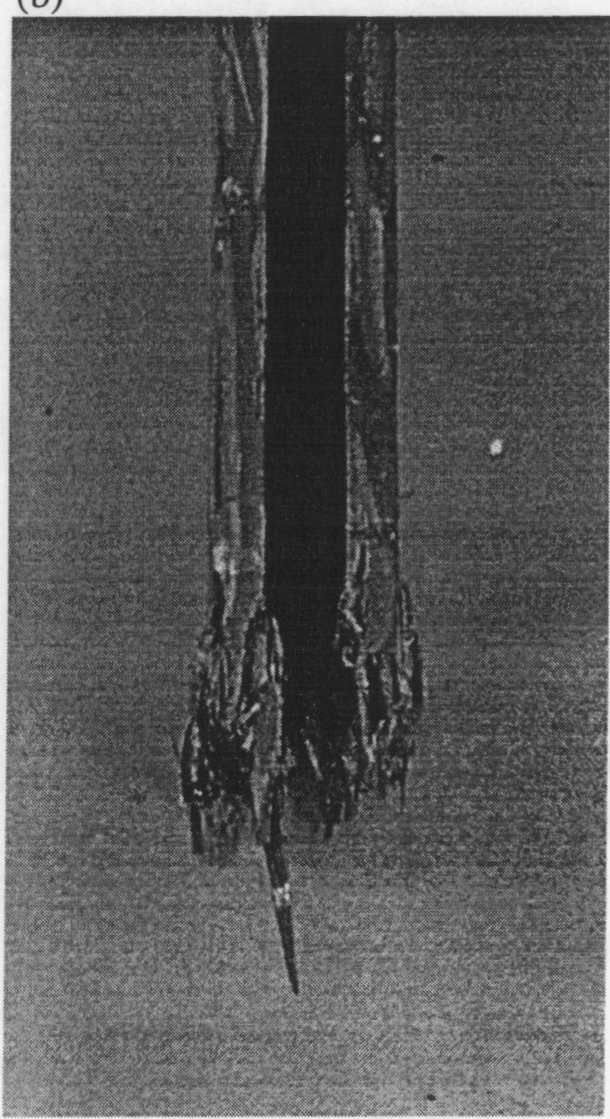

Figure 3.29 (a) Face and (b) edge views of tensile failure of $0^{\circ}$ specimen that been previously tested in compression. 


\subsection{Intermediate Rate Tests}

During the original discussions with ACC it was agreed that all participants in the program would utilize the $1.5 \mathrm{in}$. width specimens. It was the consensus that this width was necessary to avoid erroneous results from scale effects in these large tow braided composites. Consequently, our initial efforts to determine the effect of rate on the properties of the laminates concentrated on using a specimen of this width. However, the available grips and hardware for testing these wide specimens in a high-rate servohydraulic machine were not amenable to producing acceptable results at intermediate rates. Data collected using the wide specimens suffered from inertial effects and stress wave propagation through the load train. This problem was circumvented by the use of custom lightweight wedge grips that had been developed for a previous study on high-temperature fiber composites. Using these grips and associated fixturing, it was possible to collect clean data at strain rates of slightly more than $1 \mathrm{~s}^{-1}$. The one disadvantage of these lighter grips is that they could only accommodate a maximum specimen width of $1.0 \mathrm{in}$. In order to satisfy the concerns that the smaller width specimen was not representative of the panel properties or at least not representative of all the data collected with the $1.5 \mathrm{in}$. wide specimens, tests were conducted at both quasi-static and intermediate rates using the narrower specimens. In this manner at least the relative effect of rate on properties could be assessed.

The dependence of carbon fiber composite properties on deformation rate is mostly due to the contribution of the matrix material. Therefore, the tests conducted herein were limited to the matrix-dominated $60^{\circ}$ and $90^{\circ}$ laminates. Both tension and compression tests were conducted using the 1 in. wide specimens mounted in the lightweight wedge grips at a gage length of $0.9 \mathrm{in}$. An apparent strain was calculated from the machine displacement and tests were conducted at displacement rates that yielded effective strain rates of $1 \mathrm{E}-3$ and 2-3 s $\mathrm{s}^{-1}$. Stress-apparent strain response curves for the two laminates loaded in tension at the two deformation rates are shown in Figs. 3.30-3.33. The response curves for compression testing are given in Figs. 3.34-3.37. The strength data obtained from these curves is summarized in Table 3.6. By increasing the deformation rate from $1 \mathrm{E}-3 \mathrm{~s}^{-1}$ to just over $1 \mathrm{~s}^{-1}$, the average tensile strengths of $60^{\circ}$ and $90^{\circ}$ laminates increase by 20 and $15 \%$, respectively. The same rate increase raises the compression strengths of the $60^{\circ}$ and $90^{\circ}$ laminates by 37 and $18 \%$, respectively. Compare these strength increases with the corresponding enhancements to the compression yield and flow stresses of the Hetron 922 resin (see relation (2) and Table 2.8), which are 33 and 22\%, respectively. Although the results are somewhat scattered, it appears that the increased strength at intermediate deformation rate of the composite along the $60^{\circ}$ and $90^{\circ}$ orientations can be attributed to the rate-dependent plastic response of the matrix. 
Table 3.6. Effect of deformation rate on tensile and compression strengths of matrixdominated panel laminates.

\begin{tabular}{|c|c|c|c|c|}
\hline & \multicolumn{2}{|c|}{$\mathbf{6 0}^{\circ}$ Strength (ksi) } & \multicolumn{2}{c|}{$\mathbf{9 0}^{\circ}$ Strength (ksi) } \\
\cline { 2 - 5 } Load Type & $\begin{array}{c}\text { Quasi-Static } \\
\text { Rate }\end{array}$ & $\begin{array}{c}\text { Intermediate } \\
\text { Rate }\end{array}$ & $\begin{array}{c}\text { Quasi-Static } \\
\text { Rate }\end{array}$ & $\begin{array}{c}\text { Intermediate } \\
\text { Rate }\end{array}$ \\
\hline Tensile & 10.4 & 11.7 & 4.30 & 4.82 \\
\hline$"$ & 5.98 & 7.78 & 4.63 & 5.42 \\
\hline$"$ & 6.95 & 9.81 & 4.48 & 6.80 \\
\hline$"$ & 8.04 & 7.03 & 5.57 & 5.49 \\
\hline$"$ & 7.22 & 10.0 & 5.17 & 5.15 \\
\hline “ & & & 4.63 & 5.46 \\
\hline Avg.: & 7.71 & 9.27 & 4.80 & 5.52 \\
(SD): & $(1.66)$ & $(1.87)$ & $(0.48)$ & $(0.68)$ \\
\hline Compression & 9.92 & 13.8 & 10.6 & 15.1 \\
\hline " & 11.1 & 11.7 & 10.8 & 13.0 \\
\hline$"$ & 11.5 & 14.7 & 5.64 & 7.17 \\
\hline " & 7.61 & 12.9 & 10.2 & 7.25 \\
\hline " & 11.6 & 17.6 & 6.95 & 9.42 \\
\hline Avg.: & 10.4 & 14.2 & 8.83 & 10.4 \\
\hline (SD): & $(1.68)$ & $(2.23)$ & $(2.37)$ & $(3.55)$ \\
\hline
\end{tabular}




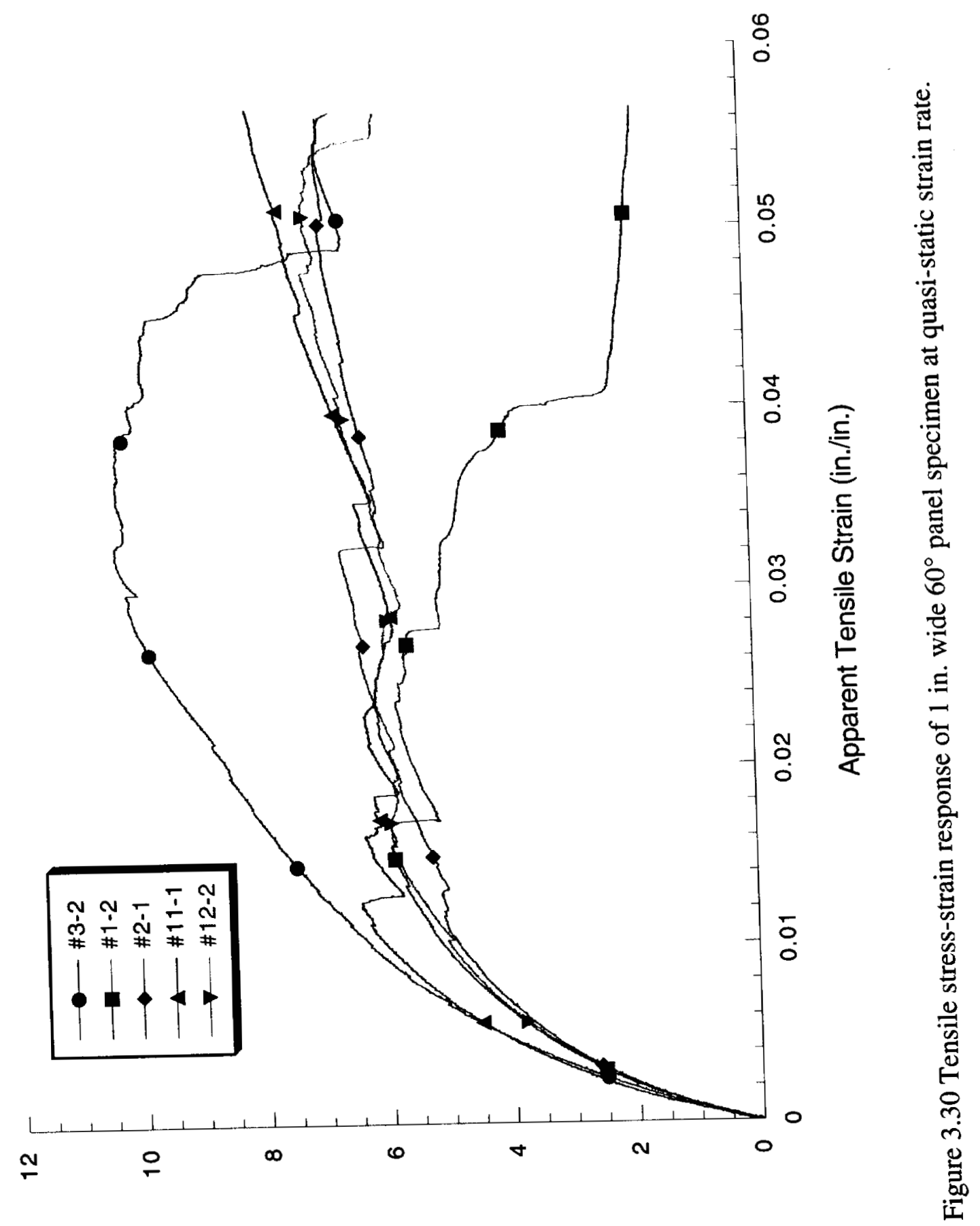

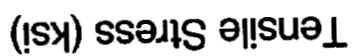




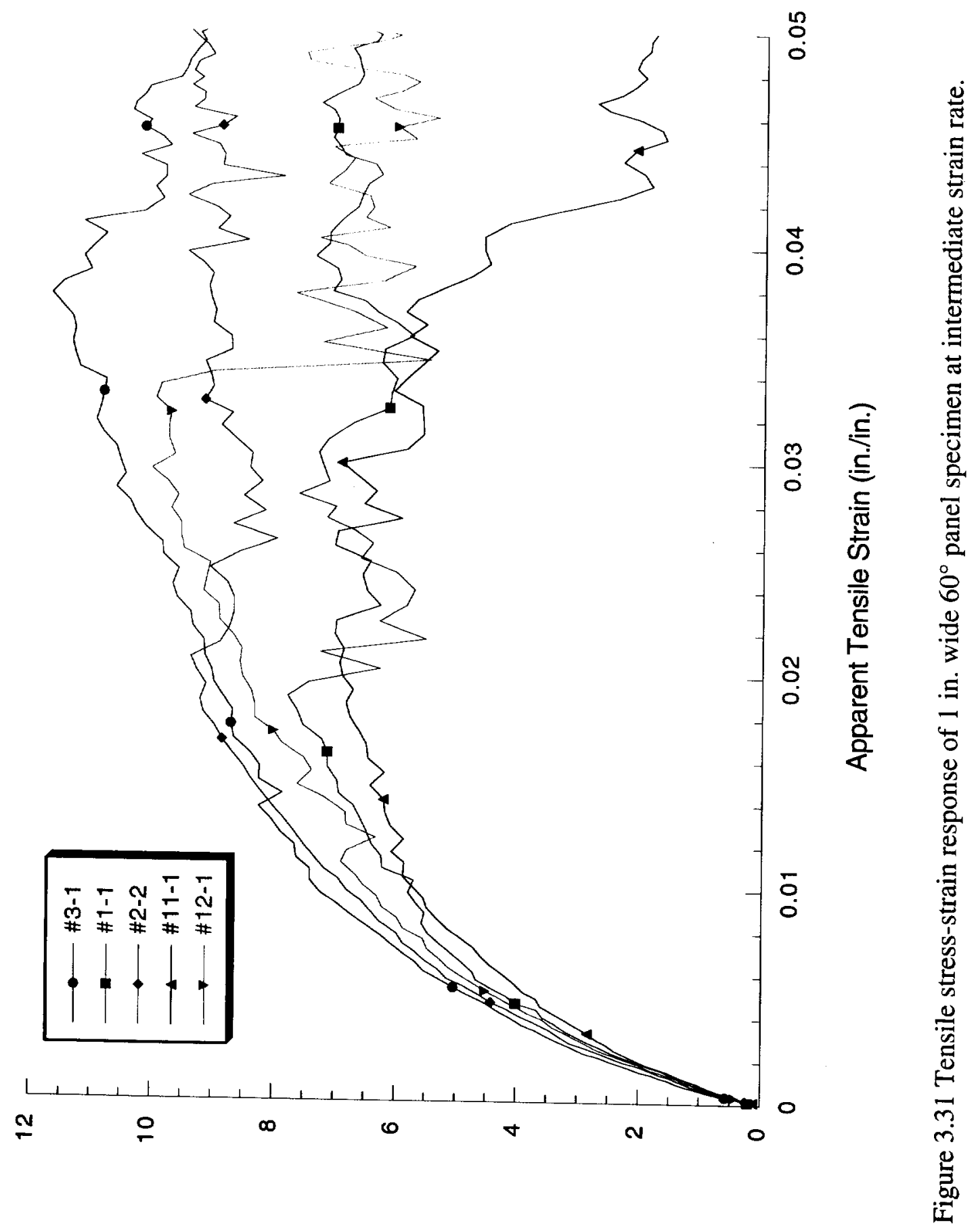

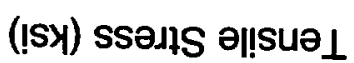




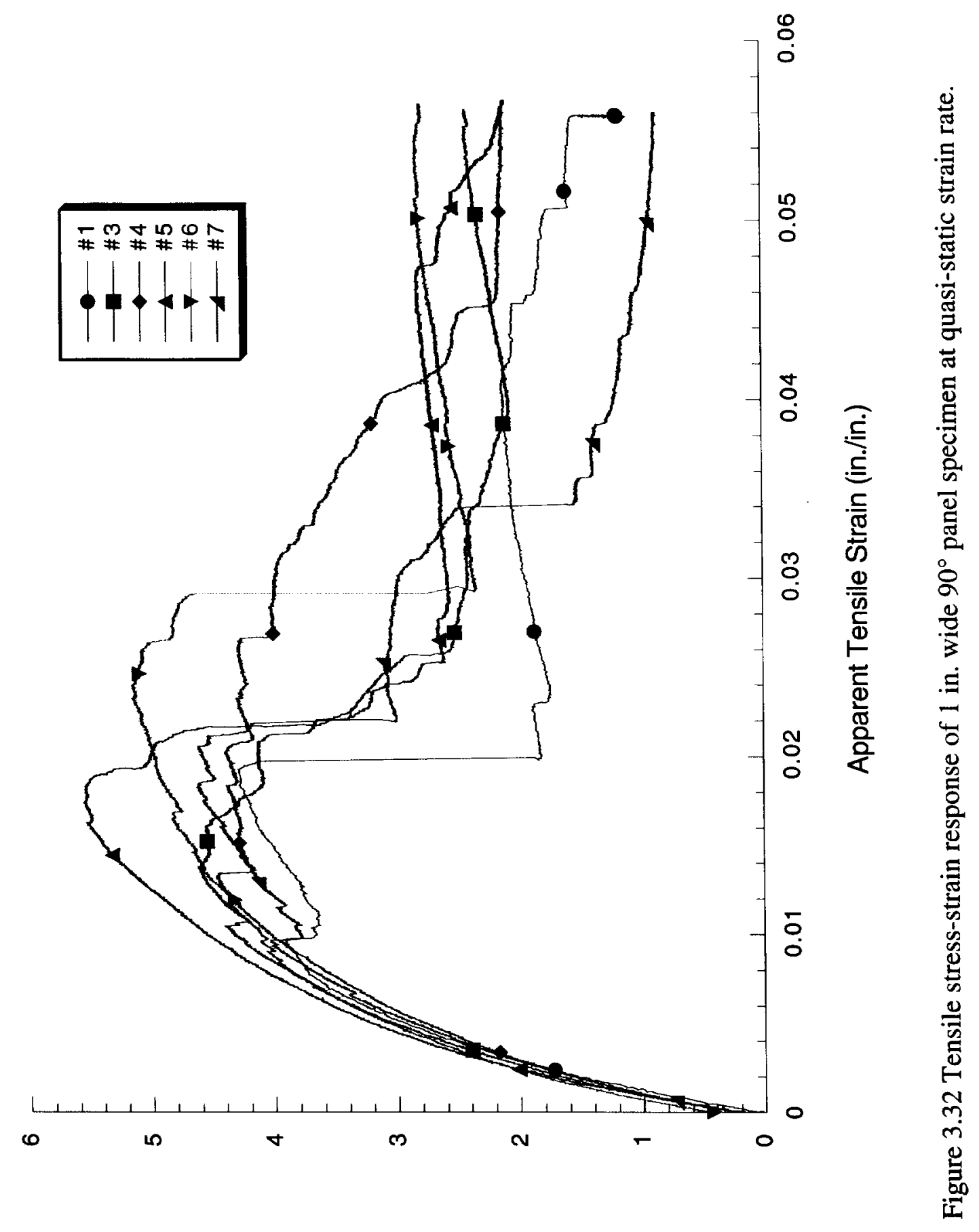

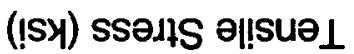




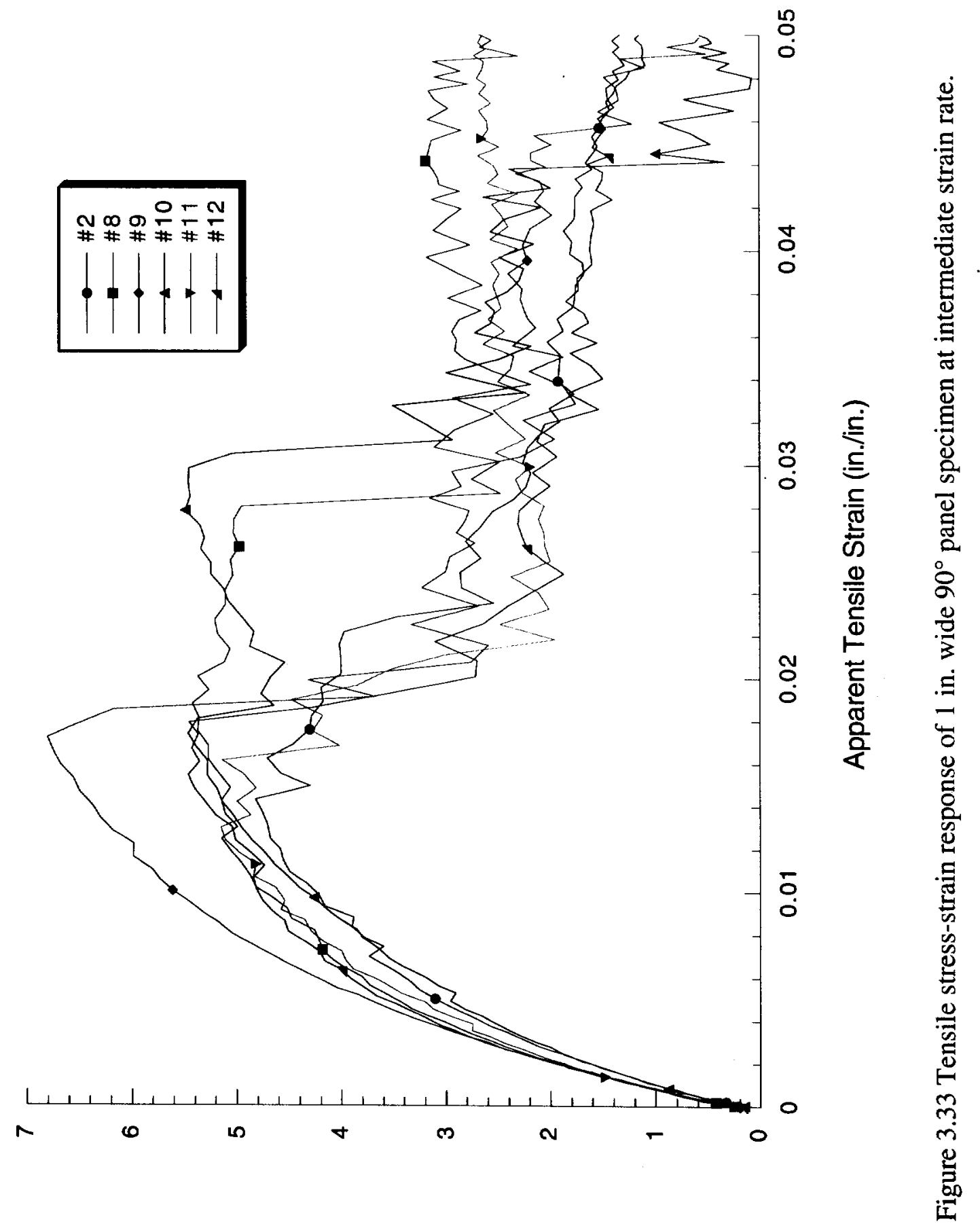

(ISY) ssəns ə!!suə। 


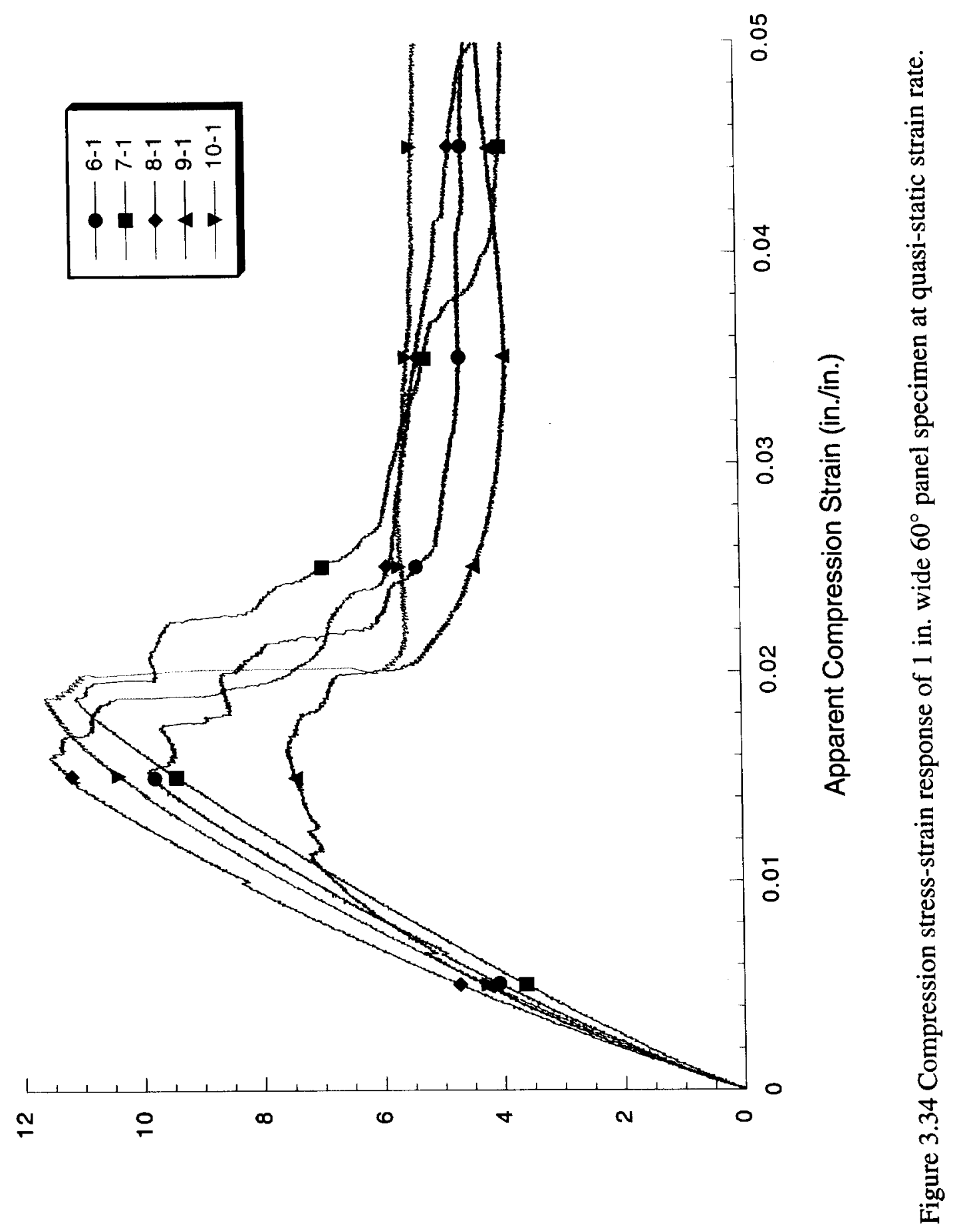

(ISY) ssalts Uo!ssadduoo 


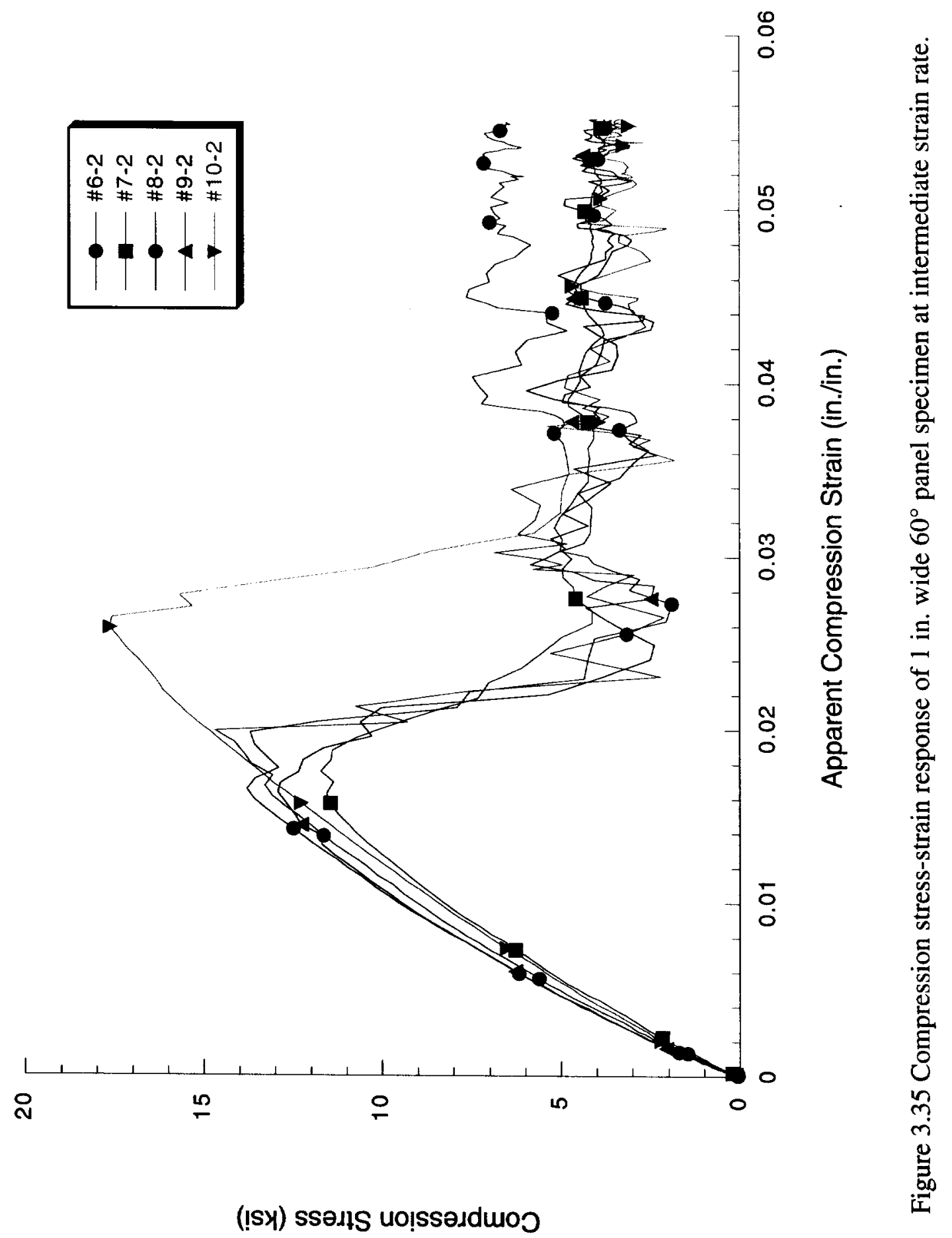




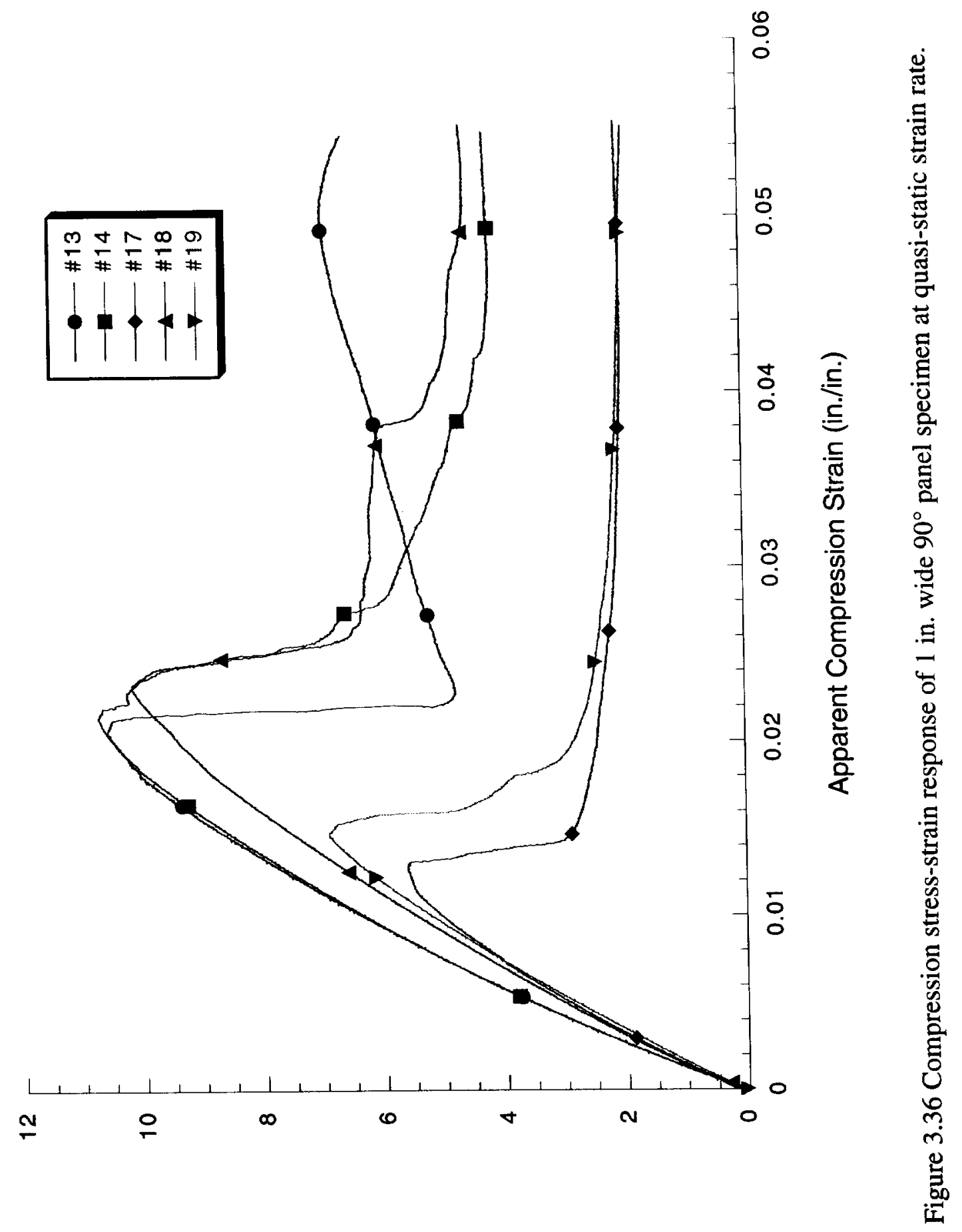

(ISY) ssalts uo!̣ssaduoo 


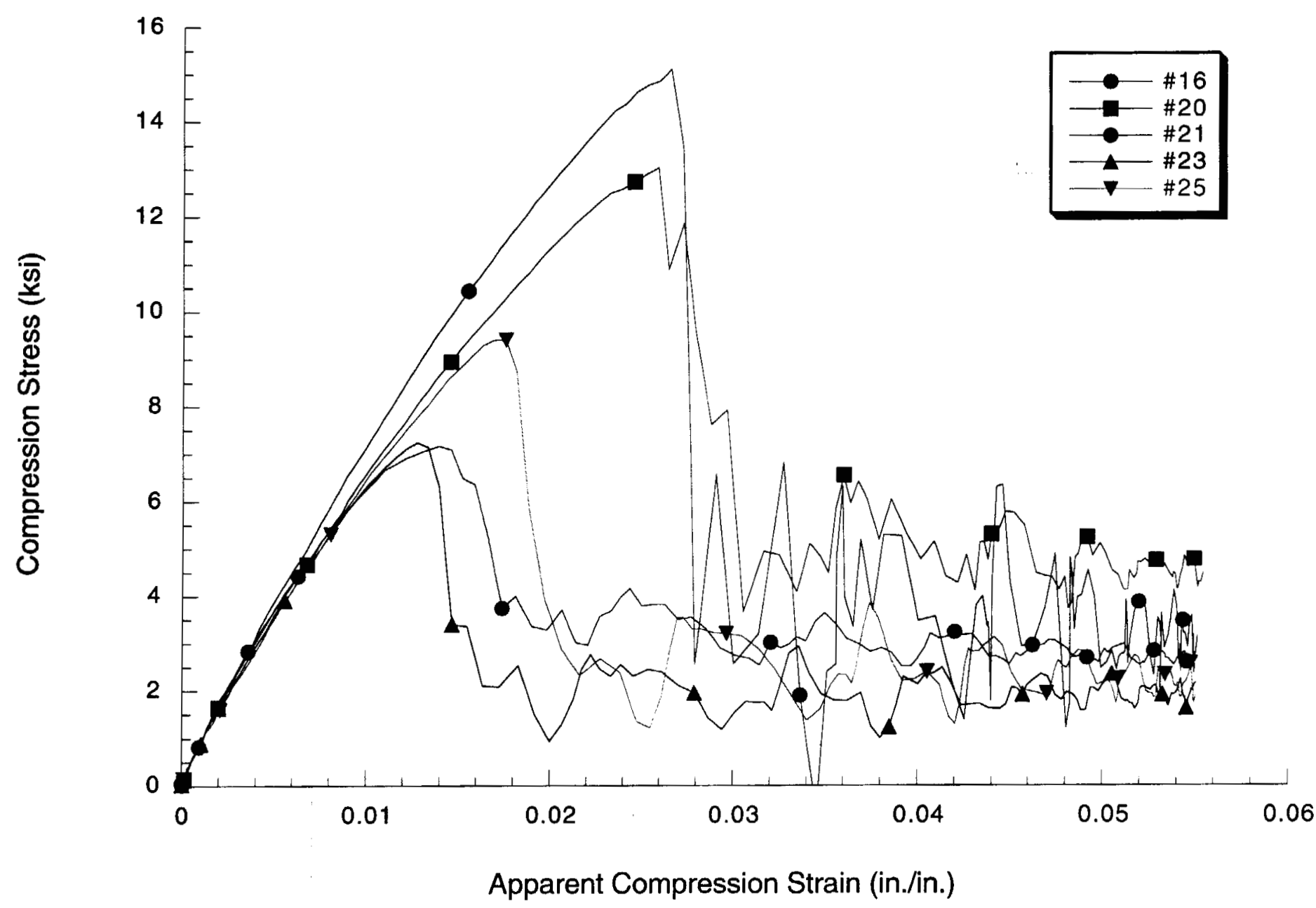

Figure 3.37 Compression stress-strain response of 1 in. wide $90^{\circ}$ panel specimen at intermediate strain rate. 


\subsection{Friction Tests}

\subsubsection{Low Normal Stress}

The coefficient of friction between steel and the ACC panels was measured using a sliding block technique. The actual procedure used for these tests is a slight variation of ASTM D1894 standard (Standard Test Method for Static and Kinetic Coefficients of Friction of Plastic Film and Sheeting). Although this series of tests was conducted using a relatively low normal force, the actual forces as well as the displacement velocity were higher than those specified in the standard.

A schematic of the friction test set-up for low normal stresses is shown in Fig. 3.38a. Sections of Panel \#10-9 were machined to dimensions of 1.5 in. by 2.5 in. for friction testing. Tests were conducted with the composite surface in the as-fabricated condition and after abrading the surface with 60 grit silicon carbide paper. Both sides of each specimen were measured for friction in the as-fabricated state and only the side that yielded the higher friction coefficient was abraded for further testing. The abraded surface of each specimen was measured two times in order to check for damage induced during the friction test. The composite pieces were fixed to the movable backing plate using double-sided adhesive tape and both composite and steel surfaces were cleaned with isopropyl alcohol prior to each test. A single test consisted of measuring the frictional forces under five different normal forces that corresponded to stress values of $3.31,5.92,8.53,11.1$, and $13.8 \mathrm{psi}$. Three measurements were made at each of these stress levels for every specimen and surface condition. All tests were conducted at a displacement velocity of $20 \mathrm{in} . / \mathrm{min}$., which is the maximum rate for the Instron Model 1125 test system used in the experiments.

Typical friction force versus displacement plots for the as-fabricated surface are shown in Fig. 3.39. The common characteristic of all these tests is the lack of a distinctive sliding initiation force that would correspond to a static coefficient of friction. In most cases, there appeared to be no significant difference between static and dynamic friction coefficients. This observation was also true for the surfaces that had been abraded. An example plot of the results for an abraded surface is shown in Fig. 3.40.

Dynamic friction coefficient data for all tests are summarized in Fig. 3.41. These plots show the effects of normal stress and surface condition on friction. One conclusion from this data is that the behavior is ideal in that there is no significant effect of normal stress on friction coefficient for the relatively low stresses used in these tests. These data also show that there is a distinct difference between the two sides of the same specimen as well as a 


\subsubsection{High Normal Stress}

During the crush of composite tubes, it is expected that some areas will see friction under normal stresses that are significantly higher than those used to measure friction coefficient as described in the previous section. In order to examine the effects of high normal stress on the friction coefficient, a strip of a composite panel was pulled, using a servo-hydraulic test machine, out of hydraulic grips that were charged to different pressure levels. The hydraulic grips (MTS Model 647.10A-03) are supplied by an adjustable pressure source (3 ksi maximum) and provide a gripping force in pounds that is 15.45 times the supply pressure in psi. Since most of the composite tube crush tests had been conducted against aluminum initiators and base plates, the measurements of friction coefficient under high normal stresses were made between composite and aluminum using the experimental setup shown schematically in Fig. 3.38b. One end of a $1.5 \mathrm{in}$. wide strip of composite was gripped directly against the wedge faces of the hydraulic grips using sufficiently high pressure to prevent slippage. The other end of the specimen was gripped against aluminum inserts using different levels of (lower) pressure to ensure that slippage would occur against the aluminum surface. Frictional forces at different normal stress levels were measured by pulling at a constant stroke rate of $0.01 \mathrm{in} . / \mathrm{min}$ and sequentially increasing the grip force after a steady-state dynamic frictional slip condition had been reached.

The series of "stick-slip" events generated by the sequential increase in gripping force is seen in the plot of frictional force versus displacement given in Fig. 3.42. The arrows in the plot show where grip pressure was increased during the first few measurements of friction force. Unlike the results from friction tests under low normal stress, the friction response under higher stresses shows distinct static and dynamic friction behavior. Furthermore, at the highest stress levels there is a drop in friction force from the high static level to a level that is less than the subsequent steady-state dynamic friction force.

Calculated values of static and dynamic friction coefficients are plotted against stress in Fig. 3.43. The friction coefficient was found to drop dramatically as stress increased and the values of the coefficient at the highest stresses were below 0.2 . Examination of the composite specimen after testing showed that some of the aluminum had been abraded and embedded into the composite surface. It is likely that some of the drop in the friction coefficient with increasing stress was due to abrasion between the two surfaces and this might explain the drop in friction force prior to the attainment of a steady-state dynamic value at the highest normal stresses. The range of friction coefficients measured in these high normal stress experiments is comparable to the variation in values measured for asfabricated and abraded surfaces under low normal stresses. 
(a)

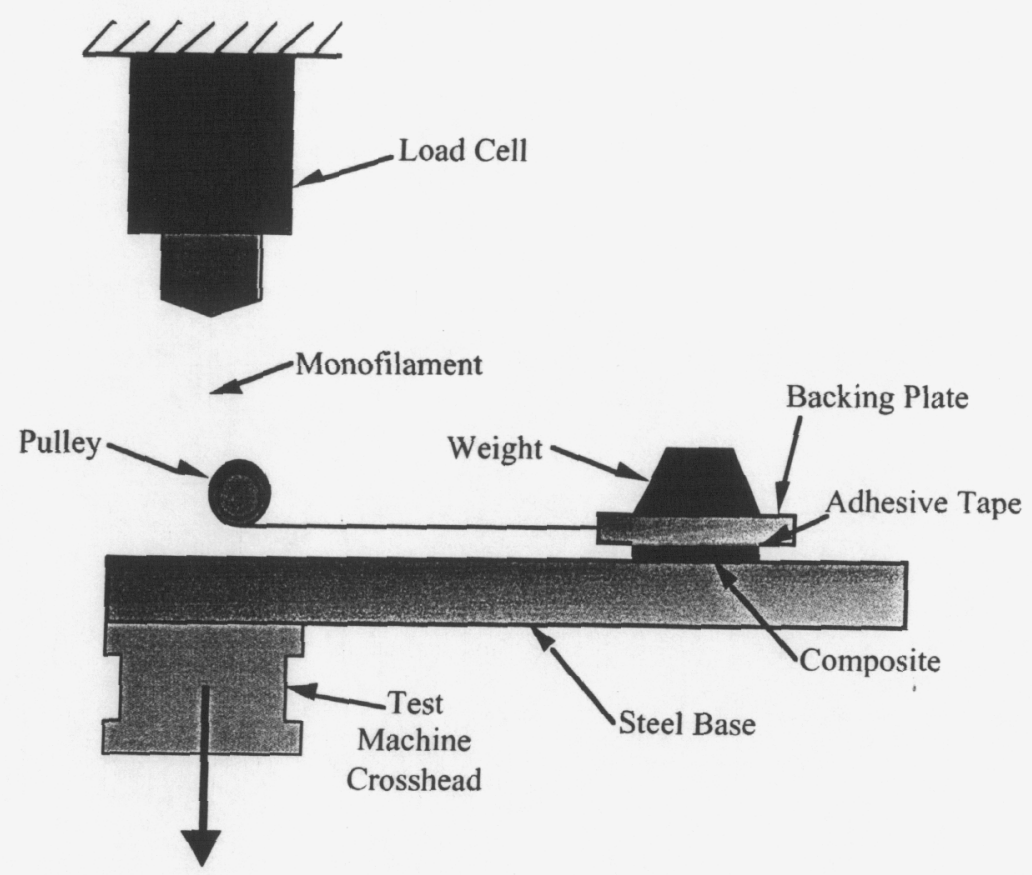

(b)

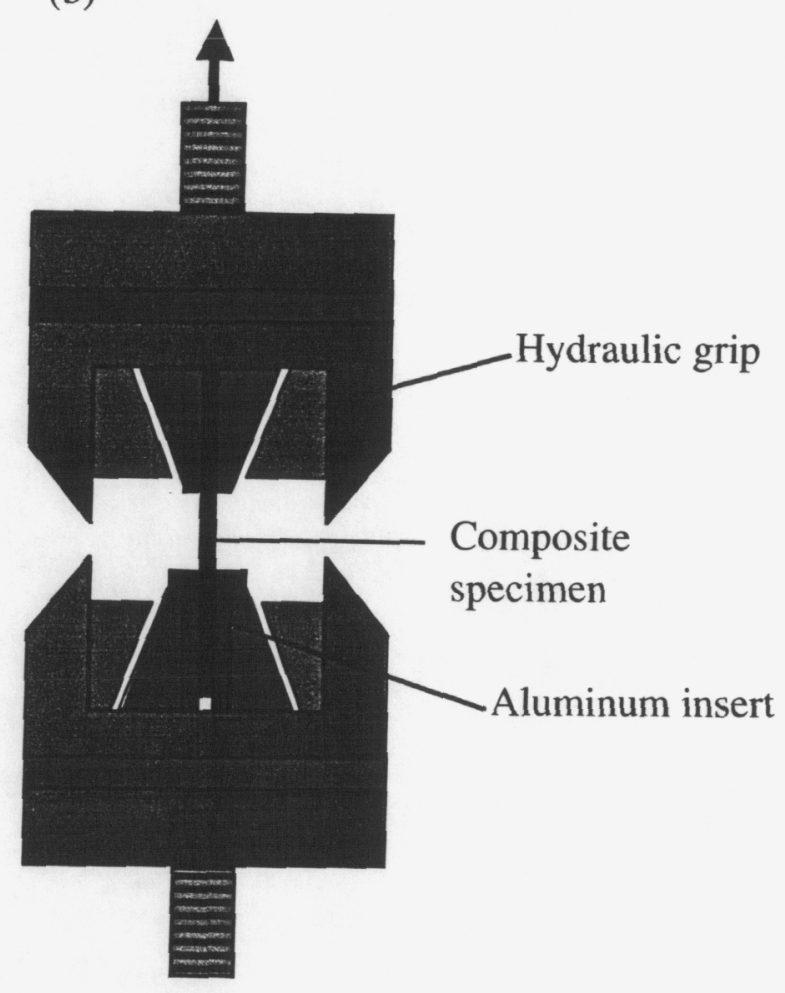

Figure 3.38 Schematics of (a) sliding block friction test and (b) high normal stress friction test. 


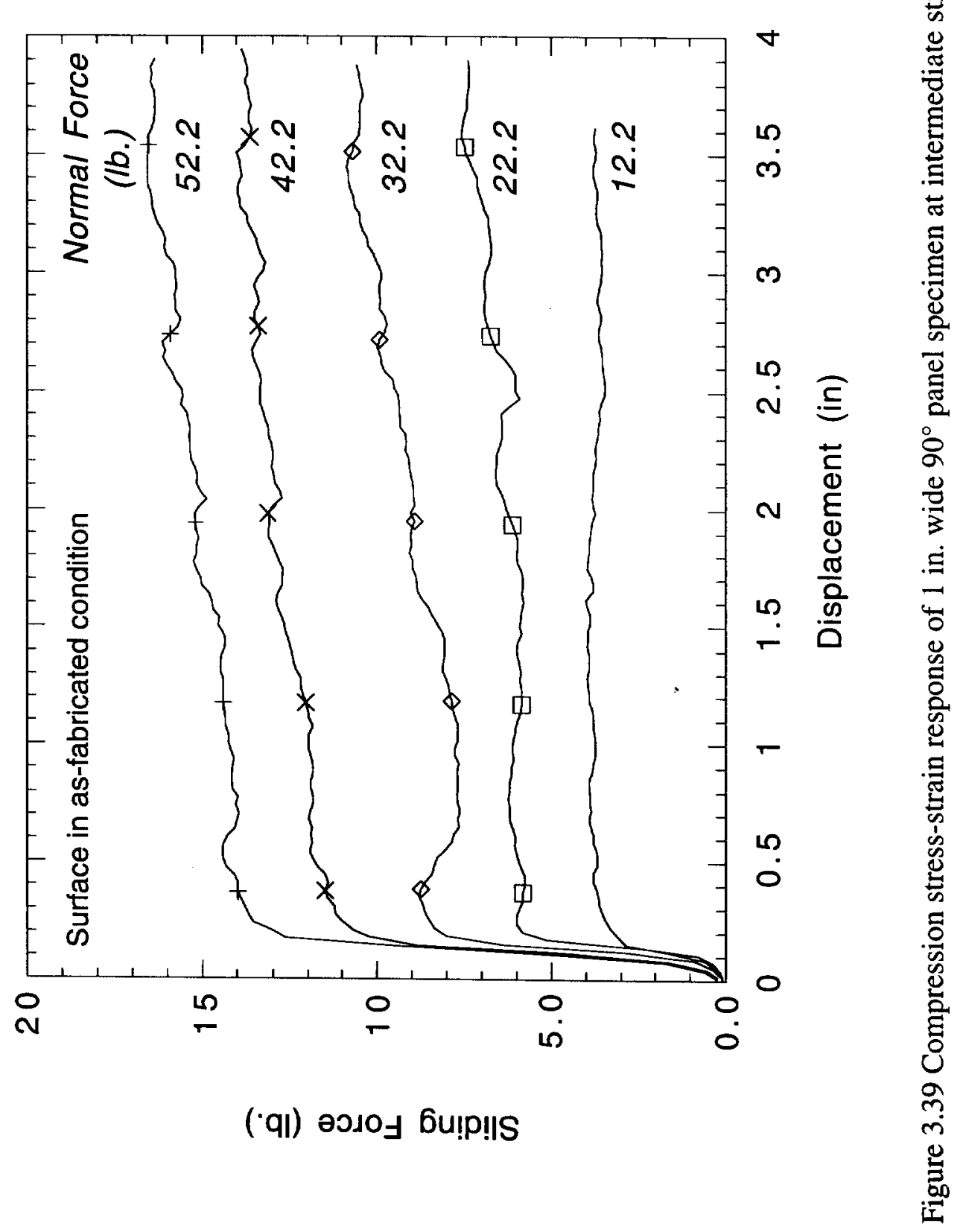




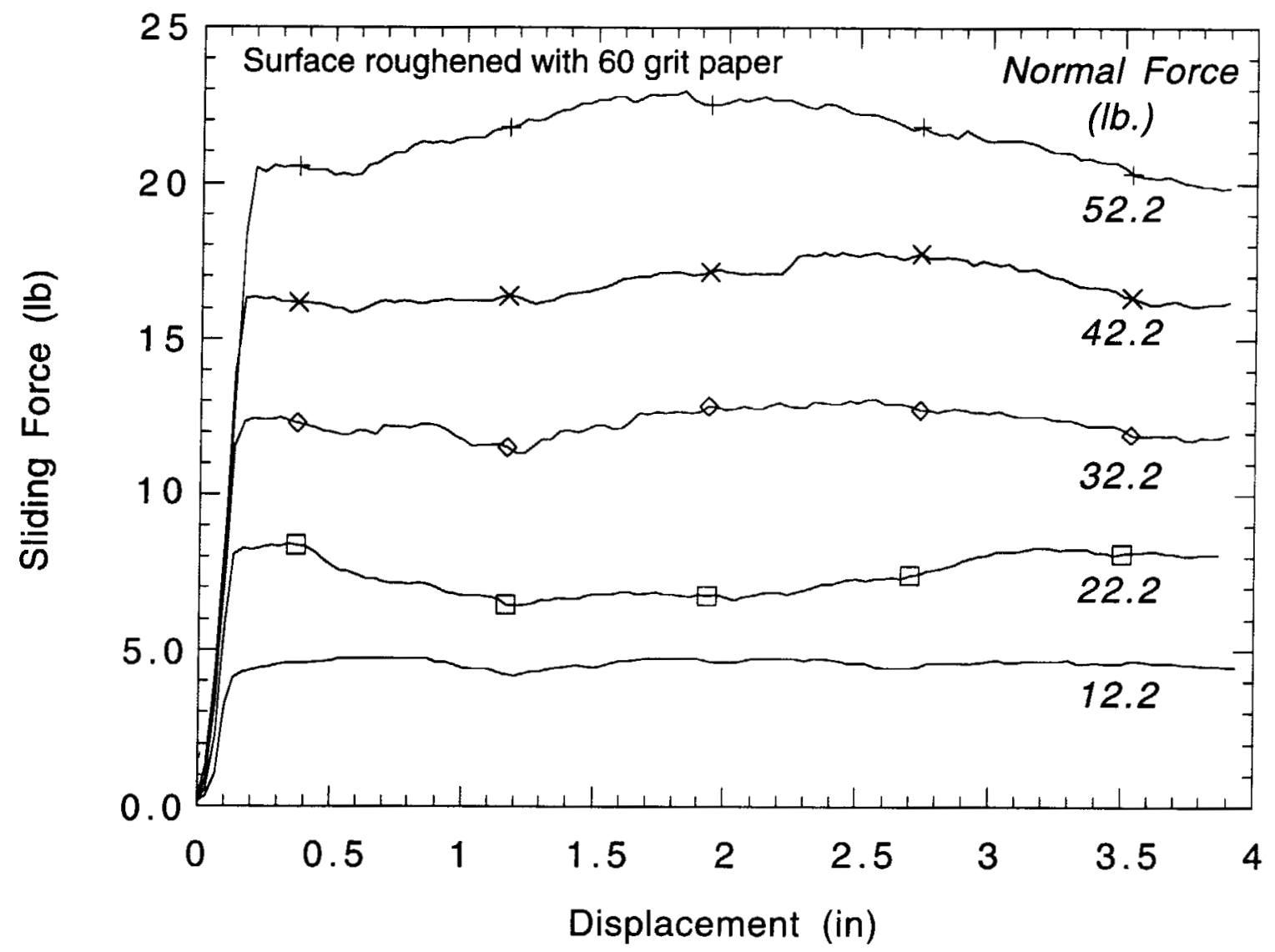

Figure 3.40 Friction force-displacement curves for steel against the roughened composite surface. 

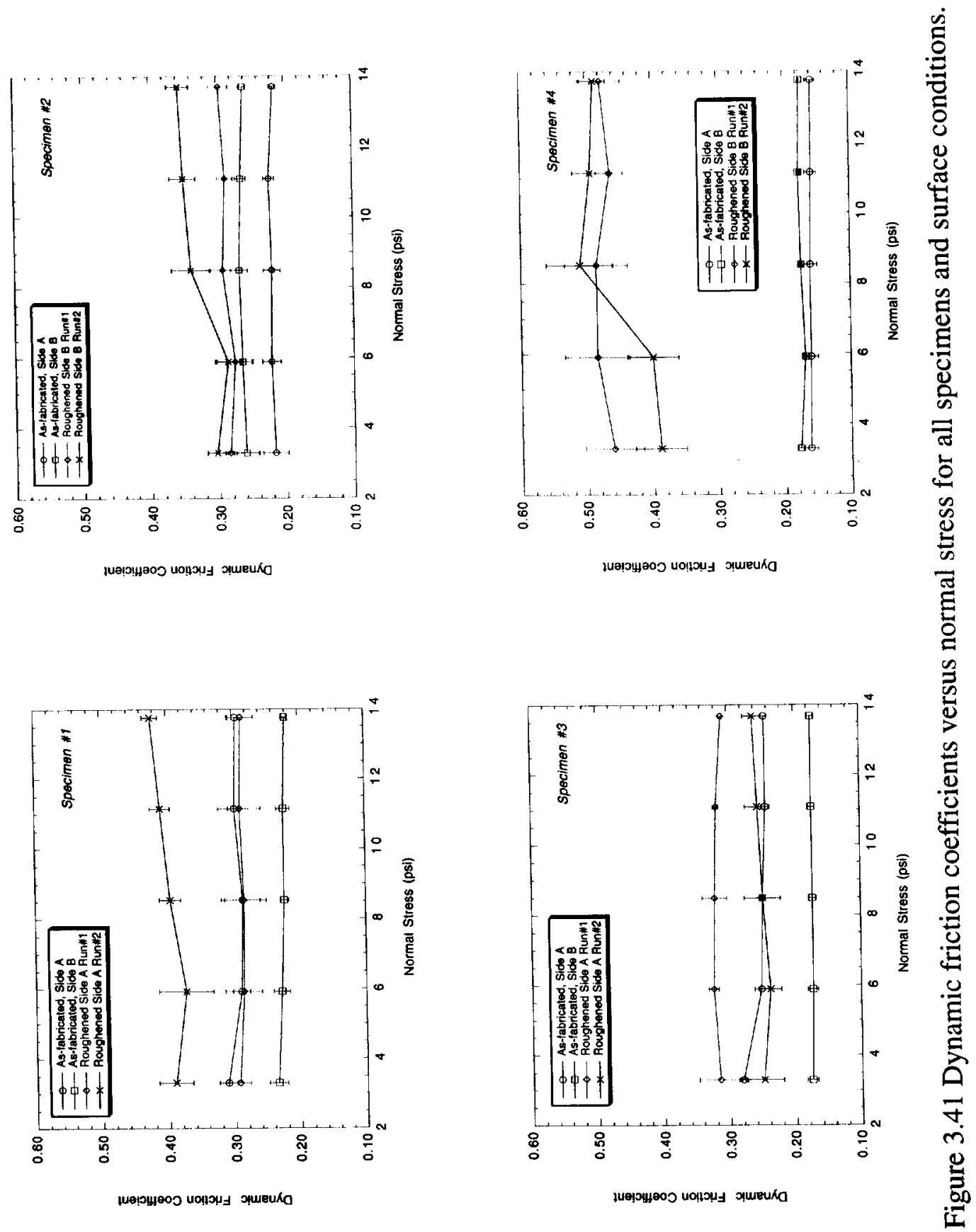


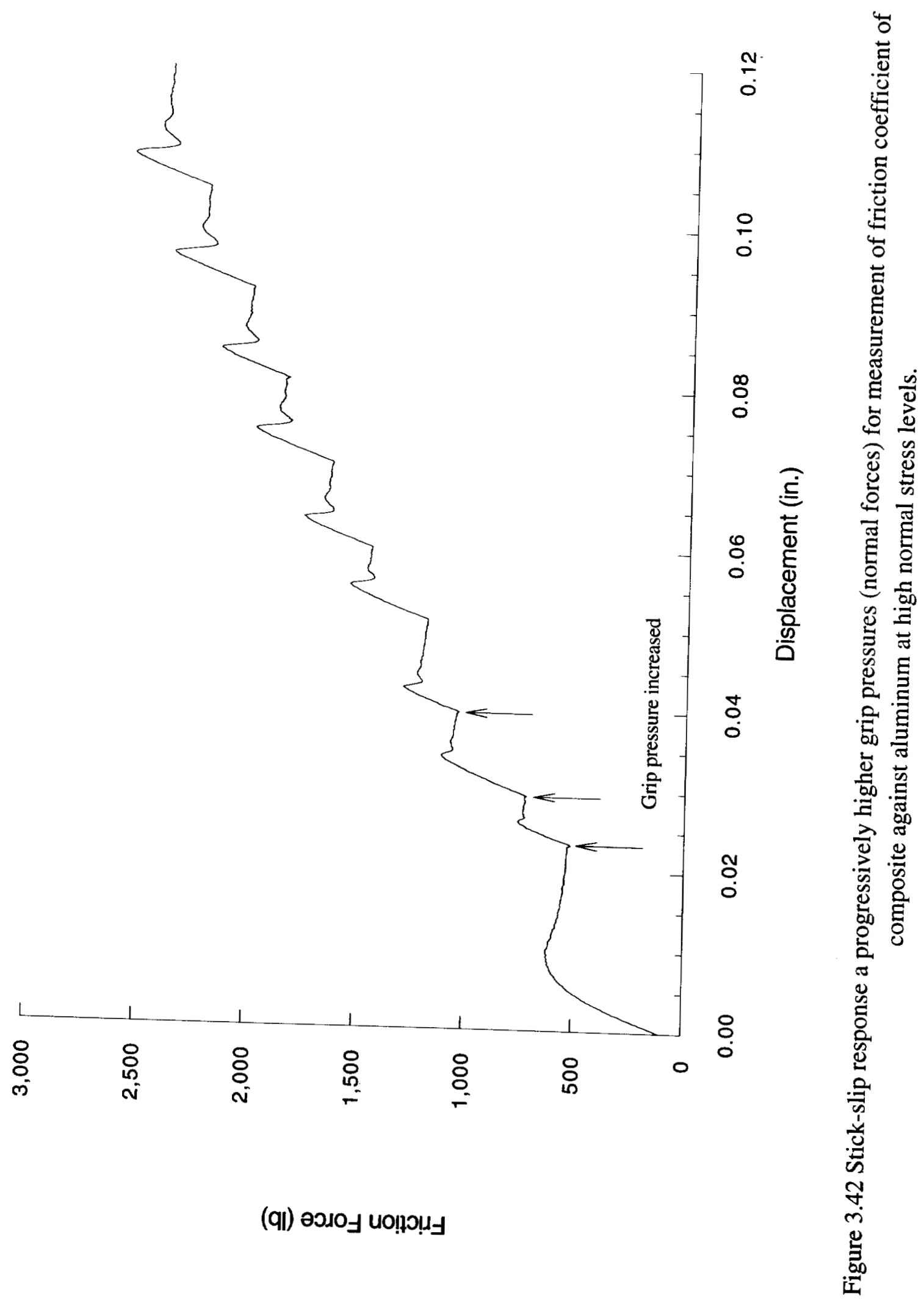




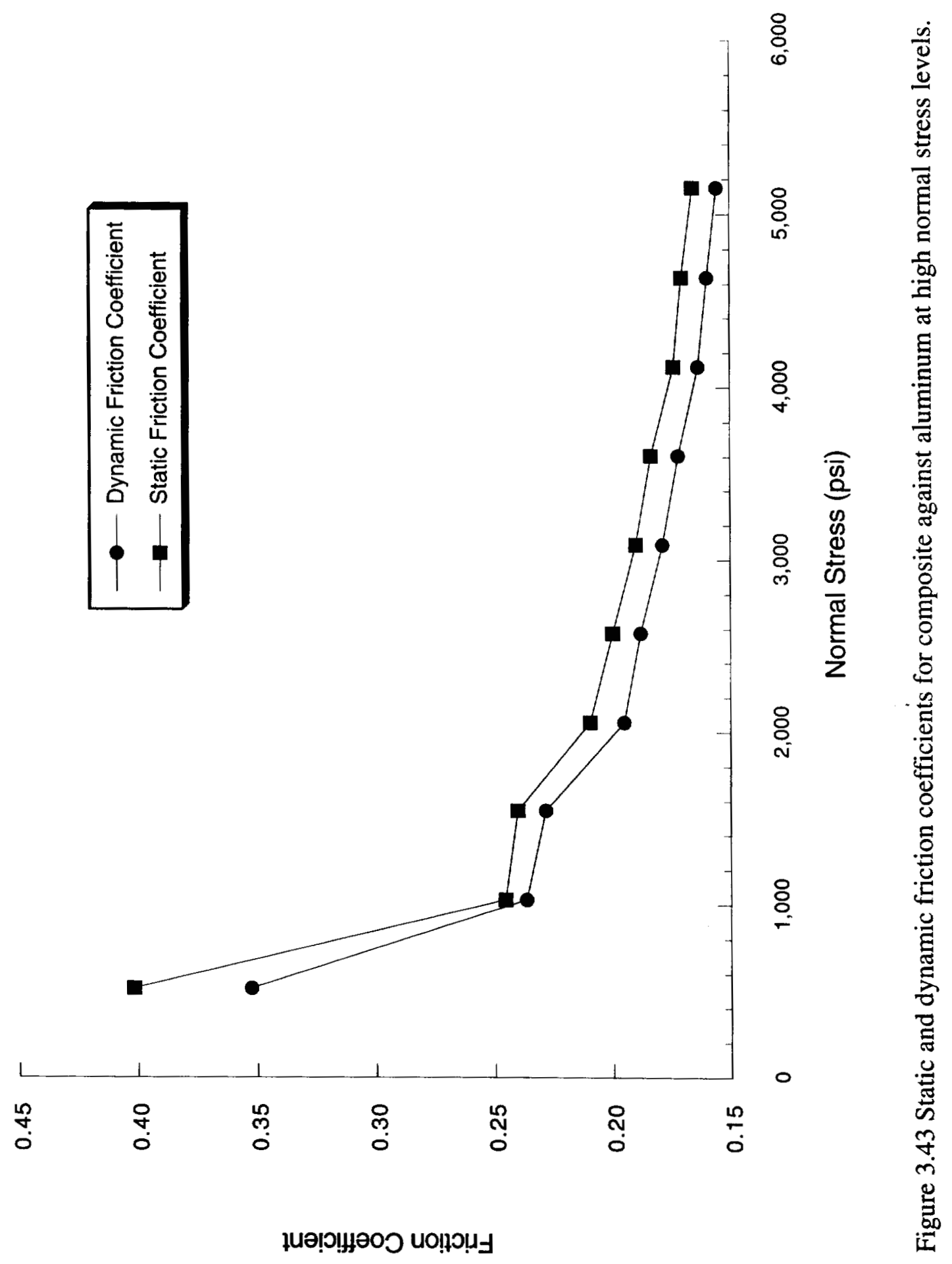




\section{Failure Analysis/Microscopy of Crush Specimens}

\subsection{Introduction}

In order to gain further insight into the failure modes that govern the energy absorption during the crushing of braided tubes, strip specimens from panels and tube crush specimens were examined using different microscopy techniques. The strip specimens were taken from molded flat panels and tested at Oak Ridge National Laboratory (ORNL) using a mandrel bend test. The tube specimens were tested by the Energy Management Working Group of the Automotive Composite Consortium (ACC). Specimens were examined both in the as-received state and after potting and polishing of sections. In order to enhance the contrast between composite and open cracks, sections of failed strip and tube specimens were potted under vacuum using an epoxy containing a white pigment. Although the vacuum aided the "impregnation" of the damaged material, it did not allow the potting epoxy resin to penetrate the dry fiber tows. The presence of this dry material made it difficult to obtain scratch-free polished surfaces. The unsupported fiber was abraded during polishing and fiber fragments damaged the surface during polishing. Nevertheless, some useful images were taken and are described in the following sections.

\subsection{ORNL Strip Test Specimens}

\subsubsection{ORNL Test Results}

A report provided by ORNL described the progressive crush tests of strip specimens using two different degrees of constraint. These tests were performed to mimic some of the deformation that occurs during the formation and deformation of fronds in the crushing of closed-section tubes. The strips were taken from panel \#10-13 and were cut to a nominal length of 7 in. $(178 \mathrm{~mm})$ and width of $1.5 \mathrm{in} .(38 \mathrm{~mm})$. The specimens were forced to bend on the inside of a curved mandrel having a radius of $0.25 \mathrm{in} .(6.4 \mathrm{~mm})$ at a loading rate of 5 $\mathrm{mm} / \mathrm{min}$. The two constraint conditions on the specimen boundary opposite the curved surface of the mandrel were a free surface and a "loose" constraint imposed by a roller. The roller was set at a gap that was greater than the thickness of the strip, hence the term loose constraint. Schematic depictions of these strip crush tests are shown in Fig. 4.1. Results of the crush tests are summarized in Table 4.1, which show that the strips without constraint had a higher initial peak load, but a lower sustained crush load than the loosely constrained specimens. 
Table 4.1. Strip crush test results from ORNL.

\begin{tabular}{|c|c|c|c|c|}
\hline Constraint & Specimen & $\begin{array}{c}\text { Initial Peak Load } \\
(\mathbf{N})\end{array}$ & $\begin{array}{c}\text { Sustained Crush } \\
\text { Load }(\mathbf{N})\end{array}$ & $\begin{array}{c}\mathbf{S E A}^{(\mathbf{( 1 )}} \\
(\mathbf{J} / \mathbf{g})\end{array}$ \\
\hline None & $0-7$ & 4,233 & 1,917 & 7.4 \\
\hline None & $0-8$ & 3,674 & 1,001 & 6.9 \\
\hline Loose & $0-6$ & 3,490 & 2,417 & 14.2 \\
\hline Loose & $0-9$ & 3,366 & 2,934 & 20.2 \\
\hline
\end{tabular}

(1) Specific Energy Absorption

\subsubsection{Failure Observations for Unconstrained Strip Specimens}

The strip specimens that were tested without constraint appear to break at "hinge" points as shown in Fig. 4.2. At these points there is severe fiber and matrix fracture but relatively little damage away from them. The end of the specimen is almost free of damage until the first hinge is formed. In these hinge areas, the outer axial $\left(0^{\circ}\right)$ tow failed in tension and the inner in compression with buckling out-of-plane as shown in the micrographs of polished sections given in Fig. 4.3. In these hinges there is severe interlaminar fracture both within the tows and between them.

On the inside curved surface of these specimens, there are out-of-plane or buckled regions only in discrete locations. These appear to coincide with the compressive buckling of the underlying axial tow. The buckled regions line up along the width of the specimen, forming the hinge points. There is some fiber fracture in both the buckled axial and braider $\left(30^{\circ}\right)$ tows, but this is very localized. There is also some evidence for resin-starved or dry tows that are severely bent, but not fractured.

On the outside curved surface of these specimens there is a slight expansion in the width direction where the material has undergone failure. There is almost no evidence of fiber fracture in the exposed braider tows, which are the only ones visible on this surface. There is some cracking between the tows and some relative motion between them (some stick out slightly from the surface). There appears to be very little matrix cracking, except between the tows. In local regions of the braider tows, there appears to be "dry" fiber that is easily separated into individual filaments. These regions occur where the out-of-plane deformation of the tows is most noticeable and seem to be roughly in line with the buckled axial tow on the inside surface. One possible explanation for the "dry" fiber is that the braider tows are subjected to excessive local strains once the underlying axial tows fail in 
tension (outer surface) and compressive buckling (inner surface). This strain localization would result in severe matrix-dominated damage due to the high transverse tension and longitudinal strains imposed on this material. The failure of these unconstrained specimens appears to be dominated by localized bending failure, which consists of fiber fracture in axial tows and local interlaminar/intertow failure.

\subsubsection{Failure Observations for Constrained Strip Specimens}

In the loosely constrained strip specimens there is some indication that "hinges" of excessive deformation had formed, but in general the damage in the curved sections of these strips is more severe and more uniformly distributed as shown in Fig. 4.4. There is some local fracture of the axial tows, but there is little evidence of compressive buckling in these supported specimens. Instead the axial tows appear to fail by compressive kinking. A distinguishing feature of these specimens is the more extensive interlaminar fracture, corresponding to failure between tows and within a tow, which occurs throughout the bent section of the strip. Examples of this mode of failure are shown in Fig. 4.5. This fracture seems to occur mostly within braider tows and between the braider and axial tows.

The inside curved surface shows more uniformly damaged material with all braider tows sticking out-of-plane. There is matrix cracking between the braider tows and a relatively large amount of fiber fracture within these tows. The damage in these off-axis tows appears to initiate by tow buckling.

The outside curved surface exhibits more lateral expansion than the unsupported specimen. There is also some out-of-plane deformation of the braider tows and cracking and separation between them to accommodate this deformation. There appears to be more resin cracking on the outside surface of these specimens, but there is little evidence for fiber damage or the "dry" fiber regions seen in the unsupported specimens. The failure of these loosely constrained specimens appears to be dominated by uniform interlaminar/intertow fracture and fiber failure within buckled braider tows on the inside surface. 


\subsubsection{Surface Area Determination by the BET Technique}

An attempt was made to quantify the differences in failure between constrained and unconstrained strip crush specimens using a measurement of surface area generated by the crush experiment. The BET technique was used to estimate free surface area for both the undamaged and damaged sections of the strips. The procedure is named after Brunauer, Emmett, and Teller, who first showed how to determine surface areas from the multilayer absorption of gases or vapors onto free surfaces [7]. Specimens are typically measured for adsorption isotherms at liquid nitrogen temperatures by measuring the relative pressure in an evacuated and sealed container after known amounts of gas are added. The technique is commonly used to determine the surface area of materials such as catalysts and other porous materials. These materials typically exhibit specific surface areas that are greater than $100 \mathrm{~m}^{2} / \mathrm{g}$.

While the crushed composite strips appear to have significant exposed surface area in the damaged region, it was expected that the amount would be far less than the porous materials normally using the BET isotherm method. Therefore, to maximize the accuracy of the BET measurements, relatively large samples were used in measurements of Krypton gas adsorption isotherms. Tests were conducted by Micromeritics (Norcross, GA) and it was their recommendation to use the Krypton gas since it apparently gives more accurate results for materials having lower specific surface area. In order to accommodate the unusually large specimens, Micromeritics contracted a local glass blower to encase the composite strip specimens in large glass holders that could fit the BET instrument.

The specific surface areas determined from the multipoint method are summarized in Table 4.2 for pristine and damaged sections of both the unconstrained and loosely constrained strip specimens. It is interesting to note that the undamaged sections of the composite had appreciable surface area. The external surface area of the sections used in these measurements corresponds to only $5 \mathrm{E}-4 \mathrm{~m}^{2} / \mathrm{g}$, which is negligible compared with the measured values. This indicates that the undamaged composite is porous and this porosity has high surface area and is accessible from the edges and faces of the specimen. Any fully enclosed pores would not be measured by the BET technique, so these values for surface area are lower bound numbers. Since the composite panels were shown to have a relatively large fraction of dry fiber tows, the measured surface area was compared with that for completely bare fiber. For the Akzo \#556 carbon fiber the specific surface area is approximately $0.35 \mathrm{~m}^{2} / \mathrm{g}$. The ACC reports a fiber weight content for the $0 / \pm 30$ triaxial braid panels at $58 \mathrm{wt}$.\%. If the contribution of the matrix surface area is ignored, then the specific surface areas measured with respect to the fiber weight in the undamaged sections of composite 0.092 and $0.105 \mathrm{~m}^{2} / \mathrm{g}$ for specimens \#0-6 and \#0-8, respectively. Even though 
these values represent only the surface area that is accessible by the Krypton gas, they indicate that about $30 \%$ of the fiber surface is exposed or "dry."

This calculated value of dry fiber percentage can be compared with the void content reported by the ACC. The reported volume fractions for this particular braided composite panel are; fiber content $=0.45$, resin content $=0.514$, and void content $=0.036$. Start with the assumptions that the fiber within the tows is packed at a volume fraction of $65 \%$ and that all the void content is due to dry fiber inside the tow. The volume fraction of tows is $0.45 / 0.65=0.692$ and the volume fraction of voids within the tows is $0.036 / 0.692=0.052$. Thus the fraction of fiber in the tow that is surrounded by voids (i.e., dry fiber) is $0.052 / 0.35=0.15$. This is only half the estimate for dry fiber content based on the BET surface area measurements.

One possible explanation for the large discrepancy is the method by which fiber, resin, and void contents are normally determined. Two measurements are required to calculate these values; namely, fiber content and composite density. Fiber content is usually measured using digestion techniques to separate and recover fiber from the composite. Density is most commonly measured using buoyancy techniques [6], which require the specimen to be immersed in liquid for a period of time. Considering that the panel composites have an appreciable quantity of dry tows, it is very likely that the liquid used in the density measurements penetrated and filled some of the void space. Under these circumstances, the value given for void content would be a lower bound and could be in error by a significant amount depending on the extent of void-filling by the immersion liquid. To test this hypothesis, a sample of the composite panel was soaked in water at room temperature for several minutes and measured for weight change after removing all the surface water. The specimen picked up $0.8 \mathrm{wt}$. \%, which corresponds to roughly 0.01 volume fraction of void space that had been filled. The amount of liquid that is actually absorbed during the density measurements depends on several factors including the type of liquid, the use of a wetting agent, the length of immersion time, and the shape and size of the specimen. However, it is probable that the measured void contents are too low and that the percentage of fiber that is dry is somewhere between the $15 \%$ calculated from void content and the $30 \%$ calculated from BET measurements.

Crushing the composite strips results in a significant increase in free surface area and the loosely constrained specimen gains more than twice the area of the unconstrained specimen. Although several processes contribute to the Specific Energy Absorption (SEA) value, it is interesting to note that the ratio of surface area increase, $0.1938 / 0.0826=2.3$, is comparable to the ratio of SEA, $14.2 / 6.9=2.1$, for the two constraint conditions. These results suggest that the improved ability to absorb energy with the loose constraint is due in 
large part to the increased fractured surface area. If the entire energy went into the formation of new surfaces, then the fracture surface energy values are only 73 and $84 \mathrm{~J} / \mathrm{m}^{2}$ for the loosely constrained and unconstrained specimens, respectively. These are relatively low values for any mode of fracture in a composite material.

Table 4.2. BET surface area values for ORNL strip crush specimens.

\begin{tabular}{|c|c|c|c|c|}
\hline Specimen & Strip Test Condition & $\begin{array}{c}\text { Weight } \\
(\mathbf{g})\end{array}$ & $\begin{array}{c}\text { BET Surface Area } \\
\left(\mathbf{m}^{2} / \mathbf{g}\right)\end{array}$ & $\begin{array}{c}\text { SEA } \\
(\mathrm{J} / \mathrm{g})\end{array}$ \\
\hline $0-6$ & Undamaged section & 19.57 & 0.0535 & \\
\hline $0-6$ & Loose constraint & 10.23 & $\begin{array}{c}0.2473 \\
(0.1938)^{(1)}\end{array}$ & 14.2 \\
\hline $0-8$ & Undamaged section & 18.26 & 0.0607 & 6.9 \\
\hline $0-8$ & Unconstrained & 10.09 & 0.1433 & $(0.0826)^{(1)}$ \\
\hline
\end{tabular}

(1) Value in parentheses is additional surface area generated in strip bend test. 

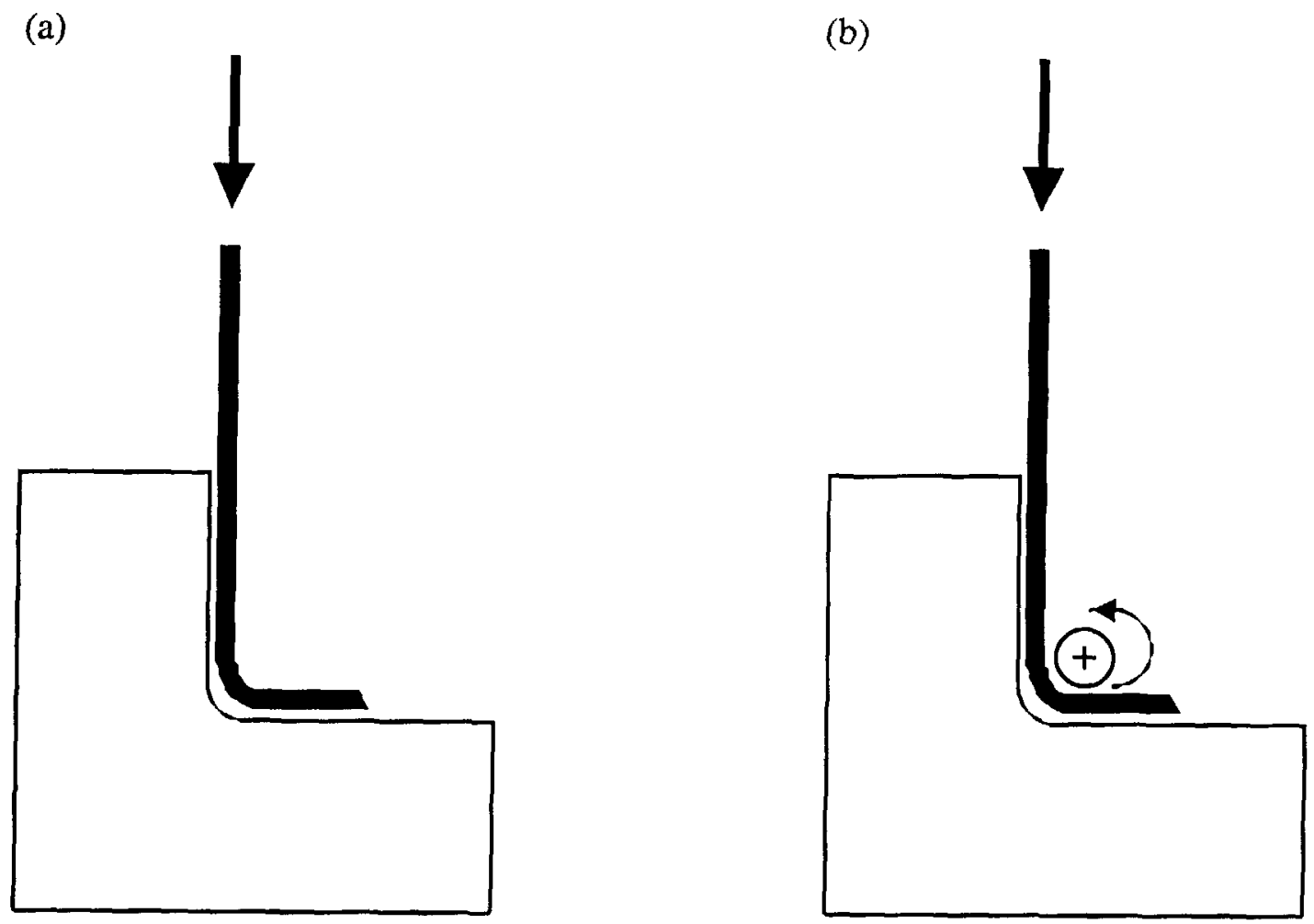

Figure 4.1 Schematic drawings of ORNL strip crush tests using (a) no constraint and (b) loose constraint. 


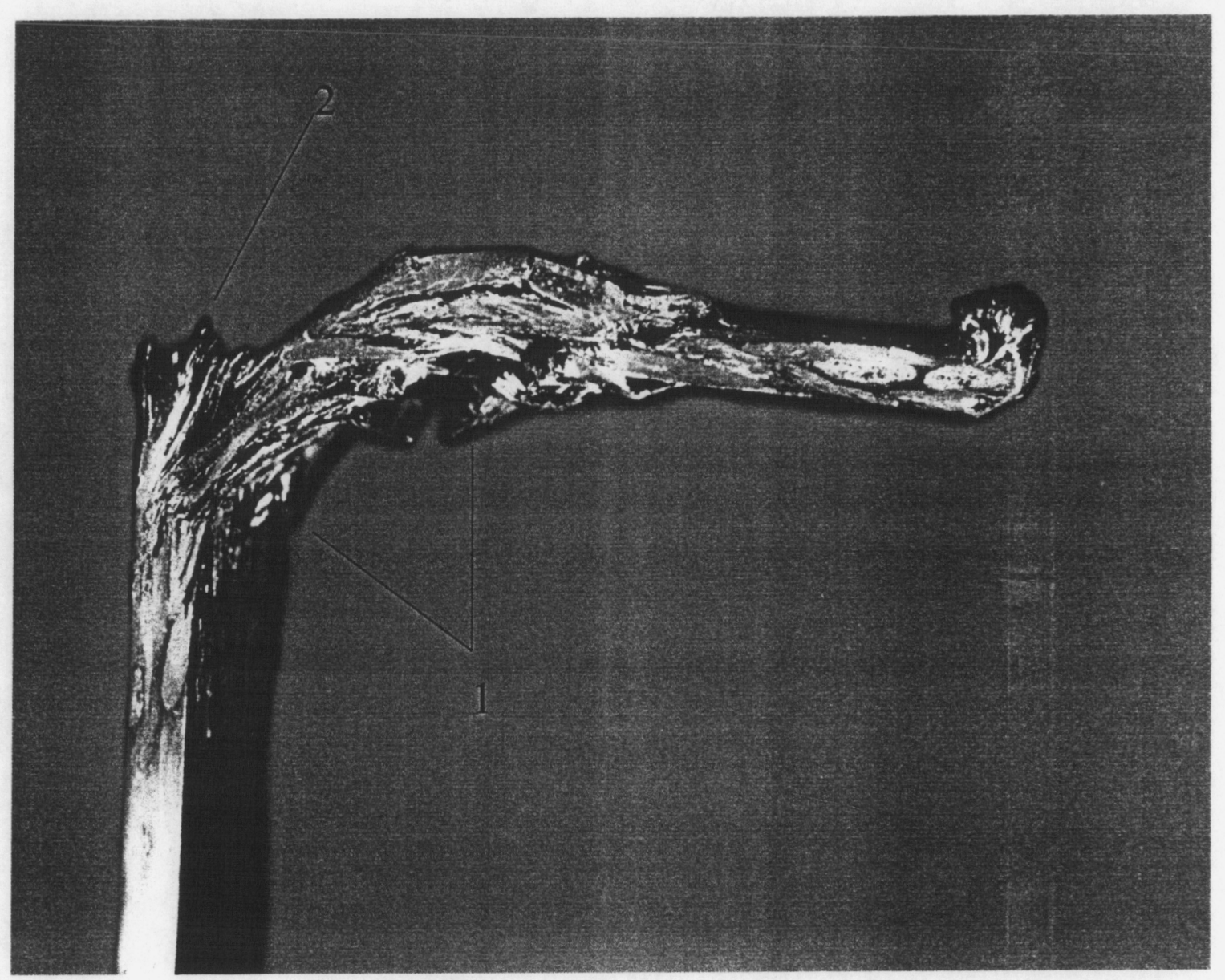

Figure 4.2 Edge view of unconstrained strip specimen \#0-7 showing (1) hinge points where axial tows have buckled out-of-plane and (2) fracture of axial tow on tensile surface. 

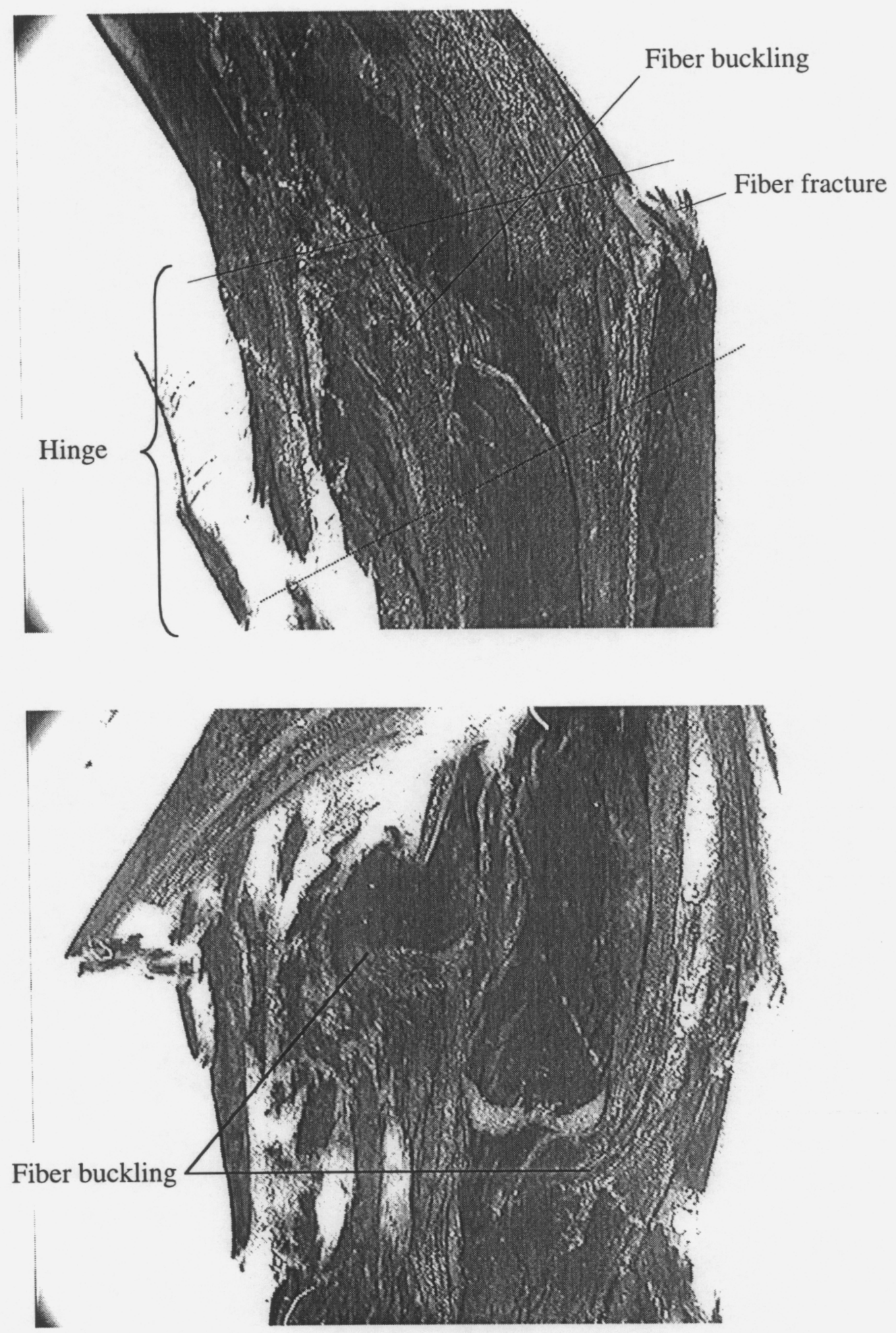

Figure 4.3 Micrographs of polished edges of unconstrained strip specimen \#0-7. 

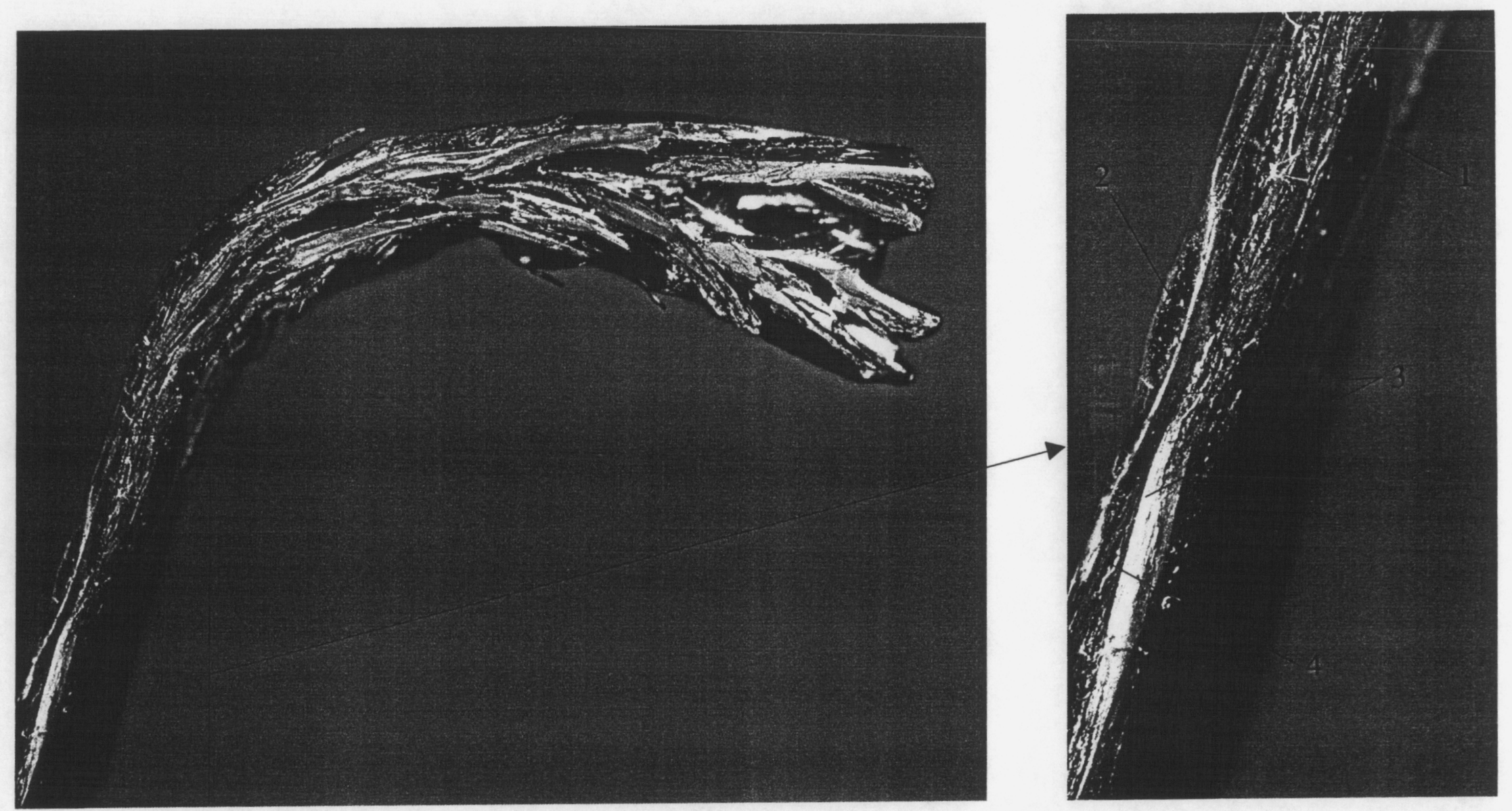

Figure 4.4 Edge views of loosely constrained strip specimen \#0-6 showing (1) delamination at onset of crush zone and in undamaged section: (2) dry braider tow, (3) undulating axial tows, and (4) voids. 


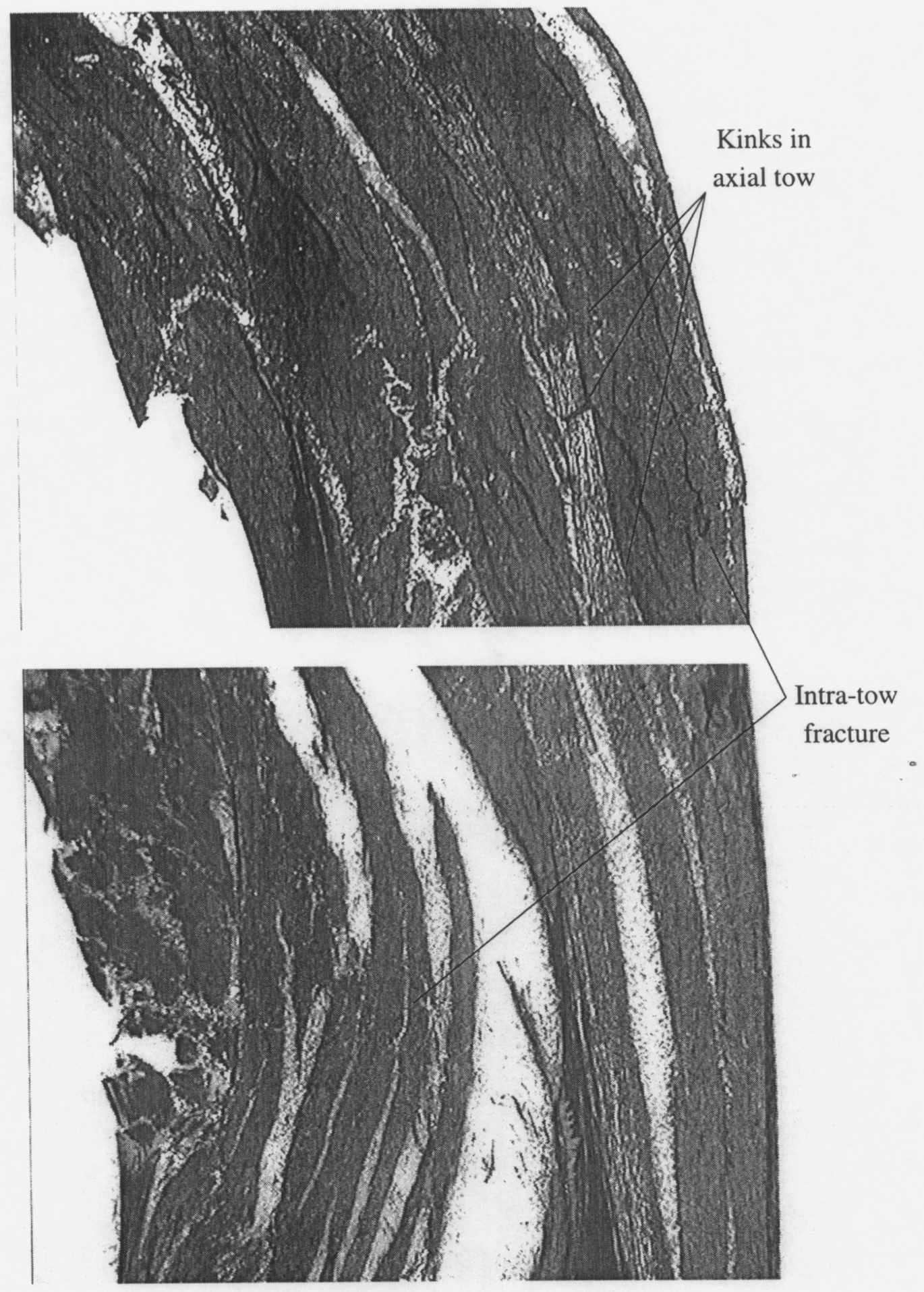

Figure 4.5 Micrographs of polished edges of loosely constrained strip specimen \#0-6. 


\subsection{ACC Crushed Tube Specimens}

Two tubes that had been crush-tested by the ACC were supplied for examination of failure modes. The tubes were marked "2-5" and "2-18". Photographs of the tubes in the asreceived condition are shown in Figs. 4.6 and 4.7. Both tubes contained some debris inside and about $12 \mathrm{~g}$ for \#2-5 and $25 \mathrm{~g}$ for \#2-18 was loose material. It appeared that the debris inside tube \#2-18 was more densely packed. The tubes had very indistinct fronds, but the tows retained much of their structure through the crush zone. These separated tows were mostly damaged by failure in bending.

Sections of the tubes in the crush zone were vacuum-potted in epoxy and polished for microscopic examination. An overall picture of the section examined is shown in Fig. 4.8. The circled area in this figure was examined in detail and a higher magnification photomicrograph is shown in Fig. 4.9. This figure shows a small debris wedge that was lost during polishing and left the void space shown in the figure. Some delamination at the center of the tube wall is apparent in the straight section of the tube. Although it was somewhat difficult to observe any common failure modes, it did appear that failure occurred first by delamination then by bending of the separated material. Fracture was seen both between and within tows. There was only minimal fiber fracture, which appeared to occur by bending. But there were no signs of the out-of-plane buckling of the surface braider tows as was seen in the strip crush specimens. Overall the failure of the tubes was different than the strip specimens, although it was more like the loosely constrained than the unconstrained ones. 


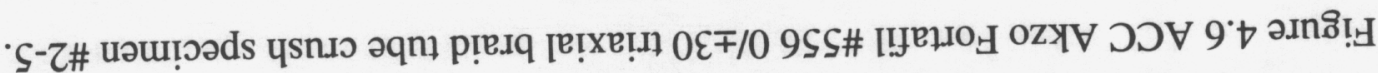
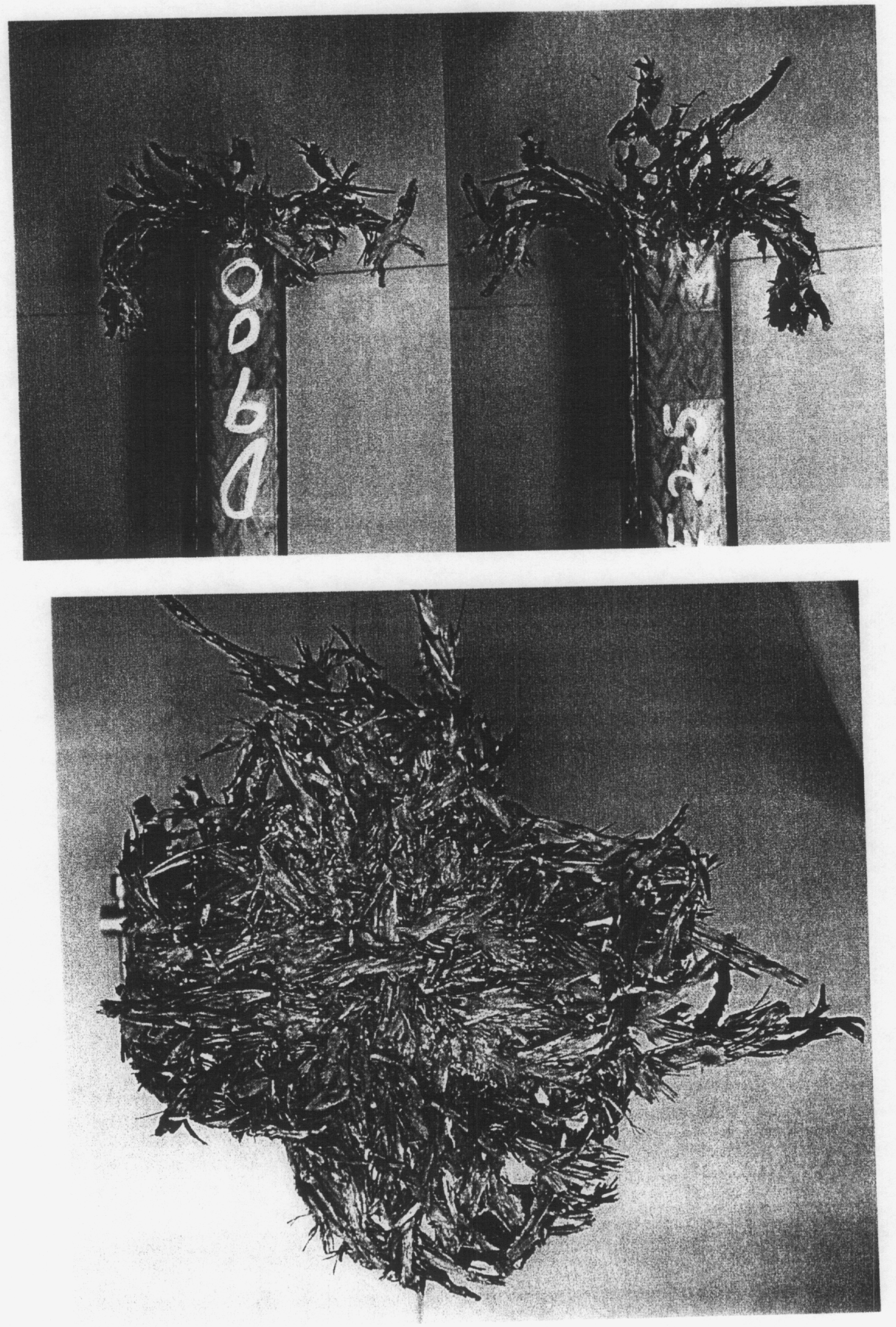

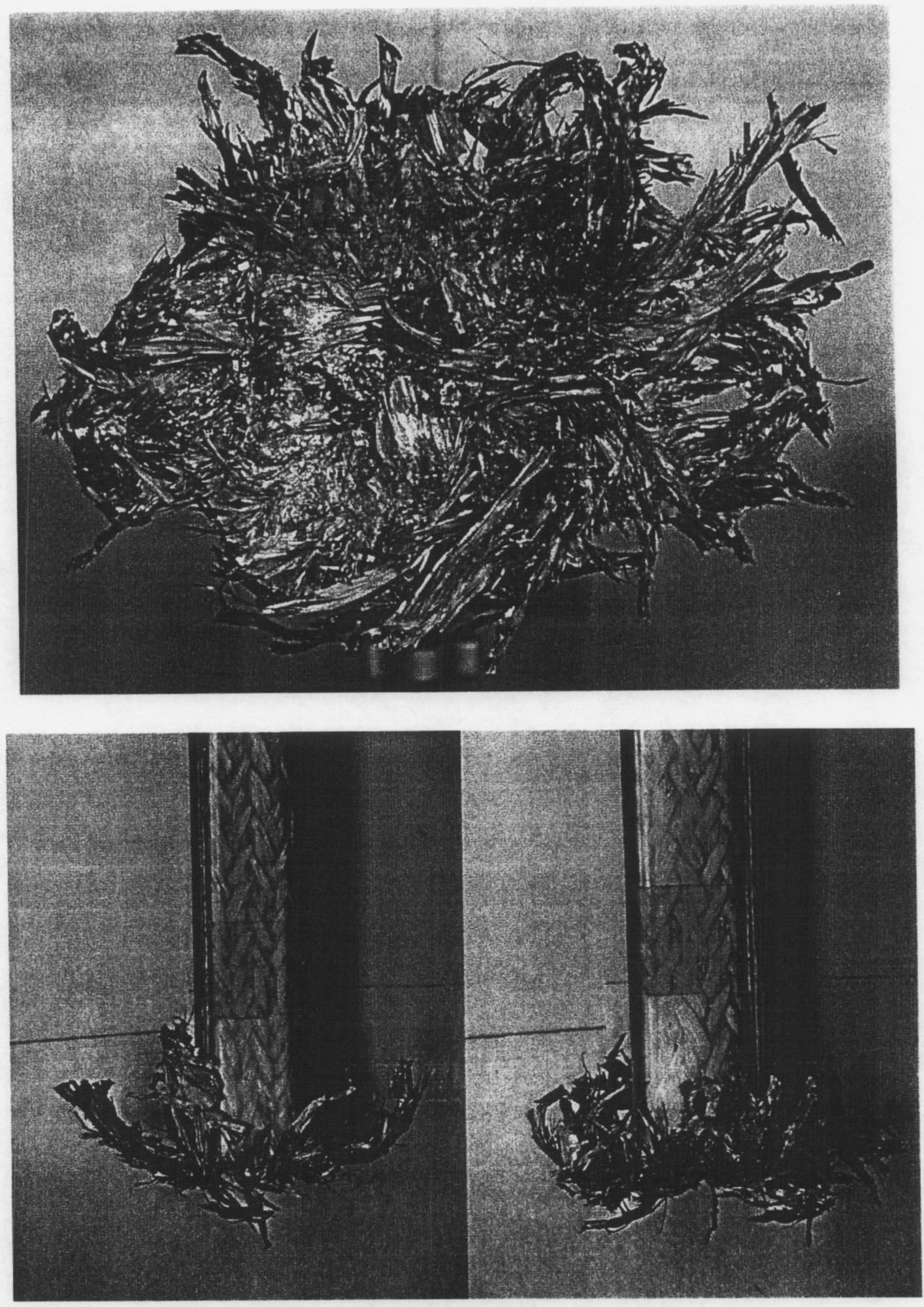

Figure 4.7 ACC Akzo Fortafil \#556 0/ \pm 30 triaxial braid tube crush specimen \#2-18. 


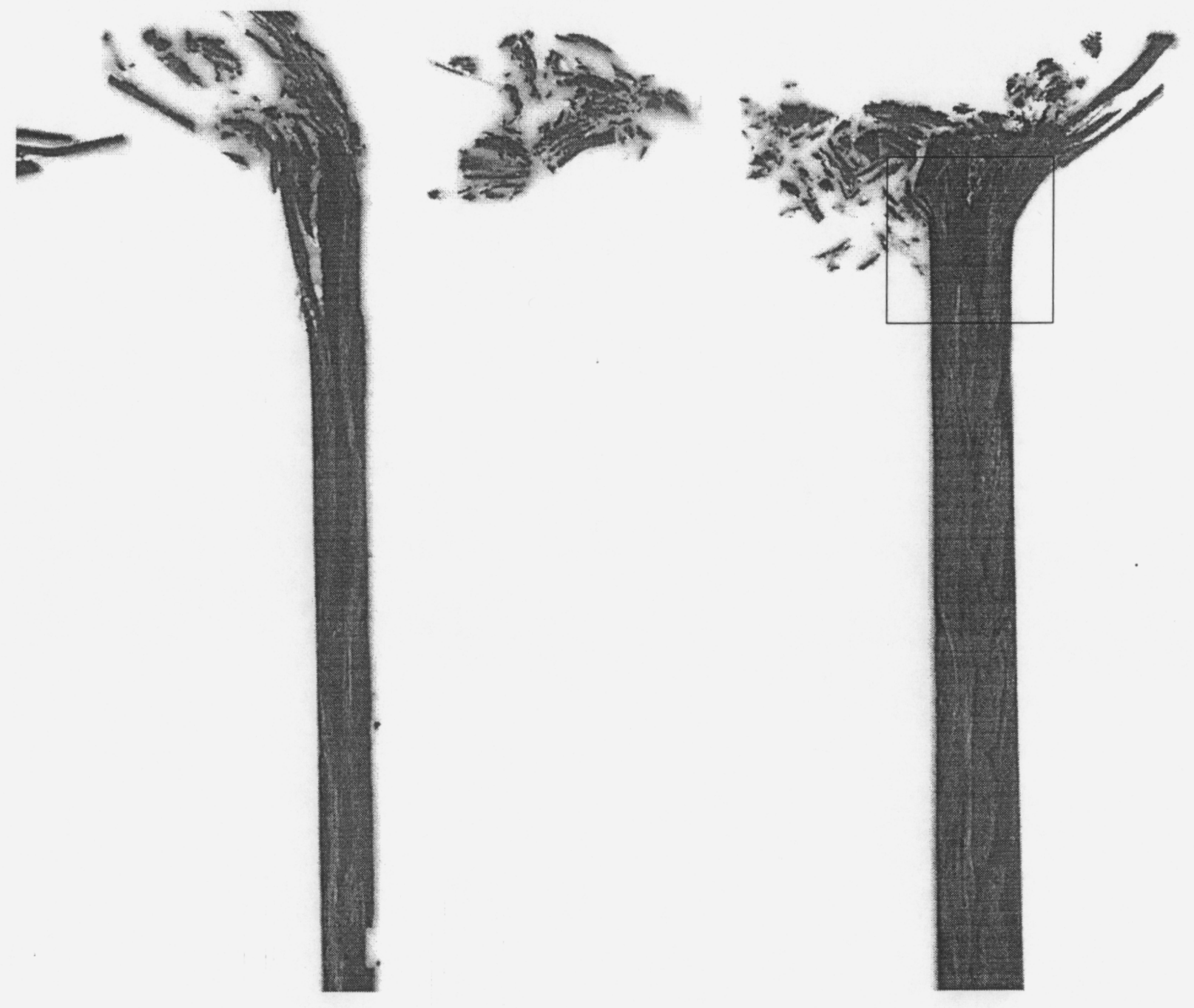

Figure 4.8 Potted and polished section of ACC crushed tube. 


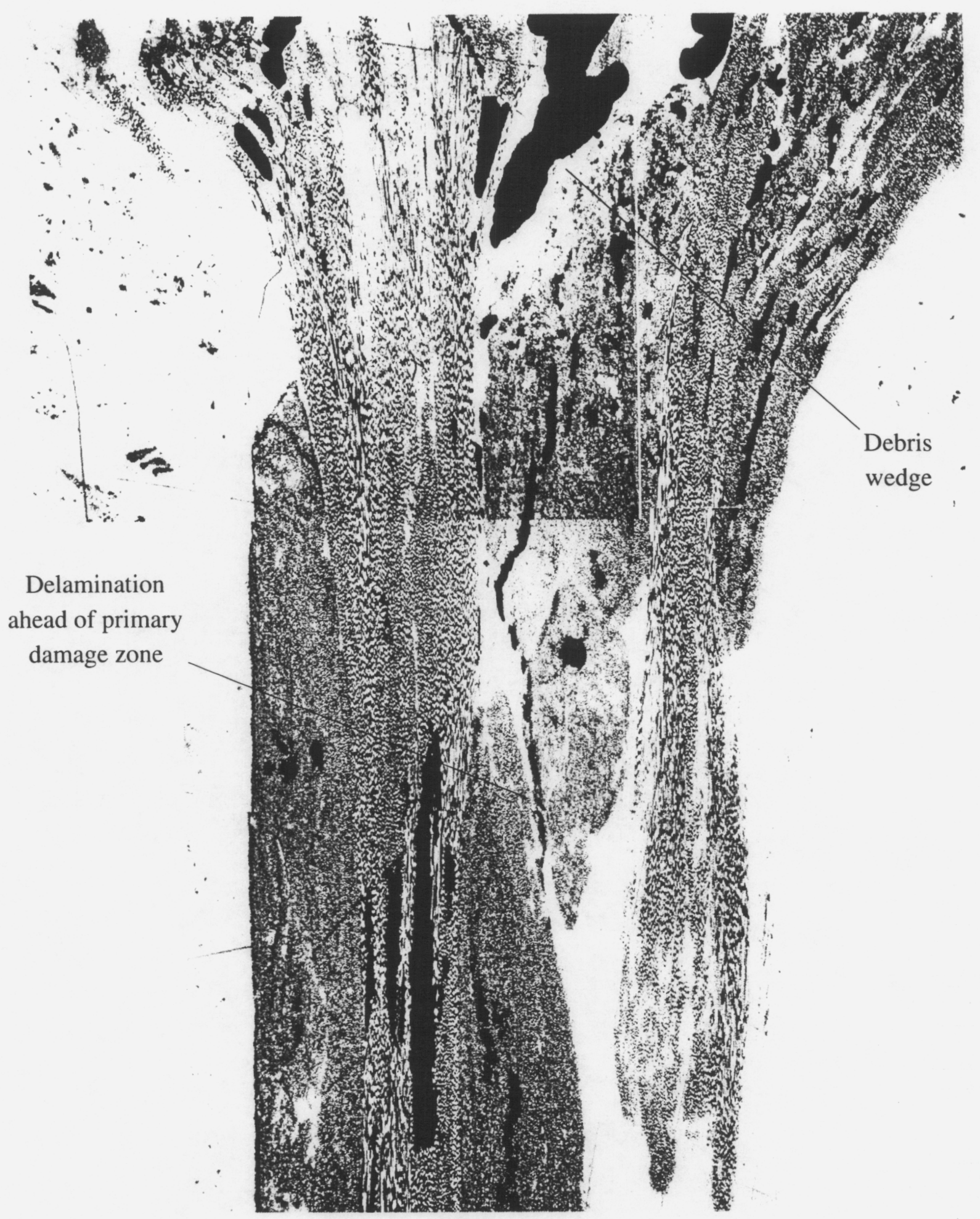

Figure 4.9 Magnified view of the section highlighted in Fig. 4.8 of the damage zone in a crushed $0 \% \pm 30^{\circ}$ triaxial braid composite tube. 


\section{Conclusions}

The overall performance of the carbon braid composites examined in this study was found to be dominated by both the relatively brittle nature of the Hetron 922 matrix material and the poor quality of the molded composite. Both of these factors contributed to failure modes that were dominated by weakly bonded tows and by poor fiber wetting within tows. The lack of matrix toughness and full wet-out of all the carbon filaments yielded an incomplete translation of the high-performance carbon fiber strength properties into the composite structure. This is perhaps most clearly demonstrated by the finding that all of the composite strengths, with the exception of tension in a tow (axial $=0^{\circ}$ or braider $=30^{\circ}$ ) direction, were equal to or less than the strengths of the pure matrix material. Certainly the poor compression strengths for tow-direction tests $\left(0^{\circ}\right.$ and $30^{\circ}$ ) are indicative of the extent of dry or poorly wet carbon filaments.

The effects of the poor fiber wet-out and matrix properties were seen in failure modes of panel specimens tested under uniaxial stress as well as strips and tubes tested under crush conditions. In almost every case failure involved mostly cracking between tows, both in-plane and throughthickness, with very little fiber fracture. Only the unconstrained strip crush specimens showed significant fiber fracture, but these failures were not representative of the tube crush failure modes.

Although improvements in material properties would be expected with better fiber wet-out and a more ductile matrix material, it is not clear that these would improve crashworthiness. The application of carbon fiber composites to crashworthy structures is unique in that successful performance relies on material failure. This failure must occur such that a required level of energy is absorbed in a stable and predictable manner. Most composite applications rely on stiffness and durability properties and the only other example that comes to mind where performance depends on material failure is in composite armor. Fiber composites for armor applications typically are resin-starved and have poor fiber-matrix adhesion. These are typically undesirable characteristics for common composite structures but are intentionally designed into armor composite plates to maximize the energy absorbed. This energy is predominantly absorbed by tensile deformation of the fiber, which must have some degree of "toughness" to function. It is no accident that carbon fiber is not typically used in armor applications - it is generally too brittle compared with glass and polymeric fibers for this application. Although the superior modulus of carbon fiber makes it an attractive candidate for primary structures in vehicles, it is not necessarily the best choice for an energy-absorbing material. Consequently, it may be desirable to design a crashworthy carbon composite structure that fails predominantly by matrix 
modes. In order to improve repeatability and therefore predictability, it is desirable to produce high-quality composites. However, studies should be undertaken to determine the specific matrix and fiber/matrix adhesion properties for optimum energy absorption by carbon composite crashworthy structures.

\section{Acknowledgements}

The authors gratefully acknowledge the guidance and support of the principal investigator for this project, Ed Zywicz. We would also like to recognize the efforts of Jeff Petersen in machining specimens and Jan Dunaway in helping to prepare this document. 


\section{References}

1. S. E. Groves, R. J. Sanchez, R. E. Lyon, and A. E. Brown, "High Strain Rate Effects for Composite Materials," Composite Materials: Testing and Design (Eleventh Volume), ASTM STP 1206, E. T. Camponeschi, Jr., Ed., ASTM, Philadelphia, 1993, pp.162-176.

2. A. Nadai, Theory of Flow and Fracture of Solids, McGraw-Hill, New York, Vol. 1, 1950, pp. 347-349.

3. R. E. Lyon, "Shear Strength of a Ductile Material from Torsion of Solid Cylinders," J. Test. Eval., 19(3) pp. 240-243 (1991).

4. "Standard Test Method for Compressive Properties of Rigid Plastics," ASTM D 695-96, American Society for Testing and Materials, West Conshohocken, PA, Vol. 8.01 (1997) pp. 73-79.

5. E. Zywicz and T. Nguyen, "On the Flexural and Extensional Behavior of a Large-Tow Triaxial Braided Composite," Comp. Sci. Tech. 60 pp. 2989-2999 (2000).

6. "Standard Test Method for Fiber Content of Resin-Matrix Composites by Matrix Digestion," ASTM D3171-76, American Society for Testing and Materials, West Conshohocken, PA, Vol. 15.03 (1997) pp. 124-126.

7. A. W. Adamson, Physical Chemistry of Surfaces, Interscience, New York, 1967, pp. 584-588. 